Aus der Klinik für Rheumatologie und Nephrologie

( Prof. Dr. G. A. Müller)

der Medizinischen Fakultät der Universität Göttingen

\title{
Effekte von Cisplatin und Carboplatin auf verschiedene Biomarker im Urin
}

\author{
INAUGURAL-DISSERTATION \\ zur Erlangung des Doktorgrades \\ für Zahnheilkunde \\ der Medizinischen Fakultät der \\ Georg-August-Universität zu Göttingen
}

vorgelegt von

Kathi Goldstein

aus Bünde

Göttingen 2016 
Dekan:

I. Referentin: Prof. Dr. med. Sabine Blaschke

II. Ko-Referent/in: Prof. Dr. med. Abdul Rahman Asif

III. Drittreferent/in: Prof. Dr. med. dent. Rainer Mausberg

Tag der Mündlichen Prüfung: 08. August 2016 
Hiermit erkläre ich, die Dissertation mit dem Titel "Effekte von Cisplatin und Carboplatin auf verschiedene Biomarker im Urin" eigenständig angefertigt und keine anderen als die von mir angegebenen Quellen und Hilfsmittel verwendet zu haben.

Göttingen, den

(Unterschrift) 
ABKÜRZUNGSVERZECHNIS

ABBILDUNGSVERZEICHNIS

VI

TABELLENVERZEICHNIS

IX

1. EINLEITUNG

1

2. MATERIAL UND METHODEN

5

2.1 Patienten und Probanden 5

$\begin{array}{ll}2.2 \text { Messmethoden } & 6\end{array}$

$\begin{array}{ll}2.3 \text { Statistische Analyse } & 11\end{array}$

3. DARSTELLUNG DER EIGENEN UNTERSUCHUNGEN (ERGEBNISSE) 13

$\begin{array}{ll}\text { 3.1 Beschreibungen des Probanden- und } & 13\end{array}$

Patientenkollektivs

$\begin{array}{ll}\text { 3.2 Beschreibung des Patientenkollektivs } & 16\end{array}$

3.3 Geschlechtsspezifische Unterschiede der Urinmarker 18 Probandenkollektivs

3.4 Darstellung der Reaktionen der Biomarker durch die 20 platinhaltige Chemotherapie

3.4.1 NIERENFUNKTIONSMARKER $\quad 21$

$\begin{array}{ll}\text { 3.4.1.1 ELEKTROLYTE } & 21\end{array}$

$\begin{array}{ll}\text { Natrium (Na) } & 21\end{array}$

$\begin{array}{ll}\text { Chlorid (Cl) } & 21\end{array}$

Kalium (K) 22

$\begin{array}{ll}\text { Calcium (Ca) } & 23\end{array}$

Magnesium (Mg) 24

Phosphat (P) 25

3.4.1.2 METABOLITE

Glukose (Gluc) 25

Urinkreatinin (Ukrea) 26

Harnstoff (Urea) 27

pH-Wert (pH) 27 
3.4.2 KLASSISCHE BIOMARKER

3.4.2.1 UBIQUITÄR AUFTRETENDE BIOMARKER

Protein (Prot)

Microalbumin (MIALB)

Laktat-Dehydrogenase (LDH)

Alkalische Phosphatase (ALP)

3.4.2.2 MARKER DES PROXIMALEN TUBULUS

Alanin-Aminotransferase (ALT)

Gamma-Glutaryltransferase (GGT)

N-Acetyl-Beta-Glucosaminidase ( $\beta \mathrm{NAG}$ )

Alpha-1-Microglobulin ( $\alpha 1 \mathrm{MG}$ )

Beta-2-Microglobulin ( $\beta 2 \mathrm{MG})$

Clusterin (CLU)

Gluthation-S-Transferase (GST $\alpha$ )

Kidney-Injury-Molecule-1 (KIM1)

Trefoil-Factor-3 (TFF3)

3.4.2.3 MARKER DES DISTALEN TUBULUS

Aspartat-Aminotransferase (AST)

Neutrophile Gelatinase-Assoziertes

Lipocalin (NGAL)

Tamm-Horsefall-Protein (THUP)

40

Vascular Endothelial Growth Factor (VEGFA)

3.4.2.4 MARKER DES SAMMELROHRS

Calbindin (Calb)

3.4.2.5 MARKER DES GLOMERULUMS

Cystatin C (CysC)

Tissue Inhibitior of Metalloprotease-2

(TIMP2)

Osteopontin (Osteo) 
4.1 Methodische Limitierung 47

4.2 Basiswerte der Biomarker im Patientenkollektiv 48

4.3 Auswirkungen der Chemotherapeutika Cis- und 49 Carboplatin auf die Biomarker im Urin

4.3.1 Geschlechtsspezifische Auswirkungen auf die Bio56 marker im Urin nach der Chemotherapie

4.3.2 Auswirkungen von Diabetes Mellitus auf die Bio58 marker im Urin nach der Chemotherapie

4.3.3 Auswirkungen einer arteriellen Hypertonie auf die 60 Biomarker im Urin nach der Chemotherapie 
ABKÜRZUNGSVERZEICHNIS

$\alpha 1 \mathrm{MG}$

Alpha-1-Microglobulin

ALT

Alanin-Aminotransferase

ALP

Alkalische Phosphatase

ANV

Akutes Nierenversagen

AST

Aspartat-Aminotransferase

$\beta 2 \mathrm{MG}$

Beta-2-Microglobulin

BNAG

N-Acetyl-Beta-Glykosaminidase

BUN

Blood-Urea-Nitrogen (Blut-Harnstoff-Stickstoff)

$\mathrm{Ca}$

Calcium

Calb

Calbindin

$\mathrm{Cl}$

Chlorid

Clu

Clusterin

CKD-EPI Chronic kidney disease epidemiology collaboration

CRF Case Record Form

CysC Cystatin C

dist. distal

EMA European Medicine Assoziation

FDA Food and Drug Association

GFR Glomeruläre Filtrationsrate

Gluc Glukose

GGT Gamma-Glutaryltransferase

GSTa Glutathion-S-Transferase $\alpha$

IFCC International Federation of Clinical Chemistry

K Kalium

KIM1 Kidney-Injury-Molecule-1

$\mathrm{LDH} \quad$ Lactatdehydrogenase 


$\begin{array}{ll}\text { MAP } & \text { Luminex-Multianalyte Plattorm } \\ \text { Mg } & \text { Magnesium } \\ \text { MILAB } & \text { Microalbumin } \\ \text { Na } & \text { Natrium } \\ \text { NAD+/NADH } & \text { Nicotinamid-Adenin-Dinukleotid } \\ \text { NaCl } & \text { Natriumchlorid } \\ \text { NGAL } & \text { Neutrophile Gelatinase-assoziiertes Lipocalin } \\ \text { NV } & \text { Nierenversagen } \\ \text { OCT } & \text { Organischer Kationen-Transporter } \\ \text { Osteo } & \text { Osteopontin } \\ \text { P } & \text { Phosphat } \\ \text { PEG } & \text { Polyethylenglykol } \\ \text { pH } & \text { pH-Wert } \\ \text { Prot } & \text { Protein } \\ \text { ROC } & \text { Receiver-Operating-Characteristic } \\ \text { SCrea } & \text { Serumkreatinin } \\ \text { TFF3 } & \text { Trefoil-Factor-3 } \\ \text { THUP } & \text { Tamm-Horsefall-Protein } \\ \text { TIMP2 } & \text { Tissue-Inhibitor of Metalloprotease-2 } \\ \text { Ukrea } & \text { Urinkreatinin } \\ \text { Urea } & \text { Harnstoff } \\ \text { VEGFA } & \text { Vascular Endothelial Growth Factor } \\ & \\ & \end{array}$




\section{ABBILDUNGSVERZEICHNIS}

Abb. 1: Darstellung der Serumkreatininwerte des Patientenkollektivs, gruppiert nach männlichen (M) und weiblichen (W) Patienten männlichen (M) und weiblichen (F) Patienten

Abb. 2: Darstellung der TFF3/Crea-Konzentration, gruppiert nach männlichen (M) und weiblichen (W) Probanden

Abb. 3: Darstellung der NGAL/Crea-Konzentration, gruppiert nach männlichen (M) und weiblichen (W) Probanden

Abb. 4: Darstellung der THUP/Crea-Konzentration, gruppiert nach männlichen (M) und weiblichen (W) Probanden

Abb. 5: Darstellung der MILAB/Crea-Konzentration, gruppiert nach männlichen (M) und weiblichen (W) Probanden

Abb. 6: Darstellung der TIMP2/Crea-Konzentration, gruppiert nach männlichen $(\mathrm{M})$ und weiblichen $(\mathrm{W})$ Probanden

Abb. 7: Darstellung der Na/Crea-Konzentrationen an den Tagen vor und nach der Chemotherapie

Abb. 8: Darstellung der $\mathrm{Cl} / \mathrm{Crea-Konzentrationen} \mathrm{an} \mathrm{den} \mathrm{Tagen}$ vor und nach der Therapie

Abb. 9: Darstellung der Basiswerte, gruppiert nach männlichen (M) und weiblichen (F) Patienten

Abb. 10: Darstellung der K/Crea-Konzentrationen an den Tagen nach Gabe des Chemotherapeutikums

Abb. 11: Darstellung der Ca/Crea-Konzentration, gruppiert nach männlichen (M) und weiblichen (F) Patienten

Abb. 12: Darstellung der Mg/Crea-Konzentrationen vor der Chemotherapie, gruppiert nach männlichen $(\mathrm{M})$ und weiblichen $(\mathrm{F})$ Patienten

Abb. 13: Darstellung der Mg/Crea-Konzentrationen an den Tagen nach Gabe des Chemotherapeutikums

Abb. 14: Darstellung der Gluc/Crea-Konzentrationen Nach Gabe des Chemotherapeutikums, gruppiert nach diabetischen (D) und nichtdiabetischen (ND) Patienten 
Abb. 16: Darstellung der Prot/Crea-Konzentrationen an den Tagen vor und nach der Chemotherapie, gruppiert nach männlichen (M) und weiblichen (F) Patienten

Abb. 17: Darstellung der MIALB/Crea-Konzentration an den Tagen vor und nach der Therapie, gruppiert nach männlichen (M) und weiblichen (F) Patienten

Abb. 18: Darstellung der ALT/Crea-Konzentration an den Tagen vor und nach der Chemotherapie, gruppiert nach männlichen (M) und weiblichen (F) Patienten

Abb. 19: Darstellung der GGT/Crea-Konzentration nach der Gabe des Chemotherapeutikums, geschlechtsspezifisch gruppiert nach männlichen (M) und weiblichen (F) Patienten

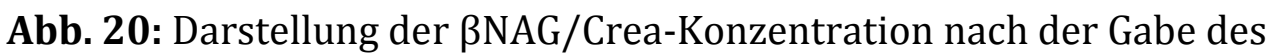
Chemotherapeutikums, gruppiert nach männlichen (M) und weiblichen (F) Patienten

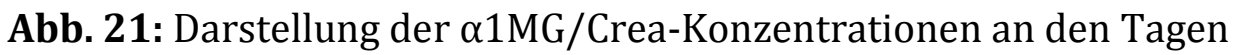
vor und nach Gabe der Chemotherapie

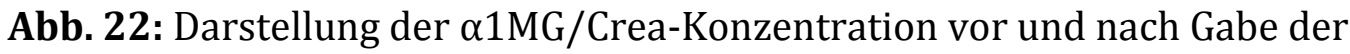
Chemotherapie, gruppiert nach diabetischen (D) und nichtdiabetischen (ND) Patienten

Abb. 23: Darstellung der $\beta 2 \mathrm{MG} /$ Crea-Konzentration an den Tagen vor und nach der Chemotherapie

Abb. 24: Darstellung der Clu/Crea-Konzentration an den Tagen vor und nach der Chemotherapie

Abb. 25: Darstellung der GST $\alpha /$ Crea-Konzentration an den Tagen vor und nach Gabe des Chemotherapeutikums

Abb. 26: Darstellung der KIM1/Crea-Konzentration an den Tagen vor und nach Gabe des Chemotherapeutikums, gruppiert nach Hypertonikern $(\mathrm{H})$ und Normotonikern $(\mathrm{NH})$

Abb. 27: Darstellung der KIM1/Crea-Konzentration vor und nach Gabe des Chemotherapeutikums, gruppiert nach diabetischen (D) und nichtdiabetischen (ND) Patienten

Abb. 28: Darstellung der AST/Crea-Konzentration an den Tagen vor und nach der Chemotherapie, gruppiert nach männlichen (M) und weiblichen (F) Patienten 
Abb. 29: Darstellung der NGAL/Crea-Konzentrationen vor und nach Gabe des 40 Chemotherapeutikums, gruppiert nach männlichen (M) und weiblichen (F) Patienten

Abb. 30: Darstellung der THUP/Crea-Konzentration an den Tagen vor und nach der Chemotherapie, gruppiert nach diabetischen (D) und nicht-diabetischen (ND) Patienten

Abb. 31: Darstellung der VEGFA/Crea-Konzentration an den Tagen vor und nach der Gabe des Chemotherapeutikums, gruppiert nach männlichen (M) und weiblichen (F) Patienten

Abb. 32: Darstellung der Calb/Crea-Konzentration an den Tagen vor und nach der Chemotherapie

Abb. 33: Darstellung der CysC/Crea-Konzentration an den Tagen vor und nach Gabe des Chemotherapeutikums

Abb. 34: Darstellung der TIMP2/Crea-Konzentration an den Tagen vor und nach der Gabe des Chemotherapeutikums, gruppiert nach männlichen (M) und weiblichen (F) Patienten

Abb. 35: Darstellung der OSTEO/Crea-Konzentrationen an den Tagen vor und nach Gabe des Chemotherapeutikums, gruppiert nach diabetischen (D) und nichtdiabetischen (ND) Patienten

Abb. 36: Darstellung der OSTEO/Crea-Konzentration an den Tagen vor und nach der Chemotherapie, gruppiert nach Cisplatin (CIS) und Carboplatin (CARBO) 
Tabelle 1: Definition der akuten Nierenschädigung

Tabelle 2: Referenzwerte der Biomarker im Probandenkollektiv

Tabelle 3: Probanden- und Patientenkollektiv

Tabelle 4: Basisdaten der Patienten

Tabelle 5: Therapieschema der hypertonischen Patienten

Tabelle 6: Tumorentitäten im Patientenkollektiv

Tabelle 7: Chemotherapien im Patientenkollektiv

Tabelle 8: Anzahl der Patienten in den 5 Stadien der Clearance

Tabelle 9: Anzahl der Therapiezyklen der Patienten im Kollektiv 


\section{EINLEITUNG}

Das akute Nierenversagen (ANV) ist definiert als eine plötzliche Verschlechterung der glomerulären und tubulären Funktion der Niere. Dieser Zustand ist prinzipiell reversibel (Schmidt et al. 2010).

Pathophysiologisch kann man zwischen ischämischen und toxisch verursachten ANV unterscheiden. Nach Coudhoury werden in etwa 19-33\% der im Krankenhaus erworbenen Fälle von akuter Nierenschädigung durch nephrotoxische Medikamente hervorgerufen (Coudhury und Ziauddin 2005).

Eine Vielzahl von Medikamenten kann potentiell zu einer Nierenschädigung führen. Hierzu gehören Medikamente wie Antibiotika, Aminoglykoside und Immunsuppressiva (Campistol und Grinyo 2001). Ebenso kann die Gabe der Chemotherapeutika Cisplatin und Carboplatin in der onkologischen Therapie nephrotoxische Wirkung haben. In der vorliegenden Studie wurden die Effekte dieser platinhaltigen Chemotherapeutika auf diverse Biomarker untersucht, die für akut toxisches Nierenversagen indizierend sein können.

Die nephrotoxische Wirkung von Cisplatin und Carboplatin wird durch eine Akkumulation in den Zielzellen und durch verschiedene Interaktionen mit intrazellulären Strukturen ausgelöst. Die Platinkonzentration in den tubulären Epithelzellen ist fünf Mal höher als im Blut (dos Santos et al. 2012).

Diese Akkumulation kann durch sogenannte organische Kationentransporter (OCT) vermittelt werden (Ciarimboli et al. 2010). In der Zelle kann die hydratisierte Form von Cis-/Carboplatin schnell mit Purinbasen interagieren (primär am N7) und bedingt somit einen DNA-Schaden, der durch das Tumor-Suppressor-Protein p53 entsteht. Dieses wiederum aktiviert pro-apoptotische Gene und inhibiert die antiapoptotische Genexpression (Lajer et al. 2005).

Ebenso sorgt das platinhaltige Chemotherapeutikum für eine Dysfunktion der Mitochondrien in den Zellen, was ebenfalls den Untergang der renalen Tubuluszellen bedingt (Santos et al. 2008).

Als weitere Aktion sorgt Cisplatin innerhalb der Zellen für oxidativen und nitrosativen Stress (Cetin et al. 2006). Zudem führt Cisplatin durch die Aktivierung von NF- 
кB zu einer inflammatorischen Reaktion (Miller et al. 2011). Das Spektrum der Nierenschädigung des ANVs, reicht von minimalen Störungen bis zum vollständigen Verlust der Nierenfunktion (Tabelle 1).

Tabelle 1: Definition der akuten Nierenschädigung (Schmidt et al. 2010)

\begin{tabular}{|c|c|l|c|}
\hline \multicolumn{4}{|c|}{ Stadieneinteilung der akuten Nierenschädigung } \\
\hline RIFLE-Stadium & AKIN-Stadium & \multicolumn{1}{|c|}{ Serumkreatinin } & Diurese \\
\hline Risk & 1 & $\begin{array}{l}\text { Anstieg oder } \geq 0.3 \\
\mathrm{mg} / \mathrm{dl}\end{array}$ & $<0.5 \mathrm{ml} / \mathrm{kgKG} / \mathrm{h}(6 \mathrm{~h})$ \\
\hline Injury & 2 & $2-3$-facher Anstieg & $<0.5 \mathrm{ml} / \mathrm{kgKG} / \mathrm{h}(12 \mathrm{~h})$ \\
\hline Failure & 3 & $\begin{array}{l}>3 \text {-facher Anstieg; } \\
>4 \mathrm{mg} / \mathrm{dl}\end{array}$ & $\begin{array}{l}<0.3 \mathrm{ml} / \mathrm{kgKG} / \mathrm{h} \\
(24 \mathrm{~h}) \text { oder Anurie }\end{array}$ \\
\hline Loss & Spätfolge & $\begin{array}{l}\text { Dauerhaftes NV } \\
>3 \text { Wochen }\end{array}$ & \\
\hline $\begin{array}{c}\text { End-stage-renal- } \\
\text { deasase (ESRD) }\end{array}$ & Spätfolge & $\begin{array}{l}\text { Dauerhaftes NV } \\
>4 \text { Monate }\end{array}$ & \\
\hline
\end{tabular}

Üblicherweise werden zur Diagnostik und Verlaufskontrolle einer Nierenschädigung die Standardblut- (Serumkreatinin (SCrea)) und Urinparameter (epitheliale Zellen, tubuläre Zylinder, fraktionelle Natriumausscheidung) herangezogen. Leider weisen diese diagnostischen Marker eine geringe Sensitivität auf und sind zudem unspezifisch. Außerdem kommt es erst nach relativ schwerer Nierenschädigung und mit Verzögerung zu einem signifikanten Anstieg der SCrea-Konzentration (Vaidya et al. 2008). Ein Anstieg der SCrea-Konzentration liefert zudem keinen Hinweis auf den primären Ort der Schädigung im Nephron.

Das Ausmaß der Schädigung wird oft unterschätzt, da signifikante Veränderungen der glomerulären Filtrationsrate und auch schwere Tubulusschädigungen initial nur zu einem geringen und zeitlich verzögerten Anstieg des Serumkreatinins führen. Bereits geringe Anstiege des Serumkreatinins können Zeichen für eine schwere Nierenschädigung und eine schlechte Prognose sein. Dadurch können Verzögerungen in der Diagnostik entstehen und dieses kann ein frühzeitiges Absetzten des toxischen Medikaments sowie eine rechtzeitige und adäquate Behandlung der Nierenschädigung verhindern.

Auch die präklinische Beurteilung (Sicherheitspharmakologie, Toxikologie) von potentiellen neuen Arzneimitteln wird erschwert, und potentiell nephrotoxische 
Medikamente werden deshalb mitunter erst spät in den klinischen Studien identifiziert.

Daher ist die Entwicklung bzw. Erkennung spezifischer, zuverlässiger Biomarker für die Diagnostik früher Nierenschädigung durch platinhaltige Chemotherapeutika in klinischen und vorklinischen Studien äußerst relevant. In der Medikamentenentwicklung erleichtern Biomarker die Auswahl von prädispositionierten Patienten (Diabetiker, Hypertoniker) und Dosierungen. Außerdem helfen sie bei der Planung klinischer Studien und liefern klare Information über das Nutzen-Risikoverhältnis einer Therapie.

Die Biomarker sollten in ihrer Spezifität (Differenzierung zwischen glomerulären und tubulären Schäden) allerdings wesentlich sensitiver sein, als sie es bisher sind. Außerdem ist es wichtig, dass sie eine renale Schädigung anzeigen, bevor dies zu einer Verschlechterung der GFR beziehungsweise bevor es zu einem Anstieg der Serumkreatininwerte kommt.

Eine Schädigung der Tubuluszellen (akut oder chronisch) führt zu einem Austritt von Enzymen (z. B. N-acetyl-beta-Glycosaminidase ( $\beta N A G)$, alkalischer Phosphatase (ALP) und Alanin-Aminotransferase $(A L T)$ ) in das tubuläre Lumen und somit in den Urin (D’Amico und Bazzi 2003). Ebenso weist das Auftreten niedermolekularer Proteine ( $\alpha 1$-Microglobulin, B2-Microglobulin) im Urin auf eine Schädigung hin, da diese normalerweise vollständig rückresorbiert werden (Trof et al. 2006). Eine Enzymurie kann einen milden, reversiblen Schaden reflektieren (Ogura et al. 1996), (Whiting und Brown 1996).

Bei verschiedenen Grunderkrankungen sind diese Marker auch ohne zusätzliche Nierenschädigung erhöht (beispielsweise BNAG bei gestörter Glukosetoleranz) (Vaidya et al. 2008). Des Weiteren weisen diese Parameter im zeitlichen Verlauf eine zum Teil erhebliche intra-individuelle Variabilität auf (Yamagami et al. 2008).

Ein einzelner Biomarker alleine ist auf Grund der Heterogenität der Schädigung nicht ausreichend, um eine renale Schädigung zu charakterisieren, deshalb wird voraussichtlich ein Muster mehrerer Parameter benötigt.

Im Juni 2008 wurden sieben Biomarker im Urin (Kidney injury molecule-1 (KIM1), Albumin (Alb), Protein (Prot), $\beta 2-$ Microglobulin ( $\beta 2 M G)$, Cystatin C (CysC), Cluste- 
rin (Clu) und der Trefoil Factor-3 (TFF3)) von der "Food and Drug Association“ (FDA) und „European Medicine Association“ (EMEA) zur Testung von akuter Nephrotoxizität in toxikologischen Untersuchungen an Ratten anerkannt (FDA-News 12.06.2008).

Nach Exposition mit verschiedenen nephrotoxischen Medikamenten konnte im Vergleich mit histologischen Untersuchungen und mittels Receiver-OperatingCharacteristic-Analysen gezeigt werden, dass diese Biomarker eine bessere Sensitivität und Spezifität als SCrea besitzen. Diese neuen Marker erlauben es, im Rattenmodell eine Nierenzellschädigung innerhalb von Stunden nach Schädigungsbeginn nachzuweisen.

Eine klinische Evaluierung der ANV-Biomarker soll durch die nephrotoxische Wirkung von Cis-/Carboplatin im Rahmen dieser Studie vorgenommen werden. 


\section{MATERIAL UND METHODEN}

\subsection{PATIENTEN UND PROBANDEN}

Für die Studie wurden Urinproben von elf männlichen und 18 weiblichen Patienten (Mindestalter: 18 Jahre) mit onkologischen Erkrankungen gesammelt, die in der Universitätsmedizin Göttingen eine Chemotherapie mit Cis-, oder Carboplatin erhielten. Die Patienten gaben vor Gabe des Chemotherapeutikums eine Urinprobe ab: mindestens eine bis maximal fünf weitere an den stationären Tagen nach der Chemotherapie. Für die Untersuchungen wurde der Morgenurin der noch nüchternen Patienten verwendet. Diese Studie erfolgte nach der Freigabe durch die lokale Ethik-Kommission (Antragsnummer: 9/11/08).

Dem Patientenkollektiv wurde ein gesundes Probandenkollektiv gegenübergestellt. Die Urinparameter der Vergleichsgruppe entstammen einer früheren Studie, die in Biberach erhoben wurde. Die Messungen dazu erfolgten unabhängig von dieser Studie. Die Messwerte wurden zur Definition des Referenzbereichs genutzt (Tabelle 2). Diese Studie erfolgte nach Freigabe durch die Ethik-Kommission der Landesärztekammer Baden Württemberg (Antragsnummer: F-2011-038).

Tabelle 2: Referenzwerte der Biomarker im Probandenkollektiv

\begin{tabular}{|c|c|c|c|c|c|c|c|c|c|}
\hline \multicolumn{2}{|c|}{ Elektrolyte } & \multicolumn{4}{|c|}{ Marker des proximalen Tubulus } & \multicolumn{2}{|c|}{ Ubiquitäre Marker } & \multicolumn{2}{|c|}{ Metabolite } \\
\hline $\begin{array}{c}\mathrm{Na} / \mathrm{Crea} \\
{[\mathrm{mmol} / \mathrm{mmol}]}\end{array}$ & 38.54 & $\begin{array}{l}\text { ALT/Crea } \\
{[\mathrm{U} / \mathrm{mmol}]}\end{array}$ & 1.04 & $\begin{array}{l}\text { GSTa/Crea } \\
{[\mu \mathrm{g} / \mathrm{mmol}]}\end{array}$ & 2.63 & $\begin{array}{l}\text { Prot/Crea } \\
{[\mathrm{mg} / \mathrm{mmol}]}\end{array}$ & 15.5 & \begin{tabular}{|c|} 
Gluc/Crea \\
{$[\mathrm{mmol} / \mathrm{mmol}]$}
\end{tabular} & 0.21 \\
\hline $\begin{array}{c}\text { K/Crea } \\
{[\mathrm{mmol} / \mathrm{mmol}]}\end{array}$ & 9.70 & $\begin{array}{c}\beta \text { BNAG/Crea } \\
{[\mathrm{U} / \mathrm{mmol}]}\end{array}$ & 0.64 & \multicolumn{2}{|c|}{$\begin{array}{c}\text { Marker des distalen } \\
\text { Tubulus }\end{array}$} & $\begin{array}{l}\text { ALP/Crea } \\
{[\text { [U/mmol] }}\end{array}$ & 5.96 & $\begin{array}{c}\text { Urea/Crea } \\
{[\mathrm{mmol} / \mathrm{mmol}]}\end{array}$ & 103.85 \\
\hline $\begin{array}{c}\text { Cl/Crea } \\
\text { [mmol/mmol] }\end{array}$ & 47.44 & \begin{tabular}{|l} 
KIM1/Crea \\
{$[\mu \mathrm{g} / \mathrm{mmol}]$}
\end{tabular} & 0.11 & $\begin{array}{l}\text { NGAL/Crea } \\
{[\mu \mathrm{g} / \mathrm{mmol}]}\end{array}$ & 60.36 & $\begin{array}{l}\text { VEGF/Crea } \\
{[\mathrm{ng} / \mathrm{mmol}]}\end{array}$ & 101.3 & $\begin{array}{l}\text { Urinkrea } \\
\text { [mmo/L] }\end{array}$ & 15.9 \\
\hline $\begin{array}{c}\text { Ca/Crea } \\
{[\mathrm{mmol} / \mathrm{mmol}]}\end{array}$ & 1.09 & $\begin{array}{l}\beta 2 \mathrm{MG} / \mathrm{Crea} \\
{[\mathrm{mg} / \mathrm{mmol}]} \\
\end{array}$ & 0.02 & $\begin{array}{l}\text { AST/Crea } \\
{[\mathrm{U} / \mathrm{mmol}]} \\
\end{array}$ & 1.01 & $\begin{array}{l}\text { LDH/Crea } \\
{[\mathrm{U} / \mathrm{mmol}]}\end{array}$ & 3.0 & $\mathrm{pH}$ & 7.8 \\
\hline $\begin{array}{c}\text { Mg/Crea } \\
{[\mathrm{mmol} / \mathrm{mmol}]}\end{array}$ & 0.8 & $\begin{array}{l}\text { a1MG/Crea } \\
{[\mathrm{mg} / \mathrm{mmol}]}\end{array}$ & 0.36 & \begin{tabular}{|c|} 
Clu/Crea \\
{$[\mathrm{mg} / \mathrm{mmol}]$}
\end{tabular} & 0.0063 & $\begin{array}{l}\text { MIALB/Crea } \\
{[\mathrm{mg} / \mathrm{mmol}]}\end{array}$ & 5.79 & \multicolumn{2}{|c|}{$\begin{array}{l}\text { Serumkreatinin } \\
\text { (Normwerte) }\end{array}$} \\
\hline $\begin{array}{l}\text { Phos/Crea } \\
{[\mathrm{mg} / \mathrm{mmol}]}\end{array}$ & 130.2 & \begin{tabular}{|l} 
TIMP2/Crea \\
[Mg/mmol]
\end{tabular} & 0.35 & $\begin{array}{l}\text { THUP/Crea } \\
{[\mathrm{mg} / \mathrm{mmol}]}\end{array}$ & 2.73 & \multicolumn{2}{|c|}{$\begin{array}{l}\text { Marker des } \\
\text { Glomerulums }\end{array}$} & $\begin{array}{l}\text { Screa (M) } \\
{[\mathrm{mg} / \mathrm{dL}]}\end{array}$ & 1.0 \\
\hline & & $\begin{array}{l}\text { GGT/Crea } \\
{[\mathrm{U} / \mathrm{mmol}]}\end{array}$ & 4.91 & \multicolumn{2}{|c|}{$\begin{array}{l}\text { Marker des } \\
\text { Sammelrohrs }\end{array}$} & $\begin{array}{l}\text { CysC/Crea } \\
{[\mu \mathrm{g} / \mathrm{mmol}]}\end{array}$ & 7.96 & $\begin{array}{l}\text { Screa }(F) \\
{[\mathrm{mg} / \mathrm{dL}]}\end{array}$ & 1.2 \\
\hline & & $\begin{array}{l}\text { TFF3/Crea } \\
\text { [mg/mmoll] }\end{array}$ & 1.77 & \begin{tabular}{|l} 
Calb/Crea \\
{$[\mu g / m m o l]$}
\end{tabular} & 10.8 & $\begin{array}{l}\text { Osteo/Crea } \\
{[\mu \mathrm{g} / \mathrm{mmol}]}\end{array}$ & 311.2 & & \\
\hline
\end{tabular}


Alle Probanden waren als maßgebend gesund einzustufen, d.h. es bestand keine Begleiterkrankung und somit lag auch keine Medikation vor, die die Nierenfunktion negativ hätte beeinflussen können.

\subsection{MESSMETHODEN}

Zur Messung wurden folgende Verfahren angewendet:

1) Die Bestimmung der Konzentration enzymatischer Marker $\beta N A G, L D H, A L T$ sowie von MIALB und Protein und von weiteren klinisch-chemischen Markern (Calcium, Magnesium, Phosphat, Glucose, Kreatinin, Harnstoff) im Urin wurde durch die Boehringer-Ingelheim Pharma GmbH \&Co KG Biberach/Riß durchgeführt.

2) Die Bestimmung verschiedener Marker mittels Luminex-Multianalyte Plattform (MAP) wurde von der Firma Rules Based Medicine INC. (Austin/Texas, U.S.A.) durchgeführt. Hierbei wurden neben Markern, die von der FDA und EMEA bereits für toxikologische Untersuchungen an Ratten anerkannt wurden ( $\beta 2 \mathrm{MG}$, Clusterin, CysC, KIM1 und TFF3) weitere Biomarker wie Calbindin, GSTa, NGAL, Osteopontin, TIMP2, VEGF, a1MG und THUP gemessen.

$\mathrm{Zu}$ allen Sammelzeitpunkten wurden jeweils $2 \mathrm{ml}$ Spontanurin benötigt. Je $1 \mathrm{ml}$ wurde in ein Eppendorfgefäß pipettiert. Außerdem wurden weitere $10 \mathrm{ml}$ zur Probe für den „Luminex-Panel“ in eine mit Borsäure versetzte Monovette gezogen (20 $\mathrm{mg} / \mathrm{ml}$ ). Die Probe zur Bestimmung von enzymatischen Markern sowie MIALB und Protein wurden sofort bei $-20^{\circ} \mathrm{C}$ eingefroren.

Die gefrorenen Proben wurden gesammelt und in regelmäßigen Abständen auf Trockeneis zur Boehringer-Ingelheim Pharma GmbH \&Co KG Biberach/Riß zur weiteren Analyse verschickt. Die Proben für das „Luminex-Panel“ wurden ab diesem Zeitpunkt ebenfalls bei $-20^{\circ} \mathrm{C}$ gelagert.

Die Messung der klinisch-chemischen Parameter erfolgte bei der BoehringerIngelheim Pharma GmbH \&Co KG Biberach/Riß im Labor von Dr. Pestel. Die Proben wurden vollautomatisch unter Verwendung eines Konelab 60i von Thermo Fisher Scientific (Vantaa, Finnland) gemessen. Die Testkits wurden überwiegend von Thermo Electron Corporation OY (Vantaa, Finnland), aber auch von Wako Chemicals GmbH (Neuss, Germany) oder Roche Diagnostics GmbH (Mannheim, 
Germany) bezogen und nach den Anweisungen des Herstellers (gegebenenfalls modifiziert an den linearen Bereich von Urinproben) angewandt.

Typischerweise wurden standardisierte und anerkannte klinisch-chemische Messverfahren eingesetzt, das heißt, der zu messende Parameter wurde zur Umsetzung einer chemischen Reaktion quantitativ begrenzend eingesetzt und ein davon abhängiges farbiges Substrat wurde photometrisch erfasst (kinetisch oder mittels Endpunkt-Bestimmungen).

Natrium, Kalium und pH wurden mit Elektronen-sensitiven Elektroden quantitativ erfasst. Insgesamt standen folgende Parameter zur Verfügung: Natrium, Kalium, Chlorid, Kalzium, Magnesium, Phosphat, pH, Glucose, Kreatinin, Harnstoff, Gesamtprotein, Microalbumin, BNAG, ALP, ALT und mit Einschränkungen LDH und AST, GGT. Die Verfahren werden einzeln wie folgt dargestellt:

1) Die Bestimmung der Aktivität von $\beta N A G$ erfolgte mittels Endpunkt-Methode. Das Testkit wurde von der Firma Roche Diagnostics $\mathrm{GmbH}$ (Mannheim, Deutschland) gestellt. 3-Cresolsulphthaleeinyl-N-acethyl- $\beta$-D-Glusaminid Natriumsalz wurde hydrolysiert mit $\beta N A G$.

Die verbliebende 3-Cresolsulfonphtalein Natriumsalz (3-Cresol purple) wurden spektralphotometrisch bei einer Wellenlänge von $575 \mathrm{~nm}$ gemessen.

2) Die Aktivität der ALP wurde durch eine Enzymeinstufungsmethode gemessen, die an die „International Federation of Clinical Chemistry and Laboratory medicine" (IFCC)-Methode anlehnt (IFCC 1983).

3) Die Bestimmung der LDH erfolgte ebenfalls durch die an die IFCC anlehnende Enzymeinstufungsmethode (IFCC 1994). LDH katalysiert die Oxidation von Lactat zu Pyruvat und reduziert parallel dazu NAD+ zu NADH (Nicotnamid-Amin-Dinukleotid) äquimolarer Konzentration. Das gebildete NADH wurde spektralphotometrisch bei einer Wellenlänge von $340 \mathrm{~nm}$ gemessen.

4) Auch die Aktivität der GGT wurde durch eine Enzymeinstufungsmethode ermittelt (IFCC 2002b). GGT katalysiert die Übertragung von Glutaminsäure 
zu Glycylglycin. Das dabei entstandene 5-Amino-2-Nitrobenzoat wurde spektralphotometrisch bei einer Wellenlänge von $405 \mathrm{~nm}$ gemessen.

5) Nach der Enzymeinstufungsmethode (basierend auf der IFCC Methode) wurde auch die Aktivität der Alanin-Aminotransferase gemessen (IFCC 2002a). Bei der auf die IFCC bezogenen Methode wurde Pyridoxal-5‘Phosphat zur Aktivierung von ALT genutzt. Bei der modifizierten Methode wurde darauf verzichtet. ALT katalysiert die Reaktion von Alanin und $\alpha$ Ketoglutarat durch die Übertragung von einer Aminogruppe zu Glutamat und Pyruvat. Das Pyruvat wird durch LDH zu Lactat reduziert, gleichzeitig wird eine äquimolare Menge NADH zu NAD+ oxidiert. Die Entfernung vom $\mathrm{NADH}$ wurde spektralphotometrisch bei einer Wellenlänge von $340 \mathrm{~nm}$ gemessen.

6) Die Aspartat-Aminotransferase-Aktivität wurde wie die vorab genannten Parameter durch eine auf der IFCC-Methode basierende Enzymeinstufungsmethode gemessen (IFCC 2002a).

Auch hier wurde bei der konventionellen IFCC-Methode Pyridoxal-54Phosphat für die AST-Aktivierung genutzt. Für die modifizierte Methode wurde darauf wieder verzichtet.

Ähnlich der ALT katalysiert auch AST durch Übertragung einer Aminogruppe eine Reaktion. Allerdings katalysiert es Aspartat und a-Ketoglutarat zu Glutamat und Oxalacetat. Oxalacetat wird durch die Malatdehydrogenase zu Malat reduziert. Parallel dazu werden äquimolare Mengen NADH zu NAD+ oxidiert. Hier wurde wieder die Umwandlung des NADHs spektralphotometrisch gemessen, bei einer Wellenlänge von $340 \mathrm{~nm}$.

7) Die Harnstoff-Stickstoff-Konzentration wurde durch eine Enzymeinstufungsmethode gemessen (Tiffany et al. 1972). Harnstoff wird von Urease in Wasser zu Ammoniak und Carbondioxid hydrolysiert. Mit Glutamatdegydrogenase wird Ammoniak mit a-Ketoglutarat zu L-Glutamat. Gleichzeitig wird eine äquimolare Menge NADH zu NAD+ oxidiert. Auch hier wurde die Umsetzung von NADH spektralphotometrisch bei einer Wellenlänge von $340 \mathrm{~nm}$ gemessen. 
8) Die Kreatinin-Konzentration wurde nach einer modifizierten Enzymeinstufungsmethode nach Jaffé gemessen (Jaffé 1986). Kreatinin bildet dabei einen rötlichen Komplex in einer alkalischen Pikrat-Lösung, und die KomplexEntstehung wird gemessen.

Der Effekt der interagierenden Substanzen wurde durch die StandardEndzeitpunkt-Methode nach Jaffé gemessen. Die Konzentration der Komplexe wurde spektralphotometrisch bei einer Wellenlänge von $510 \mathrm{~nm}$ bestimmt.

9) Die Albumin-Konzentration im Urin wurde ebenfalls mit einer zeitlichen Endpunkt-Methode gemessen. Polyethylenglykol (PEG)-verstärkte Immunpräzipitat-Entstehung mit einem speziellen Antiserum (für das humane Albumin vom Schwein) induziert einen Anstieg der Absorption, die spektralphotometrisch mit einer Wellenlänge von 450 nm gemessen wurde (Parviainen et al. 1985).

10) Die Proteinkonzentration im Urin wurde ebenfalls mit einer zeitlichen Endpunkt-Methode gemessen. Pyrogallol-Rot-Molybdat-Komplexe werden dabei an die Proteine gebunden.

Diese Bindung bewirkt ein erhöhtes Absorptionsspektrum bei einer Wellenlänge von $600 \mathrm{~nm}$ (Doumas 1975). Somit wurde die Proteinkonzentration spektralphotometrisch bei dieser Wellenlänge ermittelt.

11) Auch die Konzentration der Glukose wurde mit einer zeitlichen EndpunktMethode gemessen. Glukose wird dabei mit Adenosin-Triphosphat phosphoriliert. Diese Reaktion wird durch Hexokinase katalysiert. Das entstandene Glukose-6-Phosphat wird durch Glukose-6-PhosphatDehydrogenase zu 6-Phosphoglukonat oxidiert. In der gleichen Reaktion wird NAD+ zu NADH reduziert. Dies wurde dann bei einer Wellenlänge von $340 \mathrm{~nm}$ spektralphotometrisch gemessen.

12) Die Phosphatkonzentration wurde wie die vorangegangenen Laborparameter durch eine zeitliche Endpunkt-Methode bestimmt (Daly und Ertingshausen 1972). Das entstandene anorganische Phosphat bildet im 
sauren Milieu einen gelben Komplex mit Ammonium Molybdat. Die Konzentration von den gebildeten Komplexen wurde ebenfalls, bei einer Wellenlänge von $340 \mathrm{~nm}$, spektralphotometrisch bestimmt.

13) Die totale Kalziumkonzentration wurde ebenfalls mit der zeitlichen Endpunkt-Methode bestimmt (Janssen und Helbing 1991). Kalziumionen bilden einen stark farbigen Komplex mit Arsenazo III bei einem neutralen $\mathrm{pH}$-Wert. Diese Bildung wurde bei $660 \mathrm{~nm}$ spektralphotometrisch bestimmt.

14) Die im Urin befindliche Chloridkonzentration wurde mit der MercuryRhaodanid-Methode (ebenfalls eine zeitliche Endpunkt-Methode) ermittelt. Das Testkit (Chlorid FS) stammt von der Firma Rolf Greiner BioChemica (Flacht, Deutschland). Chloridionen hinterlassen eine äquivalente Menge an Thiocyanat vom Mercury-Thiocyanat. Thiocyanat bildet zusammen mit Eisenionen einen roten Komplex. Die Konzentration dieser Komplexe wurde spektralphotometrisch bei $510 \mathrm{~nm}$ gemessen.

15) Die Natrium- und Kaliumkonzentration, sowie der $\mathrm{pH}-$ Wert wurden durch die Messung der elektrolytischen Aktivität in der Lösung mit ionenselektiven Elektroden gemessen. Dies ist eine indirekte Messmethode.

Die Bestimmung verschiedener Marker mittels Luminex-Multianalyte Plattform (MAP) von Rules Based Medicine INC (Austin/Texas, U.S.A.) erfolgte mit Hilfe sogenannter "Microspheres“, an die assay-spezifische Reagentien (Antigene, Antikörper, Rezeptoren, Substrate etc.) kovalent gebunden wurden.

Diese Microspheres sind zusätzlich mit zwei Farbstoffen markiert. Ähnlich der Flow-Zytometrie wurden die Microspheres nach Anregung durch Laserlicht im Luminex TM100 gemessen. Mindestens 50 individuelle Microspheres wurden pro Datenpunkt analysiert.

Zur Standardisierung der Spontanurinproben wurde der jeweiligen Ratio im Verhältnis zum Urinkreatinin bestimmt, um Volumenschwankungen auszugleichen. 
Das weitere allgemeine Vorgehen verlief wie folgt:

Routinemäßig erfolgte vor und nach der Therapie eine Kontrolle der Nierenfunktion durch eine Bestimmung des Serumkreatinins. Hierfür wurden die Laborwerte der täglichen Blutentnahmen der Stationen verwertet.

Zudem erfolgten nach Anstieg des Serumkreatinins durch Carbo- bzw. Cisplatintherapie weitere Kontrollen des Serumkreatinins. Die Kreatininclearance wurde anhand der CKD-EPI Formel berechnet (Lewey et al. 2009). Hierzu wurde ein digitaler Rechner des MVZ Labors Dr. Limbach, Heidelberg, genutzt (http://www.labor-limbach.de; Zugriff am 25.11.2013).

Die routinemäßig gemessenen Serumkreatininwerte wurden für die Auswertung verwendet; andere Serumparameter (Harnstoff, Glukose, Cystatin C, HbA1C (bei Diabetikern)) wurden im Rahmen der Studie gemessen, soweit diese Werte vom Labor erfasst waren. Anonymisiert wurden demographische Parameter, Begleiterkrankungen und Begleitmedikation, die anhand des Case Record Forms (CRF) standardisiert erfasst wurden.

\subsection{STATISTISCHE ANALYSE}

Nach der Erfassung der Daten erfolgte die statistische Auswertung mit dem Statistikprogramm STATISTICA 12.

Zuerst wurden alle Werte der einzelnen Parameter durch den Shapiro-Wilk-Test auf ihre Normalverteilung untersucht, um die weiteren Tests auswählen zu können. Das Signifikanzniveau wurde bei $\alpha=0.05$ festgelegt.

Daraufhin wurde die Signifikanz der einzelnen Parameter vor und an allen Tagen nach der Gabe des Chemotherapeutikums (demnach Tag eins bis Tag fünf nach Therapie) durch ein Omnibus-Testverfahren überprüft.

Anschließend wurde für jeden einzelnen Parameter mittels des WilcoxonMatched-Pairs-Tests die Signifikanz der Änderungen an den einzelnen Tagen nach Gabe des Chemotherapeutikums in Bezug auf die Basiswerte untersucht.

Im Anschluss wurde zur weiteren Untersuchung von signifikanten Unterschieden der einzelnen Gruppen im Patientenkollektiv (männlicher/weiblicher Patient, Dia- 
betiker/Nicht-Diabetiker, Hypertoniker/Normotoniker, Cisplatinpatient/Carboplatinpatient) der Mann-Whitney-U-Test durchgeführt.

Diese Patientenfaktoren wurden hinsichtlich ihrer möglichen $\mathrm{Be}$ einflussung der Niere auf die zu untersuchenden Biomarker analysiert. 


\section{ERGEBNISSE}

\subsection{BESCHREIBUNG DES PROBANDEN- UND DES PATIENTENKOLLEKTIVS}

Die Darstellung des Probanden- und Probandenkollektivs erfolgte durch die Daten des Case Record Form (CRF), die für jeden Patienten und Probanden ausgefüllt wurden. Ziel war es, Parameter zu erfassen, die die Nierenfunktion beziehungsweise die Ausscheidungsraten bestimmter Stoffe beeinflussen können.

Tabelle 3: Probanden- und Patientenkollektiv

\begin{tabular}{|l|c|c|}
\hline Total $n$ & Probanden & Patienten \\
\hline Geschlecht & 71 & 29 \\
\hline Alter (Jahre) & W 37 & M 11 \\
Median (min-max) & $39 \pm 10.06$ & W 18 \\
\hline BMI & $42(18-61)$ & $64 \pm 10.14$ \\
Median (min-max) & $23.4 \pm 3.98$ & $29.5 \pm 8.84$ \\
\hline Größe (m) & $23(17-34)$ & $27(21-54)$ \\
Median (min-max) & $1.73 \pm 0.09$ & $1.68 \pm 0.097$ \\
\hline Gewicht (kg) & $71 \pm 15.94$ & $83 \pm 27.22$ \\
Median (min-max) & $70(41.5-110)$ & $75(56-152)$ \\
\hline Ernährungstyp & & \\
normal & $69(97.18 \%)$ & $29(100 \%)$ \\
vegetarisch & $0(0 \%)$ & $0(0 \%)$ \\
proteinreich & $2(2.82 \%)$ & $0(0 \%)$ \\
Raucher & $6(8.45 \%)$ & $2(6.9 \%)$ \\
\hline Alkohol & $18.94)$ & 17.97 (58.62 \%) \\
Ja & $43(60.56 \%)$ & $12(41.38 \%)$ \\
Nein & $28(39.44 \%)$ & $13(44.82 \%)$ \\
\hline Sport & $14(19.72 \%)$ & $0(0 \%)$ \\
Nein & $38(53.52 \%)$ & $0(0 \%)$ \\
persönl. Fitness & $18(25.35 \%)$ & \\
Ausdauersport & $(1.41 \%)$ & $18 \%)$ \\
Leistungssport & & \\
\hline
\end{tabular}

Das Patientenkollektiv $(n=29)$ teilte sich in elf männliche und 18 weibliche Patienten. Der Altersdurchschnitt der Patienten/-innen lag bei 64 Jahren $( \pm 10$; Median (min-max) 65 (35-79)) (Tabelle 3). Der durchschnittlich errechnete Body-MassIndex der Patienten betrug 29.4 ( \pm 8.8 ; Median (min-max) 27 (21-54)). 
Der Ernährungstyp ergab bei allen Patienten/-innen eine normale Ernährungsweise (keine angegebenen Diäten, vegetarische Kost oder proteinreiches Essverhalten). $6.9 \%$ der Patienten gaben Nikotinkonsum an, und $58.7 \%$ konsumierten gelegentlich Alkohol. $55.2 \%$ gaben an, für ihre persönliche Fitness Sport zu treiben. $47.8 \%$ waren sportlich inaktiv. Der Serumkreatininwert betrug durchschnittlich 0.79 mg/dl ( \pm 0.19 ; Median (min-max) 0.74 (0.61-1.56)). $20.69 \%$ der Patienten waren an Diabetes mellitus erkrankt, davon waren $83.33 \%$ insulinpflichtig (Tabelle 4).

Tabelle 4: Basisdaten der Patienten

\begin{tabular}{|c|c|}
\hline \multicolumn{2}{|c|}{$\begin{array}{c}\text { Basisdaten der Patienten } \\
\text { Total } \mathbf{n}=29 \text { Patienten }\end{array}$} \\
\hline S Crea in mg/dL & $0.79 \pm 0.19$ \\
Median (min-max) & $0.74(0.61-1.56)$ \\
\hline Diabetes & $6(20.69 \%)$ \\
Insulinpflichtig & $5(83.33 \%)$ \\
Nicht Insulinpflichtig & $1(16.67 \%)$ \\
\hline
\end{tabular}

$65.52 \%$ der Pateinten/-innen wiesen einen arteriellen Hypertonus auf. 31,58 \% $(n=6)$ der Hypertoniker wurden mit Angiotensin-Converting-Enzyme-Hemmern (ACE-Hemmern) bzw. mit Angiotensin-II-Rezeptorblockern therapiert, $15.79 \%$ $(n=3)$ mit Schleifendiuretika, $5.26 \%(n=1)$ mit Medikamenten, die im distalen Tubulus und Sammelrohr wirken und $47.37 \%(n=9)$ wurden primär oder additiv mit weiteren Medikamenten gegen hypertonische Erkrankungen therapiert (Tabelle 5).

Tabelle 5: Therapieschema der hypertonischen Patienten

\begin{tabular}{|l|c|}
\hline \multicolumn{2}{|c|}{$\begin{array}{c}\text { Therapie der Patienten mit Hypertonus } \\
\mathbf{n}=19\end{array}$} \\
\hline Hypertonus & $19(65.52 \%)$ \\
\hline ACE/ARB & $6(31.58 \%)$ \\
\hline Schleifendiuretika & $3(15.79 \%)$ \\
\hline dist. Tubulus \& Sammelrohr & $1(5.26 \%)$ \\
\hline andere Hypertensiva & $9(47.37 \%)$ \\
\hline
\end{tabular}


Die Patienten wiesen diverse onkologische Erkrankungen auf (Tabelle 6). Neben Patienten mit Hodgkin- und Non-Hodgkin-Lymphom (10.34 \%, 17.24 \%), zeigte jeweils ein Patient ( $3.45 \%$ ) aus dem Kollektiv ein follikuläres Lymphom, ein Bronchialkarzinom, ein Nierenzellkarzinom und Adenokarzinom. Weiterhin zeigte der weibliche Anteil des Kollektivs gynäkologische Tumoren: Ovarialkarzinom (34.48 \%), Endometriumkarzinom (10.34 \%) und Zervixkarzinom (13.8\%).

Tabelle 6: Tumorentitäten im Patientenkollektiv

\begin{tabular}{|l|c|}
\hline \multicolumn{1}{|c|}{ Tumoreinteilung } & Patientenzahl \\
\hline Non-Hodgkin-Lymphom & $5(17.24 \%)$ \\
\hline Bronchialkarzinom & $1(3.45 \%)$ \\
\hline Morbus Hodgkin & $3(10.34 \%)$ \\
\hline Nierenzellkarzinom & $1(3.45 \%)$ \\
\hline Adenokarzinom & $1(3.45 \%)$ \\
\hline Ovarialkarzinom & $10(34.48 \%)$ \\
\hline Endometriumkarzinom & $3(10.34 \%)$ \\
\hline follikuläres Lymphom & $1(3.45 \%)$ \\
\hline Zervixkarzinom & $4(13.80 \%)$ \\
\hline
\end{tabular}

Die verschiedenen Tumore wurden mit den platinhaltigen Chemotherapeutika Cisplatin $(37.93 \%)$ und Carboplatin $(62.07 \%)$ behandelt (Tabelle 7 ).

Tabelle 7: Chemotherapien im Patientenkollektiv

\begin{tabular}{|l|c|}
\hline \multicolumn{1}{|c|}{ Therapie } & Patientenzahl \\
\hline Cisplatin & $11(37.93 \%)$ \\
\hline Carboplatin & $18(62.07 \%)$ \\
\hline
\end{tabular}

Dem Patientenkollektiv wurde das gesunde Probandenkollektiv (Tabelle 3), mit der Gesamtanzahl von $n=71$, gegenübergestellt. Die geschlechtsspeifische Verteilung umfasste 34 männliche und 37 weibliche Teilnehmer der Probandenstudie (Tabelle 3). Das Durchschnittsalter betrug 39 Jahre ( \pm 10 ; Median (min-max) 42 (18-61)). Der Body-Mass-Index zeigte im Mittel 23.4 ( \pm 4 ; Median (min-max) 23 (17-34)). $97.18 \%$ der Probanden zeigten eine normale Ernährungsweise; $2.82 \%$ ein proteinreiches Ernährungsmuster. $8.45 \%$ gaben Nikotinkonsum, $60.56 \%$ gelegentlichen Alkoholkonsum an. $19.72 \%$ waren sportlich inaktiv, der Rest teilte sich auf folgende sportliche Gruppen auf: Sport für die persönliche Fitness (53.52 $\%)$, Ausdauersport (25.25\%) und Leistungssportler (1.41\%). 


\subsection{BESCHREIBUNG DES PATIENTENKOLLEKTIVS}

Die im Labor gemessenen Konzentrationen aller Parameter wurden auf den Urinkreatininwert normalisiert, um die Varianz der Parameter durch die individuelle Flüssigkeitsaufnahme und Abgabe zu minimieren. Die Kreatininausscheidung gilt als volumenunabhängig und ist dementsprechend als Normierung akzeptiert.

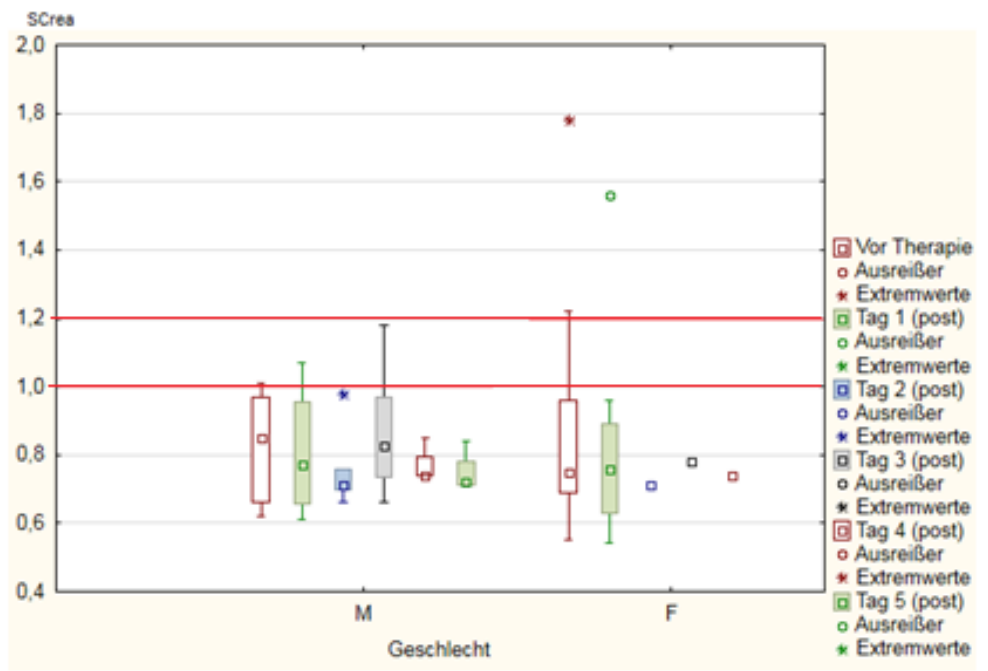

Abbildung 1: Darstellung der Serumkreatininwerte des Patientenkollektivs, gruppiert nach männlichen (M) und weiblichen Patienten (F) - die rote Linie markiert die Referenzwerte der SCrea-Konentrationen

Die Serumkreatininwerte zweier Patienten (Abbildung 1) zeigten Werte die sich über dem Referenzbereich bewegten (Referenzwert SCrea: bis $1 \mathrm{mg} / \mathrm{dl}$ bei den weiblichen Patientinnen und bis $1.2 \mathrm{mg} / \mathrm{dl}$ bei den männlichen Patienten). Von den Probanden wurden keine Blutparameterdaten erhoben. Zum interkollektiven Vergleich wurden hier die Referenzwerte der Urinparameter herangezogen (siehe Tabelle 2 im Material und Methodenteil). Um die Patienten nach dem Grad einer möglichen Nierenfunktionsstörung einzuteilen, wurde die Kreatinin-Clearance nach der CDK-EPI berechnet (Tabelle 8).

Tabelle 8: Anzahl der Patienten in den 5 Stadien der Clearance

\begin{tabular}{|c|c|c|c|c|c|c|}
\hline \multicolumn{2}{|c|}{} & \multicolumn{5}{|c|}{ Tage nach Therapie } \\
\hline $\begin{array}{c}\text { Clearance } \\
\text { Stadium vor } \\
\text { Therapie }\end{array}$ & $\begin{array}{c}\text { Anzahl der } \\
\text { Patienten }\end{array}$ & 1 & 2 & 3 & 4 & 5 \\
\hline 1 & 15 & 9 & 4 & 5 & 4 & 5 \\
\hline 2 & 8 & 12 & 2 & 4 & 1 & 0 \\
\hline 3 & 4 & 1 & 0 & 0 & 0 & 0 \\
\hline 4 & 1 & 0 & 0 & 0 & 0 & 0 \\
\hline 5 & 0 & 0 & 0 & 0 & 0 & 0 \\
\hline
\end{tabular}


$51.72 \%$ der Patienten/-innen zeigten vor der Therapie eine GFR über $90 \mathrm{ml} / \mathrm{min} / 1.73 \mathrm{~m}^{2}$ (Stadium 1, normale oder erhöhte GFR). $27.59 \%$ wiesen vor der Therapie eine Nierenschädigung mit geringfügiger Einschränkung der GFR auf (Stadium 2). $13.79 \%$ der Patienten/-innen hatten vor Therapiebeginn eine Nierenfunktionsstörung mit mittelschwerer Einschränkung der GFR (Stadium 3, 30-59 $\mathrm{ml} / \mathrm{min} / 1.73 \mathrm{~m}^{2}$ ) und $3.45 \%$ eine Nierenfunktionsstörung mit schwerer Einschränkung der GFR (Stadium 4, 15-29 ml/min/1.73 m²).

Am ersten Tag nach Verabreichung von Cis-/Carboplatin wiesen $40.91 \%$ der $\mathrm{Pa}-$ tienten/-innen des Kollektivs eine normale GFR auf (Stadium 1), $54.55 \%$ eine leicht eingeschränkte Nierenfunktion (Stadium 2) und $4.55 \%$ eine Nierenfunktion Stadium 3.

Vom zweiten bis zum vierten Tag post curationem ließen sich nur noch Werte im Stadium 1 und 2 der Clearance berechnen. An Tag fünf wiesen alle Patienten/ -innen eine normale Nierenfunktion auf (Stadium 1).

Die eingeschränkten Nierenfunktionen im Stadium 3 und 4 ließen sich ausschließlich bei den untersuchten weiblichen Patientinnen nachweisen. Die weiblichen Patientinnen wiesen bei der statistischen Untersuchung der Basiswerte eine signifikant erniedrigte Clearance im Vergleich zu den männlichen Patienten $(p=0.006)$ auf (Mittelwert: $74.8 \mathrm{ml} / \mathrm{min} / 1.73 \mathrm{~m}^{2}$ vs. $95.2 \mathrm{ml} / \mathrm{min} / 1.73 \mathrm{~m}^{2}$ ) (Abbildung1.1).

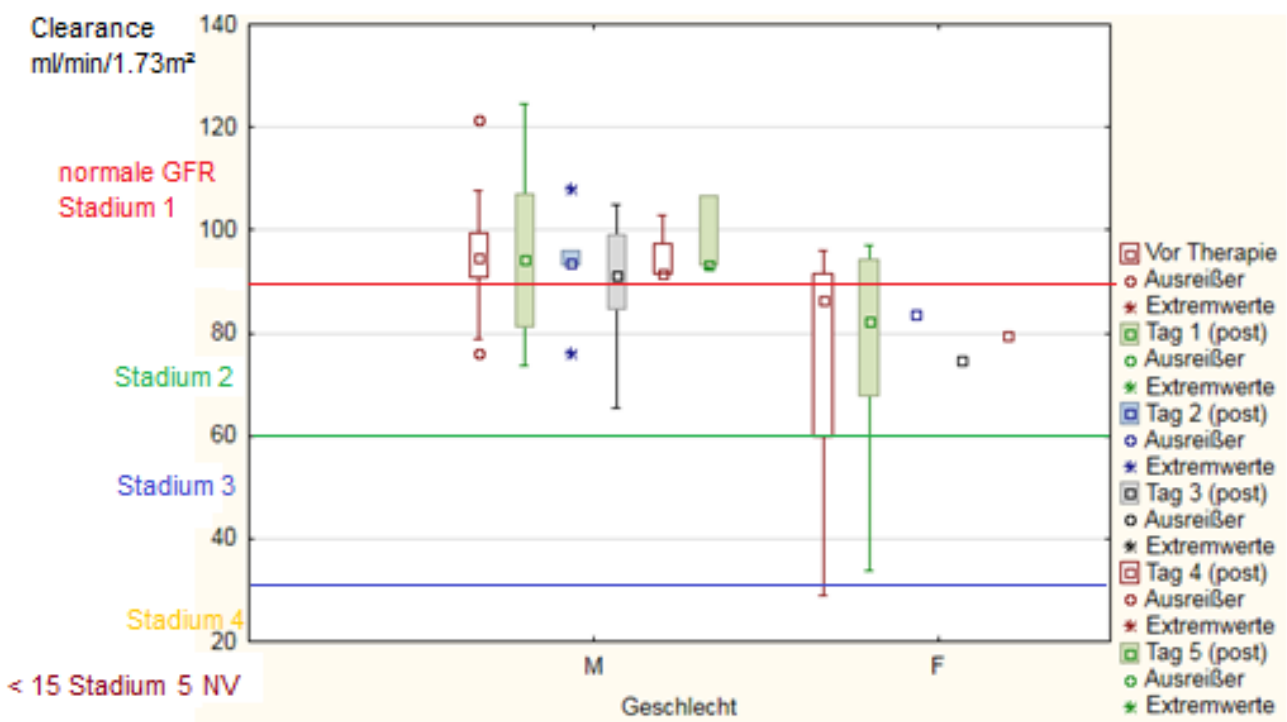

Abbildung 1.1: Darstellung der Clearance nach CDK-EPI, gruppiert nach männlichen (M) Patienten und weiblichen (F) Patientinnen 
Zudem wurden die Therapiezyklen der Patienten des Kollektivs in die Untersuchung integriert. Dies könnte hinweisgebend sein auf bereits medikamentös induzierte Schäden in der Niere und stellt eine Grundlage für die Basiswerte dar (Tabelle 9).

Tabelle 9: Anzahl der Therapiezyklen der Patienten im Kollektiv

\begin{tabular}{|c|c|c|c|}
\hline \multirow{2}{*}{ Therapiezyklus } & \multirow{2}{*}{ Patientenanzahl gesamt } & \multicolumn{2}{|c|}{ Patienten } \\
\cline { 3 - 4 } & & männlich & weiblich \\
\hline 1 & 9 & 7 & 2 \\
\hline 2 & 6 & 2 & 4 \\
\hline 3 & 10 & 1 & 9 \\
\hline 4 & 2 & 1 & 1 \\
\hline 5 & 2 & 0 & 2 \\
\hline
\end{tabular}

$88.89 \%$ der weiblichen Patientinnen hatten mindestens einen Therapiezyklus, $66.67 \%$ sogar mindestens zwei Therapiezyklen mit Cis- oder Carboplatin erhalten. Bei den männlichen Patienten befanden sich $64 \%$ im ersten Therapiezyklus. $36.36 \%$ hatten vor Studienbeginn mindestens eine Chemotherapie erhalten.

\subsection{GESCHLECHTSSPEZIFISCHE UNTERSCHIEDE DER URINMARKER IM PROBANDENKOLLEKTIVS}

Zu den oben genannten Referenzwerten der Probanden, zeigten sich bei der statistische Auswertung geschlechtsspezifische Unterschiede im Probandenkollektiv: Die weiblichen Probanden wiesen signifikant höhere Konzentrationen von TFF3/Crea (Abbildung 2), NGAL/Crea (Abbildung 3), THUP/Crea (Abbildung 4) und MIALB/Crea (Abbildung 5) im Urin auf $(p=0.000025, p=0.007, p=0.026$, $\mathrm{p}=0.024)$.

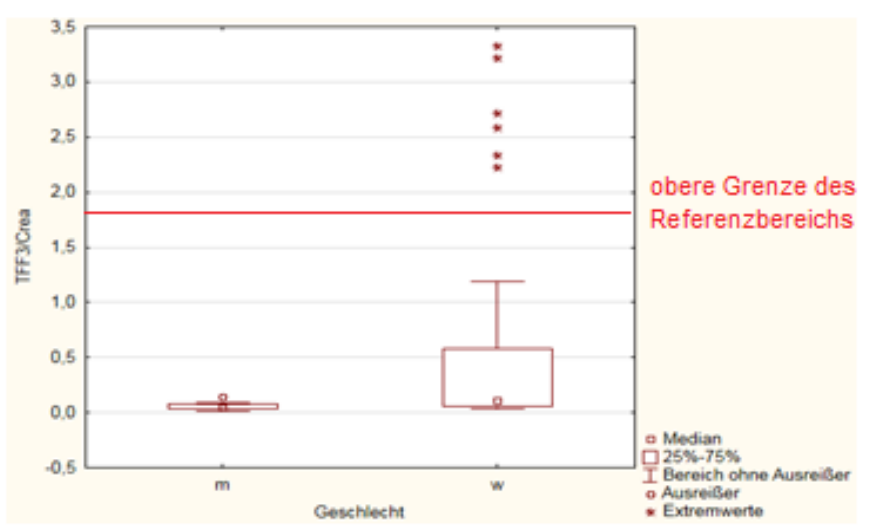

Abbildung 2: Darstellung der TFF3/Crea-Konzentration, gruppiert nach männlichen (m) und weiblichen (w) Probanden 


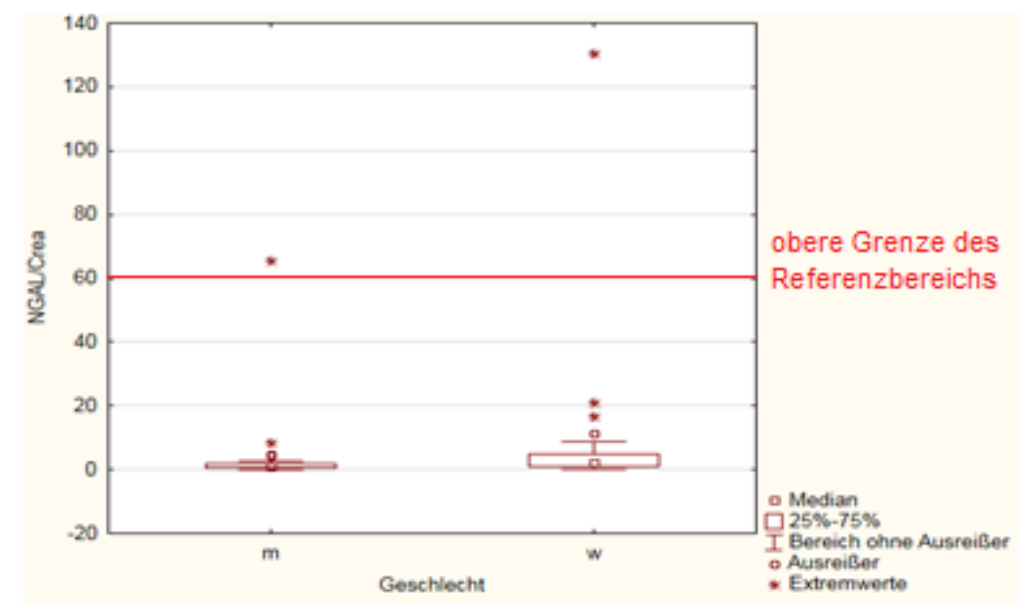

Abbildung 3: Darstellung der NGAL/Crea-Konzentration, gruppiert nach männlichen $(\mathrm{m})$ und weiblichen (w) Probanden

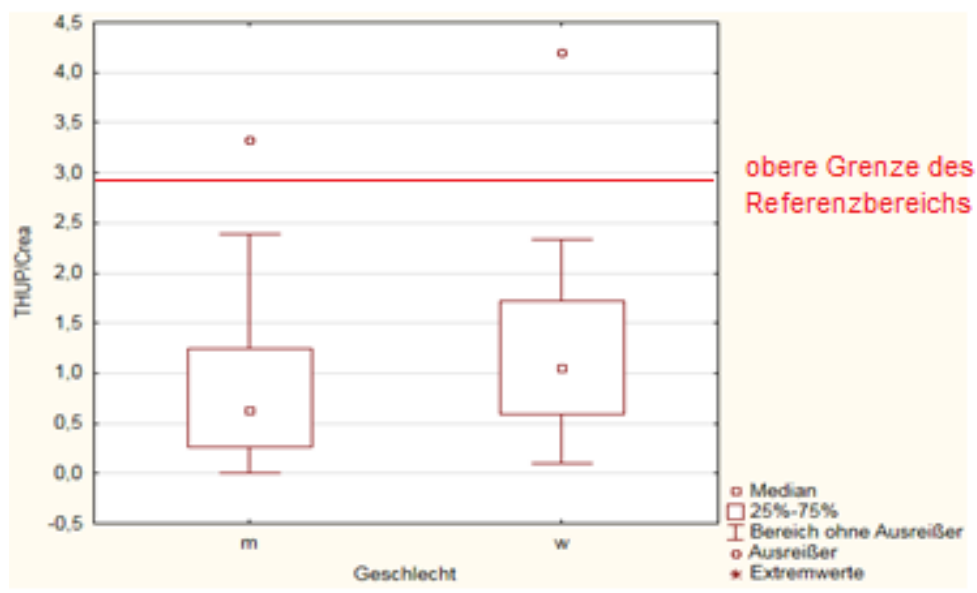

Abbildung 4: Darstellung der THUP/Crea-Konzentration, gruppiert nach männlichen $(\mathrm{m})$ und weiblichen (w) Probanden

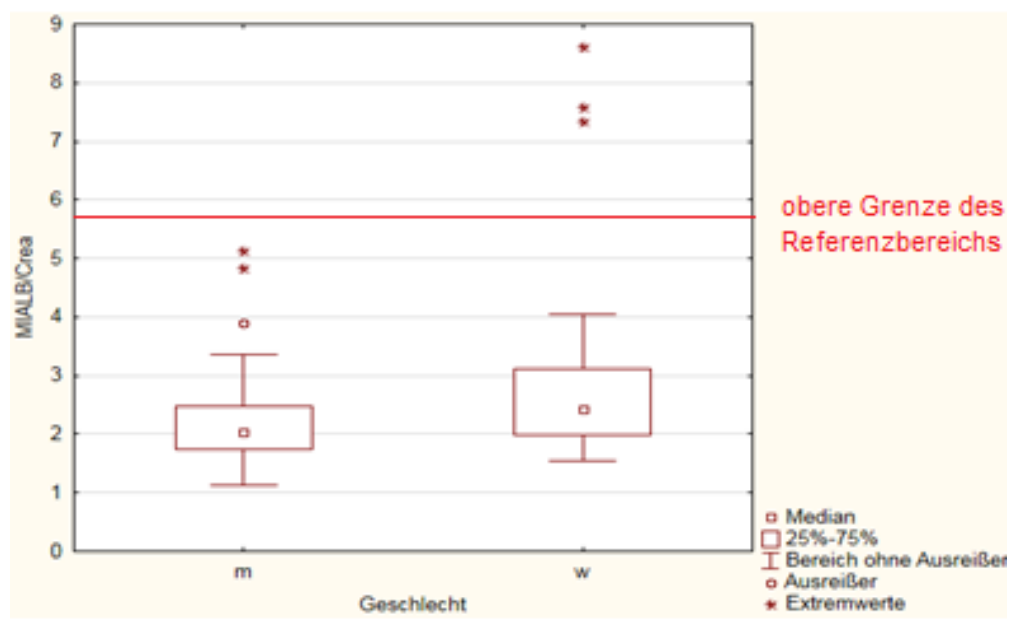

Abbildung 5: Darstellung der MILAB/Crea-Konzentration, gruppiert nach männlichen (m) und weiblichen (w) Probanden 


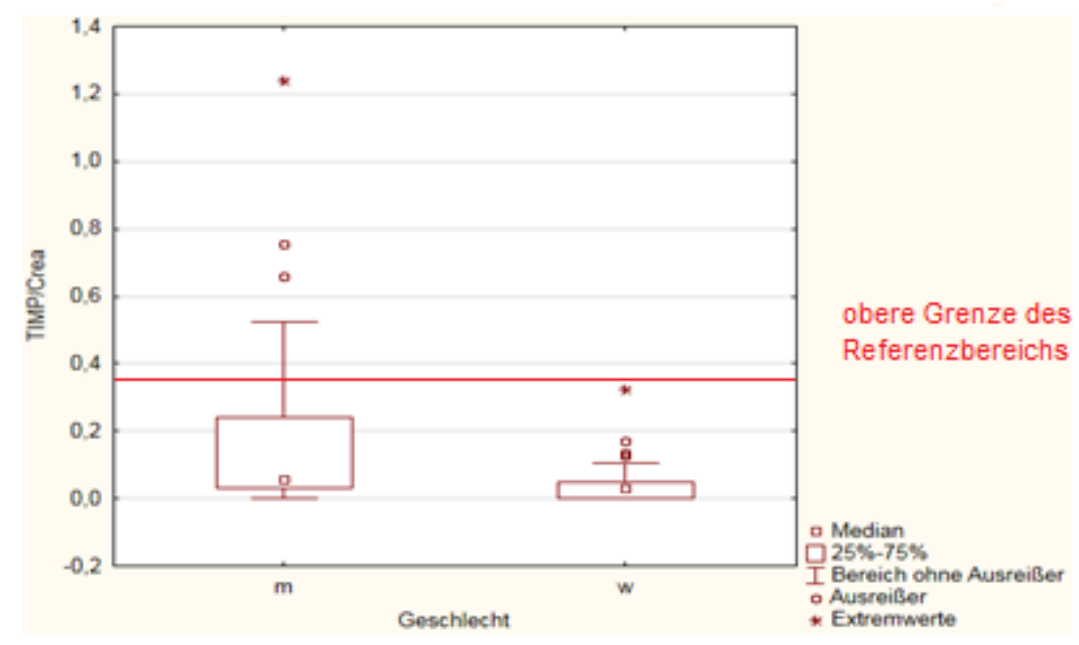

Abbildung 6: Darstellung der TIMP2/Crea-Konzentration, gruppiert nach männlichen (m) und weiblichen (w) Probanden

Die männlichen Probanden wiesen gegenüber den weiblichen Probanden statistisch höhere Urinkonzentrationen der TIMP2/Crea-Rate auf $(\mathrm{p}=0.003)$ (Abbildung 6). Dies muss bei der Ergebnisdarstellung des Patientenkollektivs berücksichtigt werden.

\subsection{DARSTELLUNG DER REAKTIONEN DER BIOMARKER DURCH DIE PLATINHALTIGE CHEMOTHERAPIE}

Für eine übersichtliche Darstellung der Ergebnisse wurden die 30 Biomarker in folgende Kategorien eingeteilt:

3.4.1 Nierenfunktionsmarker

3.4.1.1 Elektrolyte

3.4.1.2 Metabolite

3.4.2 Klassische Biomarker

3.4.2.1 Ubiquitär vorkommende Marker

3.4.2.2 Marker des proximalen Tubulus

3.4.2.3 Marker des distalen Tubulus

3.4.2.4 Marker des Sammelrohrs

3.4.2.5 Marker des Glomerulums 


\subsubsection{NIERENFUNKTIONSMARKER}

\subsubsection{ELEKTROLYTE}

NATRIUM

Vor der Chemotherapie waren statistisch keine Konzentrationsunterschiede der $\mathrm{Na} /$ Crea-Rate innerhalb des Patientenkollektivs nachweisbar. An Tag zwei und vier nach Verabreichung des Chemotherapeutikums zeigten sich signifikante Veränderungen im Vergleich zu den Basiswerten ( $p=0.003, p=0.04)$ (Abbildung 7). Konzentrationsunterschiede zwischen den einzelnen Patientengruppen ließen sich statistisch nicht nachweisen.

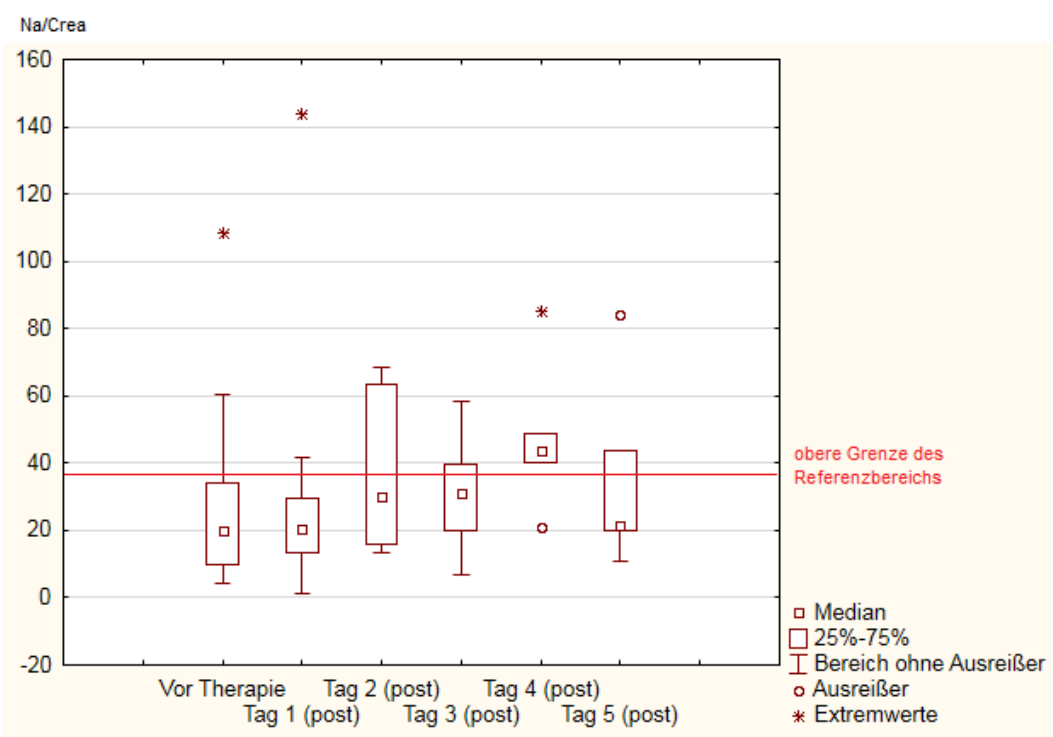

Abbildung 7: Darstellung der $\mathrm{Na} /$ Crea-Konzentrationen an den Tagen vor und nach der Chemotherapie

CHLORID

Vor der Chemotherapie ließen sich statistisch keine signifikanten Konzentrationsunterschiede der Cl/Crea-Rate zwischen den einzelnen Gruppen im Patientenkollektiv nachweisen.

Am zweiten Tag nach Gabe der platinhaltigen Medikation zeigte sich, analog zu den $\mathrm{Na} / \mathrm{Crea}$-Konzentrationen, ein signifikanter Konzentrationsanstieg im Vergleich zu den Basiswerten ( $p=0.02)$ (Abbildung 8). 
Eine gruppenspezifische Differenzierung konnte statistisch nicht nachgewiesen werden.

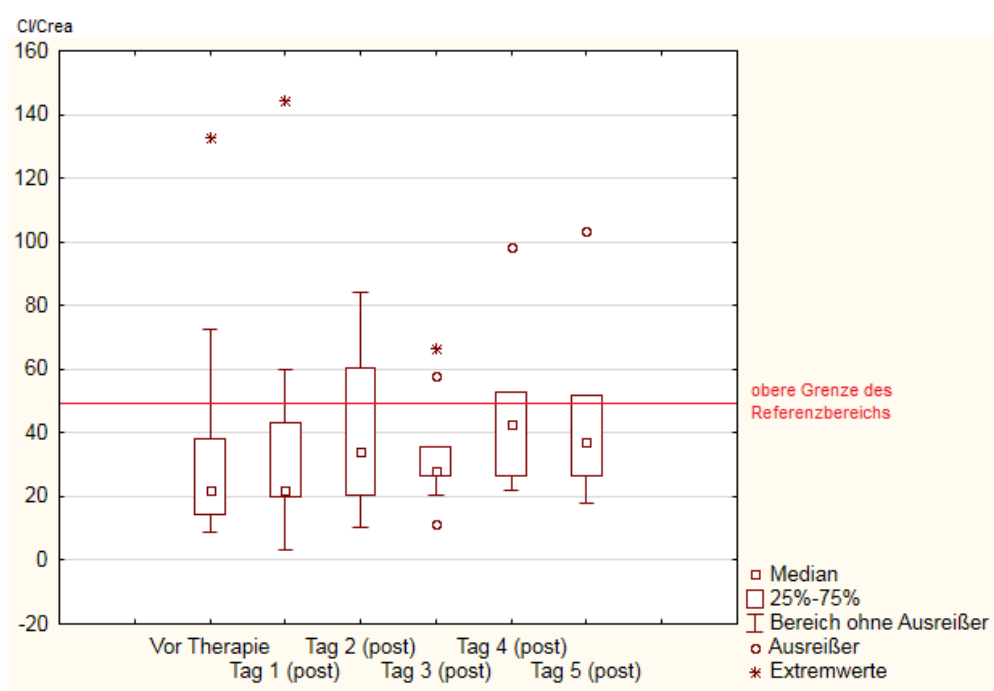

Abbildung 8: Darstellung der Cl/Crea-Konzentrationen an den Tagen vor und nach der Therapie

\section{KALIUM}

Vor der Behandlung ließ sich statistisch ein signifikanter geschlechtsspezifischer Unterschied ( $\mathrm{p}=0.00002)$ zwischen den männlichen und weiblichen Patienten des Kollektivs nachweisen (Abbildung 9). Dabei lagen die Urinkonzentrationen der weiblichen Patientinnen dreimal höher als die K/Crea-Konzentrationen der männlichen Patienten (Mittelwert: $9.9 \mathrm{mmol} / \mathrm{mmol}$ vs. $3.3 \mathrm{mmol} / \mathrm{mmol}$ ).

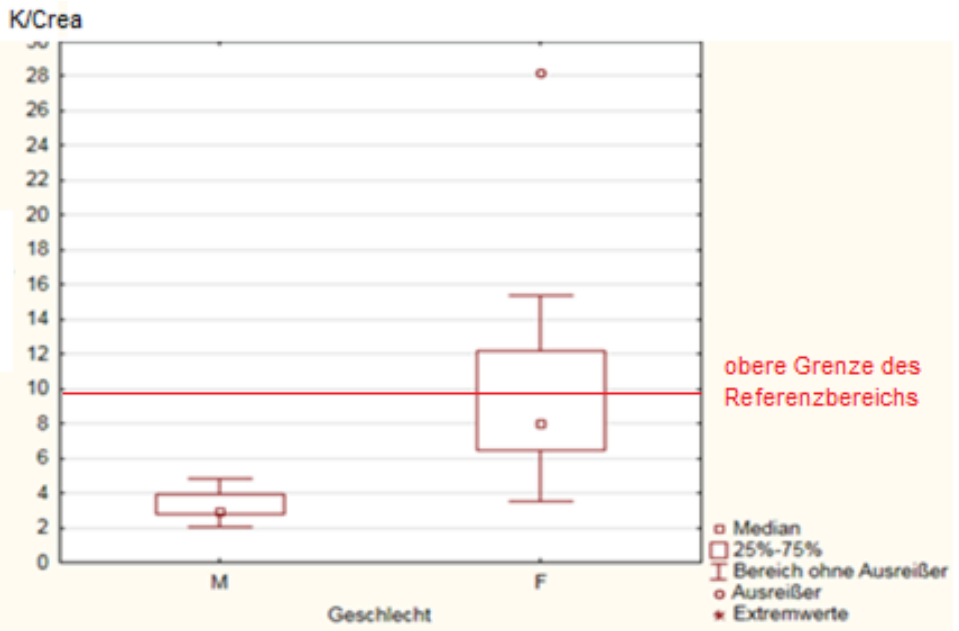

Abbildung 9: Darstellung der Basiswerte gruppiert nach männlichen (M) und weiblichen (F) Patienten 
An den Tagen nach Gabe des Chemotherapeutikums unterschieden sich die Konzentrationen der Geschlechter nicht. An Tag zwei und vier ließen sich im Vergleich zu den Basiswerten statistisch signifikante Veränderungen der K/CreaKonzentration im Urin nachweisen $(p=0.008, p=0.005)$.

Diese Konzentrationsanstiege bewegten sich innerhalb des Referenzbereichs (Abbildung10).

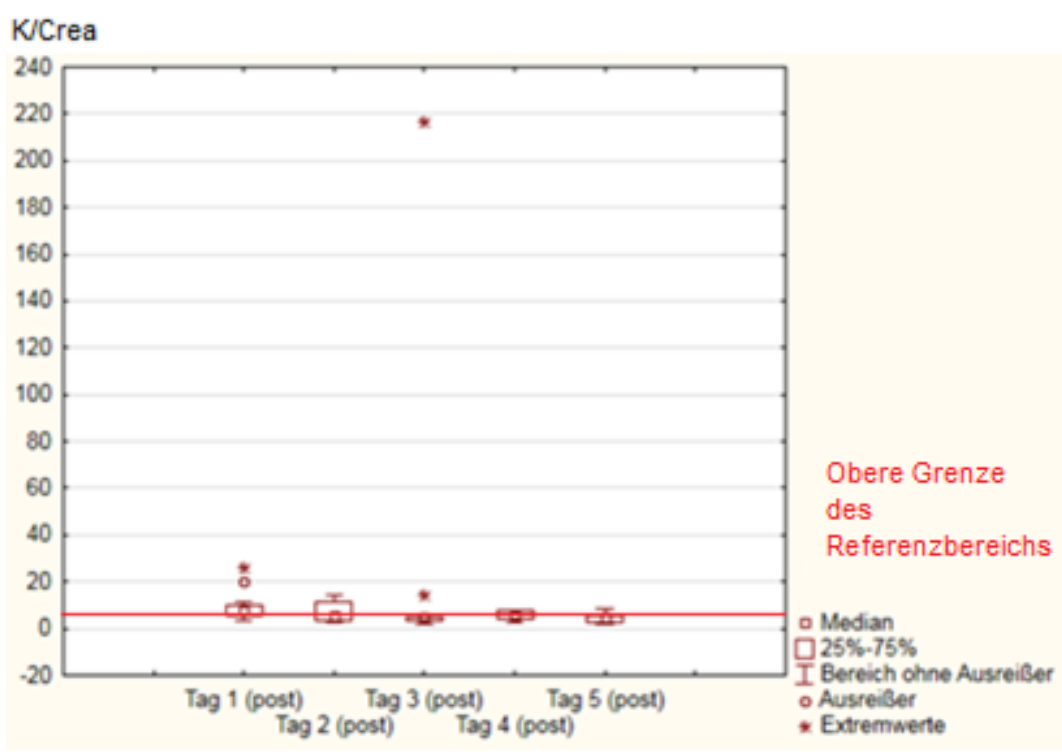

Abbildung 10: Darstellung der K/Crea-Konzentrationen an den Tagen nach Gabe des Chemotherapeutikums

CALCIUM

Ante curatio ließ sich statistisch kein signifikanter Konzentrationsunterschied der $\mathrm{Ca} / \mathrm{Crea-Rate} \mathrm{innerhalb} \mathrm{der} \mathrm{Gruppen} \mathrm{des} \mathrm{Patientenkollektivs} \mathrm{nachweisen.}$

Am zweiten Tag nach der Chemotherapie zeigte sich ein signifikanter Unterschied zwischen den Geschlechtern ( $p=0.007)$.

Die männlichen Patienten wiesen eine höhere $\mathrm{Ca} / \mathrm{Crea-Ausscheidungsrate} \mathrm{im}$ Urin auf im Vergleich zu den weiblichen Patientinnen (Mittelwert: $0.55 \mathrm{mmol} / \mathrm{mmol}$ vs. $0.16 \mathrm{mmol} / \mathrm{mmol}$ ) (Abbildung 11). 


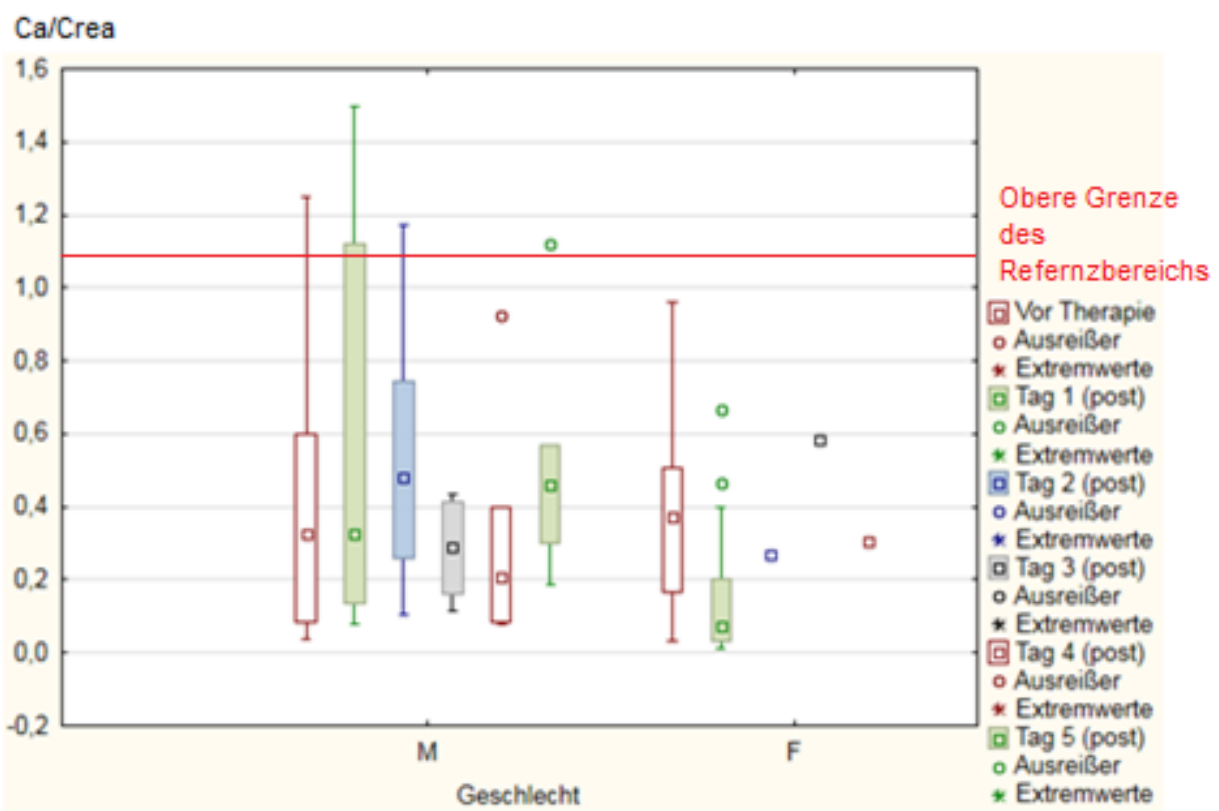

Abbildung 11: Darstellung der Ca/Crea-Konzentration gruppiert nach männlichen (M) und weiblichen (F) Patienten

\section{MAGNESIUM}

Vor der Chemotherapie zeigte sich ein signifikanter geschlechtsspezifischer Unterschied im Patientenkollektiv $(p=0.03)$. Die weiblichen Patientinnen wiesen im Mittel eine höhere Mg/Crea-Konzentration im Urin auf als die männlichen Patienten (Mittelwert: $0.68 \mathrm{mmol} / \mathrm{mmol}$ vs. $0.39 \mathrm{mmol} / \mathrm{mmol}$ ) (Abbildung 12).

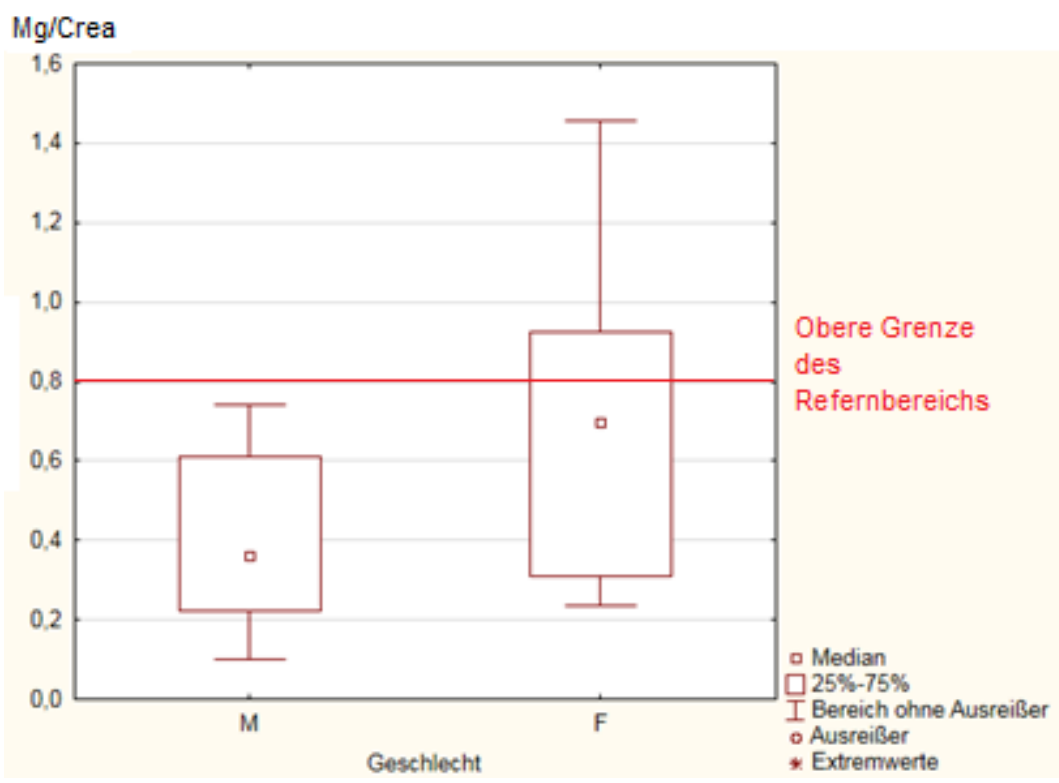

Abbildung 12: Darstellung der Mg/Crea-Konzentrationen vor der Chemotherapie, gruppiert nach männlichen (M) und weiblichen (F) Patienten 
An Tag zwei post curationem zeigte sich eine signifikante Konzentrationserhöhung der Mg/Crea-Rate im Vergleich zu den Basiswerten ( $\mathrm{p}=0.006)$. Ab dem dritten Tag nach Gabe des Chemotherapeutikums, ließ sich ein Konzentrationsrückgang bei allen Patienten des Kollektivs zurück in den Referenzbereich verzeichnen (Abbildung 13).

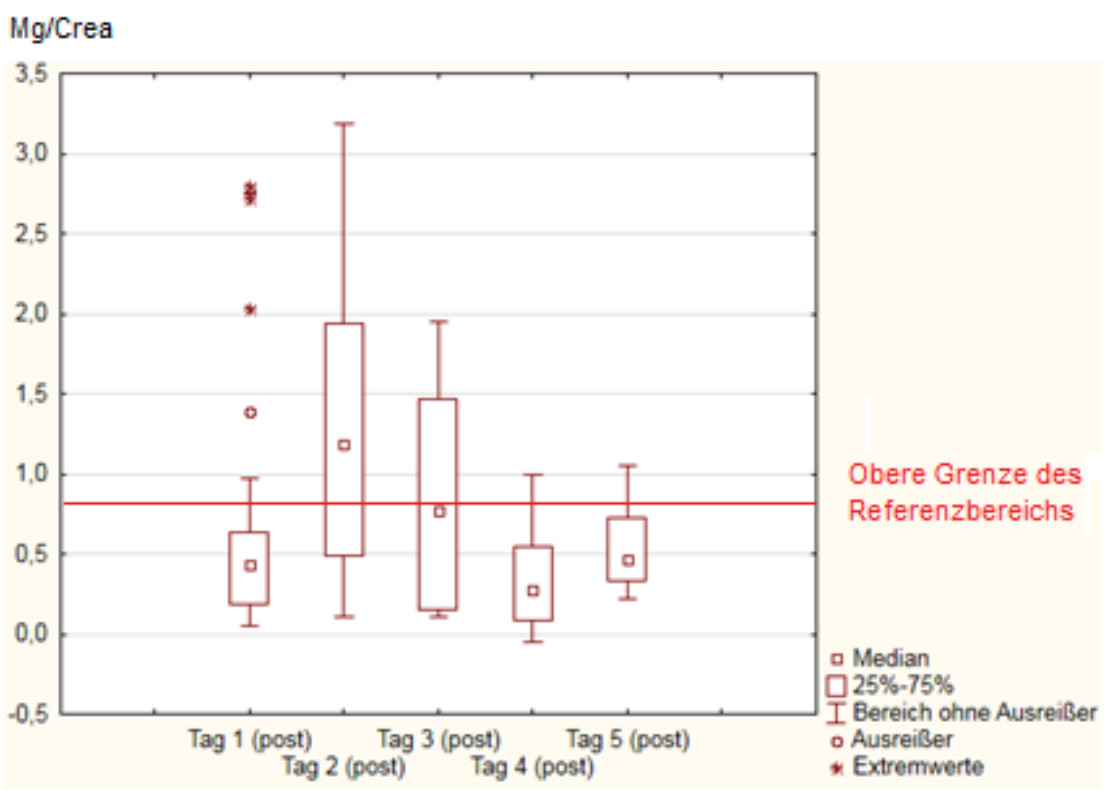

Abbildung 13: Darstellung der Mg/Crea-Konzentrationen an den Tagen nach Gabe des Chemotherapeutikums

\section{PHOSPHAT}

Im Basiswertbereich ließen sich statistisch keine signifikanten Unterschiede in der $\mathrm{P} /$ Crea-Urinkonzentration zwischen den einzelnen Patientengruppen im Kollektiv nachweisen. Am ersten Tag nach der Chemotherapie stieg die P/CreaKonzentration signifikant an $(p=0.03)$. Die Konzentrationen lagen innerhalb des Referenzbereichs. Im weiteren Verlauf zeigten sich keine weiteren signifikanten Konzentrationsänderungen oder Differenzierungen in der Gruppenspezifität innerhalb des Kollektivs.

\subsubsection{METABOLITE}

\section{GLUKOSE}

Vor der Chemotherapie zeigte sich statistisch kein signifikanter Unterschied der Gluc/Crea-Konzentrationen in den einzelnen Gruppierungen des Patientenkollektivs. An Tag eins nach Gabe des Chemotherapeutikums zeigte sich ein signifikan- 
ter Konzentrationsanstieg der Gluc/Crea-Rate im Urin ( $p=0.03)$ : Die diabetischen Patienten wiesen im Mittel eine wesentlich höhere Gluc/Crea-Rate auf im Vergleich zu den nicht-diabetischen Patienten (Mittelwert: $4.17 \mathrm{mmol} / \mathrm{mmol}$ vs. 0.17 $\mathrm{mmol} / \mathrm{mmol}$ ) (Abbildung 14).

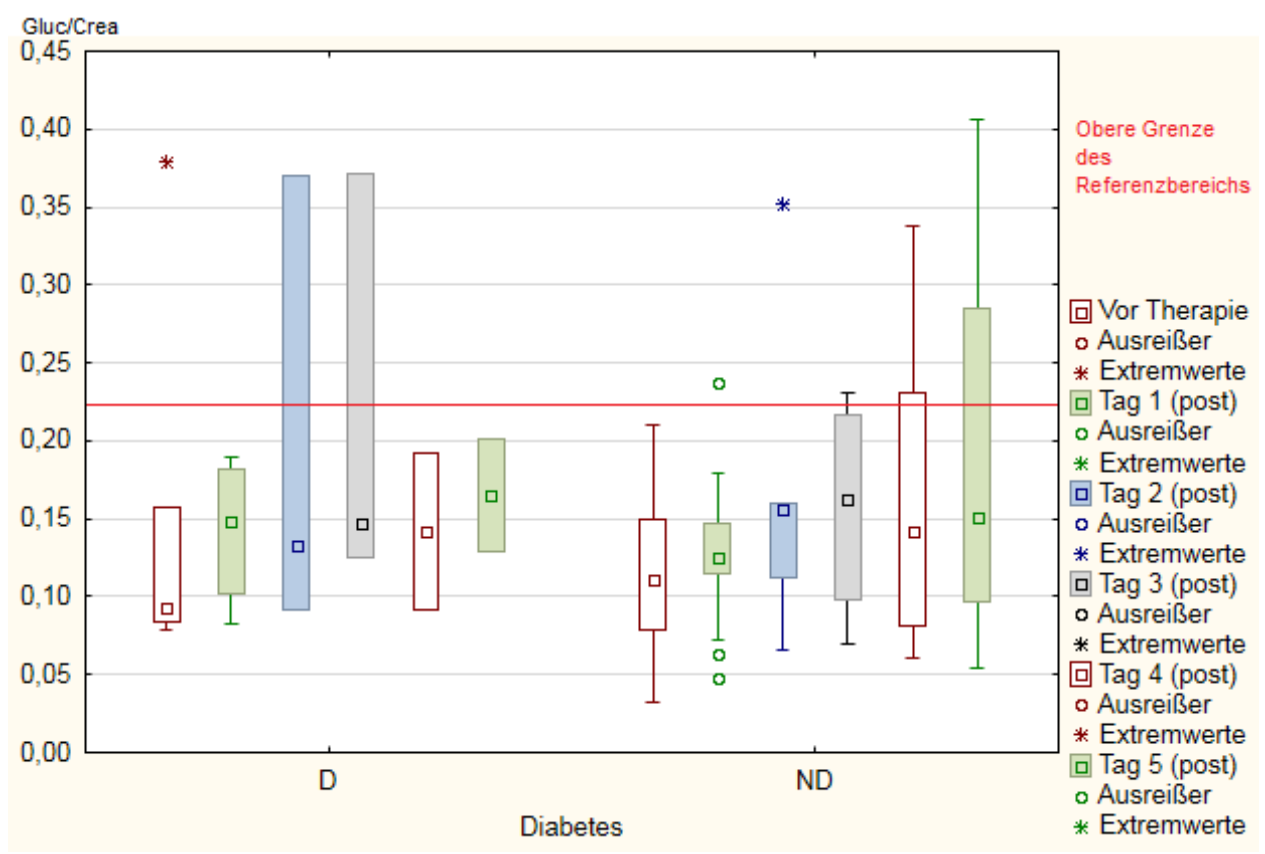

Abbildung 14: Darstellung der Gluc/Crea-Konzentrationen nach Gabe des Chemotherapeutikums gruppiert nach diabetischen (D) und nicht-diabetischen (ND) Patienten (aus Darstellungsgründen ohne Extremwertausreißer)

$24.14 \%$ Patienten/-innen aus dem Kollektiv bekamen eine Glukoselösung substituiert, um eine Hypoglykämie zu vermeiden. $42.86 \%$ reagierten daraufhin mit einem Konzentrationsanstieg der Gluc/Crea-Rate.

\section{URINKREATININ}

Ante curatio zeigte die Urinkreatininkonzentration einen signifikanten geschlechtsspezifischen Unterschied ( $p=0.001$ ): Die männlichen Patienten wiesen eine höhere Ausscheidungsrate auf als die weiblichen Patientinnen (Mittelwert: $8 \mathrm{mmol} / \mathrm{L}$ vs. $3.8 \mathrm{mmol} / \mathrm{L}$ ). Dieser Unterschied lässt sich auf den insgesamt höheren Muskelanteil der männlichen Patienten im Vergleich zu den weiblichen Patienten zurückführen. Die Konzentrationen beider Geschlechter bewegten sich innerhalb des Referenzbereichs. An den Tagen nach der Chemotherapie zeigten sich keine signifikanten Kreatininkonzentrationsanstiege im Urin. 


\section{HARNSTOFF}

Vor der Chemotherapie zeigte die Urea/Crea-Konzentration eine signifikante Differenz zwischen Normotonikern und Hypertonikern $(p=0.003)$. Die hypertonischen Patienten wiesen eine geringere Urea/Crea-Urinkonzentration auf als die normotonischen Patienten (Mittelwert: $58 \mathrm{mmol} / \mathrm{mmol}$ vs. $80 \mathrm{mmol} / \mathrm{mmol}$ ). Die Konzentrationsunterschiede bewegten sich innerhalb des Referenzbereichs.

An den Tagen nach der Behandlung zeigte sich ein signifikanter Konzentrationsanstieg an Tag zwei und drei $(p=0.004, p=0.008)$. Diese bewegten sich jedoch innerhalb des Referenzbereiches.

PH-WERT

Vor der Chemotherapie zeigte der pH-Wert keine signifikanten Änderungen innerhalb des Patientenkollektivs. Nach der Behandlung waren statistisch signifikante Veränderungen im Vergleich zu den Basiswerten an den Tagen zwei, drei und vier $(p=0.01, p=0.02, p=0.04)$ erkennbar. Die Konzentrationsänderungen bewegten sich innerhalb des Referenzbereichs. 


\subsubsection{KLASSISCHE BIOMARKER}

\subsubsection{UBIQUITÄR VORKOMMENDE MARKER}

\section{PROTEIN}

Vor der Behandlung mit Cis-/Carboplatin zeigte sich ein signifikanter geschlechtsspezifischer Unterschied ( $p=0.0003)$.

Die weiblichen Patientinnen wiesen im Mittel eine wesentlich höhere Ausscheidungsrate auf als die männlichen Patienten (Mittelwert: $49.9 \mathrm{mg} / \mathrm{mmol}$ vs. 8.5 $\mathrm{mg} / \mathrm{mmol}$ ) (Abbildung 15).

An den Tagen zwei bis fünf nach Gabe des Chemotherapeutikums ließ sich statistisch ein signifikanter Prot/Crea-Konzentrationsanstieg im Urin der Patienten $(p=0.02, p=0.04, p=0.02, p=0.03$ ) nachweisen (Abbildung 16).

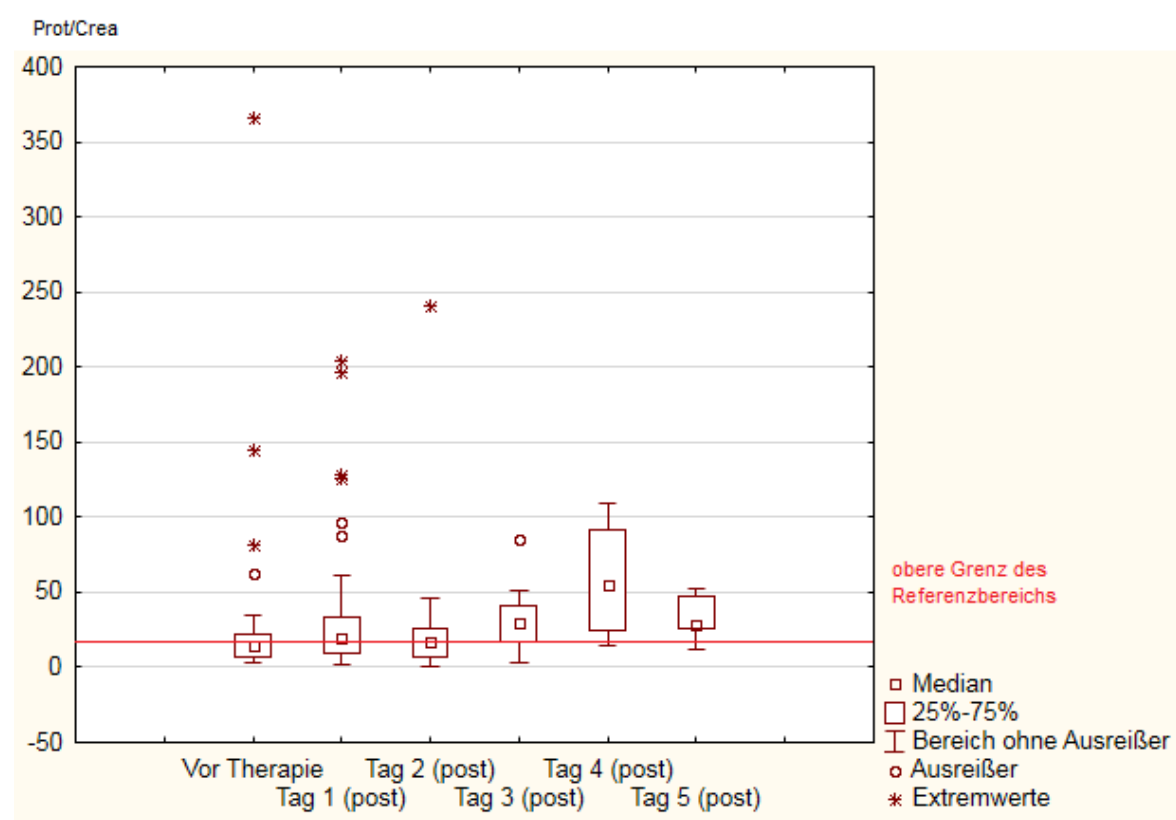

Abbildung 15: Darstellung der Prot/Crea-Konzentrationen an den Tagen vor und nach Gabe des Chemotherapeutikums

Die geschlechtsspezifische Differenzierung zeigte sich auch am ersten Tag nach Gabe des Chemotherapeutikums (Mittelwert: 55.9 mg/mmol vs. 20.5 mg/mmol).

An den Folgetagen ließen sich keine statistisch signifikanten Differenzierungen der Geschlechter mehr aufzeigen. Es konnte statistisch ebenfalls kein Unterschied zwischen den diabetischen und den nicht-diabetischen Patienten ermittelt werden. 


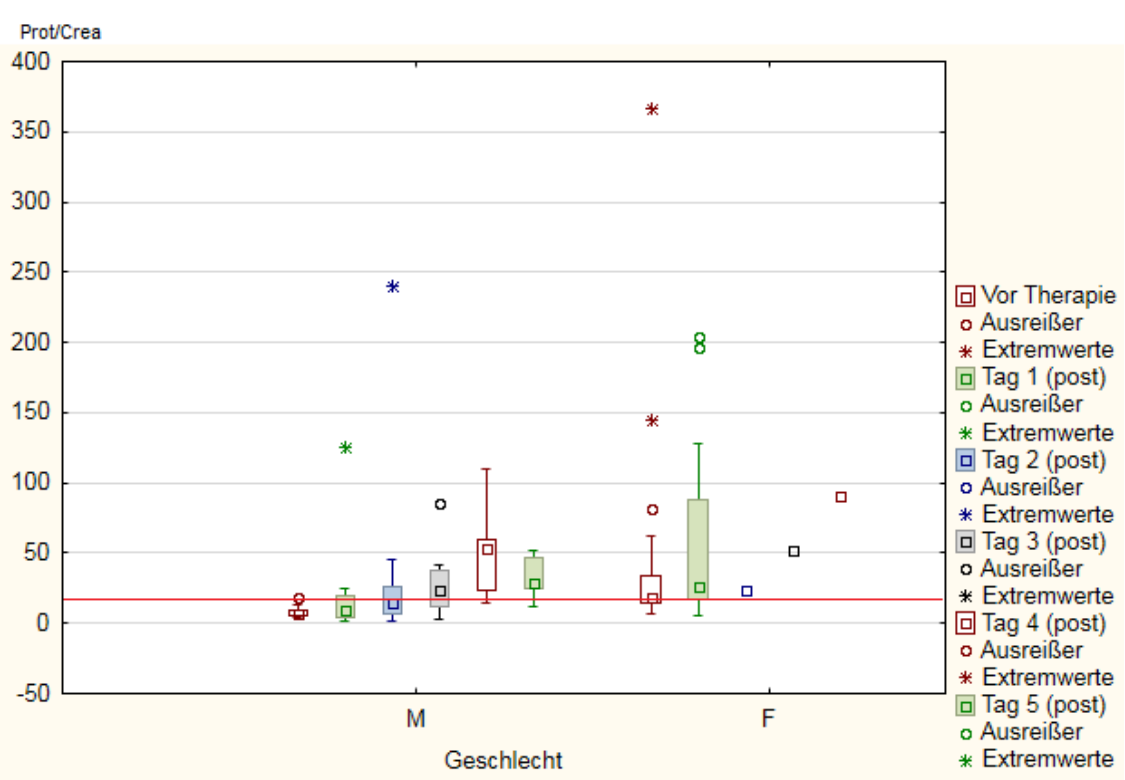

Abbildung 16: Darstellung der Prot/Crea-Konzentrationen an den Tagen vor und nach der Chemotherapie, gruppiert nach männlichen (M) und weiblichen (F) Patienten (die obere Grenze des Referenzbereichs ist durch eine rote Linie gekennzeichnet)

An den Tagen vier und fünf bewegten sich alle Prot/Crea-Konzentrationen der Patienten/-innen im Kollektiv oberhalb des Referenzbereichs.

\section{MICROALBUMIN}

Vor der Behandlung mit Cis-/Carboplatin zeigte sich statistisch eine signifikante geschlechtsspezifische Differenzierung der MIALB/Crea-Urinkonzentration $(p=0.002)$. 94.44 \% der weiblichen Patienten wiesen eine Albuminurie mit einem Mittelwert der MIALB/Crea-Konzentration von $28.6 \mathrm{mg} / \mathrm{mmol}$ auf (vgl. Mittelwert der männlichen Patienten: 3.6 mg/mmol).

Bereits im gesunden Probandenkollektiv zeigten die weiblichen Probanden signifikant höhere MIALB/Crea-Urinkonzentrationen $(p=0.024)$ im Vergleich $z u$ den männlichen Probanden (Mittelwert: $2.91 \mathrm{mg} / \mathrm{mmol}$ vs. $2.28 \mathrm{mg} / \mathrm{mmol}$ ).

Im Patientenkollektiv ließen sich nach Gabe der platinhaltigen Chemotherapeutika an den Tagen zwei, vier und fünf statistisch signifikante Erhöhungen der MIALB/Crea-Konzentration im Urin ( $p=0.005, p=0.02, p=0.03$ ) nachweisen (Abbildung 17). Die geschlechtsspezifische Verteilung der Patienten wurde auch am Tag nach der Therapie $(p=0.003)$ sichtbar. 
Die weiblichen Patientinnen zeigten einen Mittelwert von $34 \mathrm{mg} / \mathrm{mmol}$ die männlichen Patienten einen Mittelwert von $6.8 \mathrm{mg} / \mathrm{mmol}$.

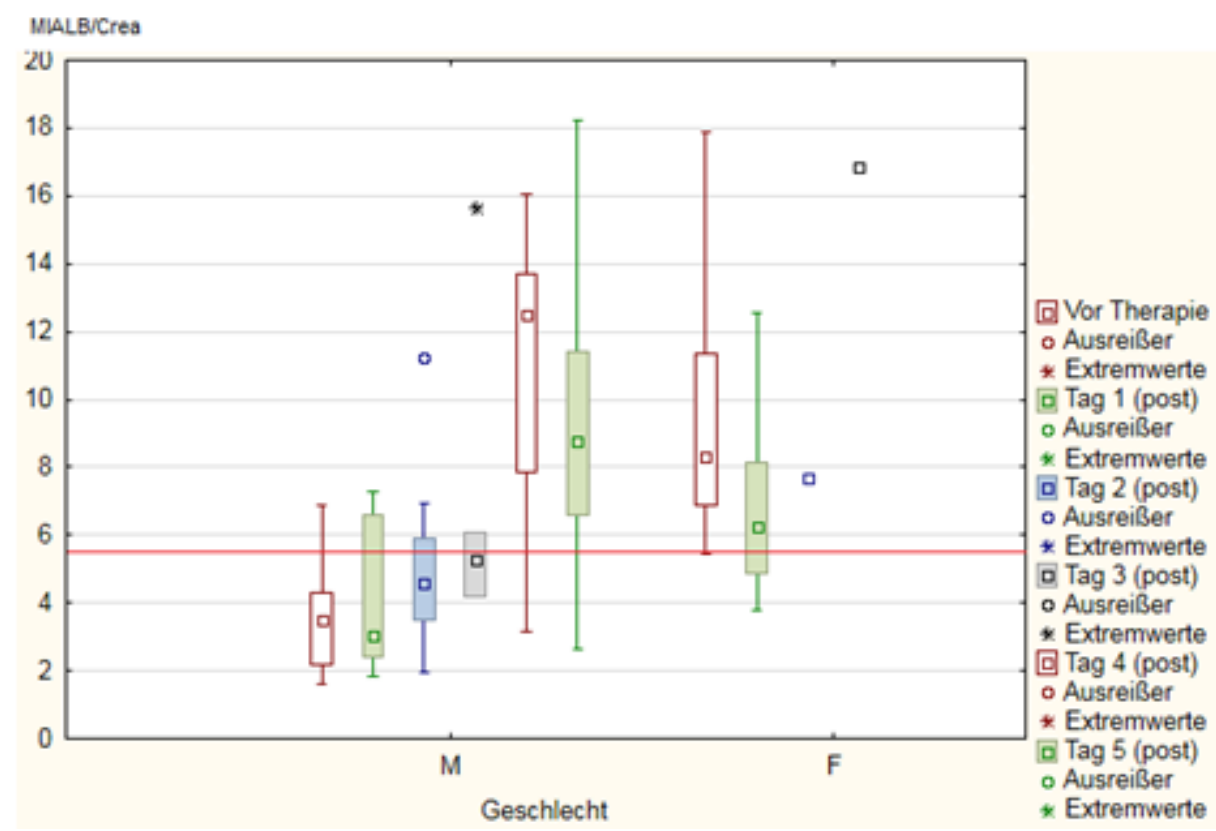

Abbildung 17: Darstellung der MIALB/Crea-Konzentration an den Tagen vor und nach der Therapie, gruppiert nach männlichen (M) und weiblichen (F) Patienten (ohne extreme Ausreißer dargestellt), die obere Grenze des Referenzbereichs ist durch eine rote Linie gekennzeichnet

Es ließ sich auch bei der MIALB/Crea Konzentration-Rate weder vor noch nach der Therapie, ein Unterschied zwischen den diabetischen und den nichtdiabetischen Patienten feststellen.

\section{LAKTATDEHYDROGENASE}

Vor der Behandlung mit Cis-/Carboplatin zeigte sich ein signifikanter geschlechtsspezifischer Unterschied im Patientenkollektiv. Die LDH/Crea-Konzentration der männlichen Patienten war vor der Therapie höher als die LDH/Crea-Konzentration im Urin der weiblichen Patientinnen (Mittelwert: $2.1 \mathrm{U} / \mathrm{mmol}$ vs. $1.4 \mathrm{U} / \mathrm{mmol}$ ). Beide Mittelwerte liegen somit unter der oberen Referenzwertgrenze.

Nach der Chemotherapie konnten keine signifikant erhöhten LDH/CreaKonzentrationen oder Konzentrationsunterschiede zwischen den unterschiedlichen Gruppen im Kollektiv festgestellt werden. 


\section{ALKALISCHE PHOSPHATASE}

Vor der Gabe des Chemotherapeutikums wurde statistisch kein signifikanter Konzentrationsunterschied der ALP/Crea-Rate innerhalb der verschiedenen Gruppen im Kollektiv sichtbar. An den Tagen zwei und vier nach der Therapie zeigten sich signifikante Konzentrationsänderungen $(p=0.005, p=0.017)$, jedoch innerhalb des Referenzbereichs.

\subsubsection{MARKER DES PROXIMALEN TUBULUS}

\section{ALANIN-AMINOTRANSFERASE}

Im Patientenkollektiv zeigte sich ante curatio mit Cis-/Carboplatin ein signifikanter geschlechtsspezifischer Unterschied der ALT/Crea-Konzentration ( $p=0.007)$ : Die weiblichen Patientinnen wiesen höhere Konzentrationen im Urin auf im Vergleich zu den männlichen Patienten (Mittelwert: $0.87 \mathrm{U} / \mathrm{mmol}$ vs. $0.029 \mathrm{U} / \mathrm{mmol}$ ). An den Tagen nach der Therapie wurden keine signifikanten Konzentrationsanstiege oder Konzentrationsunterschiede zwischen den einzelnen Patientengruppen im Kollektiv sichtbar (Abbildung 18).

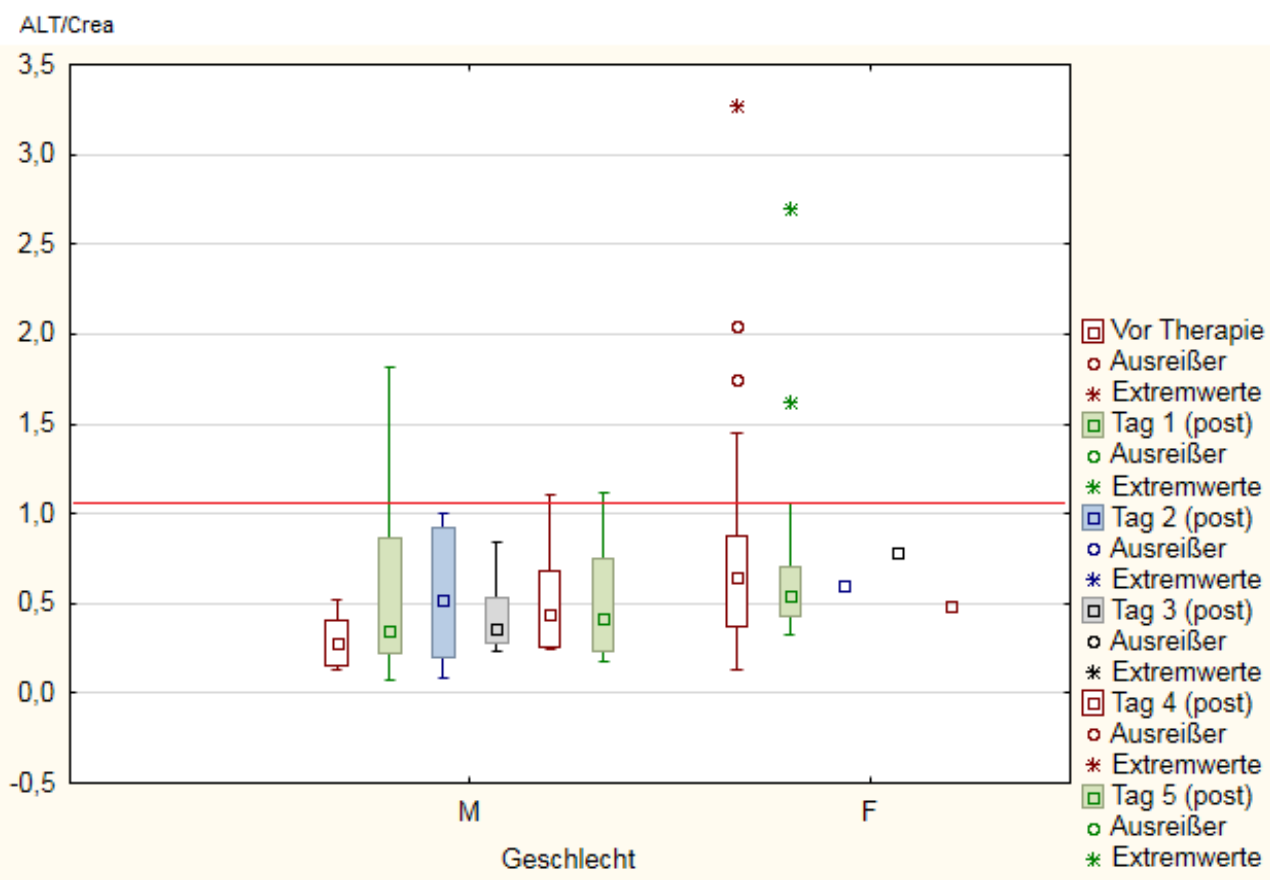

Abbildung 18: Darstellung der ALT/Crea-Konzentration an den Tagen vor und nach der Chemotherapie, gruppiert nach männlichen (M) und weiblichen (F) Patienten (die obere Grenze des Referenzbereichs ist durch eine rote Linie gekennzeichnet) 


\section{GAMMA-GLUTARYL-TRANSFERASE}

Vor der Behandlung unterschieden sich die GGT/Crea-Konzentrationen im Urin des Patientenkollektivs geschlechtsspezifisch $(p=0.001)$. Die weiblichen Patientinnen hatten eine höhere Ausscheidungsrate als die männlichen Patienten (Mittelwert: $4.05 \mathrm{U} / \mathrm{mmol}$ vs. $0.93 \mathrm{U} / \mathrm{mmol}$ ) (Abbildung 19). Beide Geschlechter lagen mit ihren Mittelwerten jedoch im Referenzbereich der gesunden Probanden. Nach Gabe des Chemotherapeutikums blieben die geschlechtsspezifischen Unterschiede erhalten (Mittelwerte: $5.4 \mathrm{U} / \mathrm{mmol}$ vs. $1.9 \mathrm{U} / \mathrm{mmol}$ ), $(\mathrm{p}=0.02)$. Der Mittelwert der weiblichen Patienten lag somit über dem Referenzbereich von $4.91 \mathrm{U} / \mathrm{mmol}$ der gesunden Probanden, jedoch ohne statistisch signifikante Änderung gegenüber dem Wert vor der Therapie. Am Tag vier nach Behandlung zeigte der Omnibustest, dass die GGT/Crea-Rate aller Patienten gegenüber dem Wert vor der Behandlung signifikant erhöht war $(p=0.02)$, jedoch innerhalb des Referenzbereichs lag.

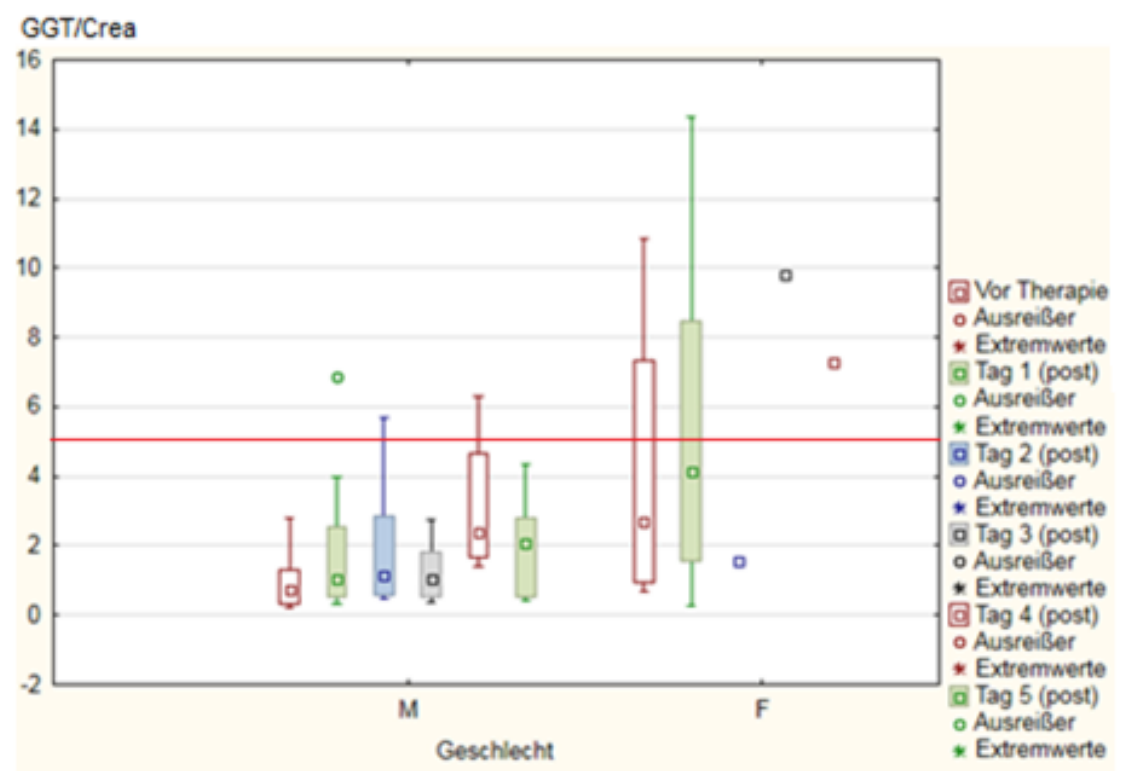

Abbildung 19: Darstellung der GGT/Crea-Konzentration nach Gabe des Chemotherapeutikums, geschlechtsspezifisch gruppiert nach männlichen (M) und weiblichen (F) Patienten (die obere Grenze des Referenzbereichs ist durch eine rote Linie gekennzeichnet)

\section{N-ACETYL-BETA-GLUCOSAMINIDASE}

Vor der Behandlung mit Cis- oder Carboplatin zeigte sich statistisch kein signifikanter Unterschied innerhalb des Patientenkollektivs. Allerdings waren ante cura- 
tio 16 Messwerte basal erhöht. Nach Gabe des Chemotherapeutikums konnten im Vergleich zu den Basiswerten signifikante Unterschiede an den Tagen eins bis fünf ( $p=0.01, p=0.02, p=0.02, p=0.04, p=0.03$ ) festgestellt werden (Abbildung 20).

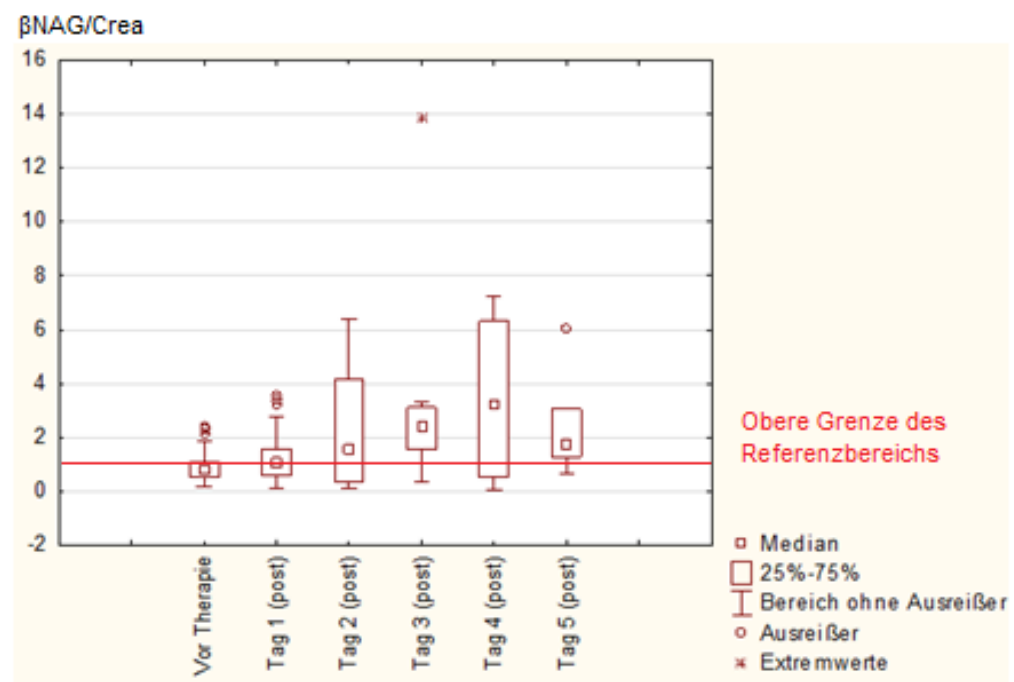

Abbildung 20: Darstellung der $\beta$ NAG/Crea-Konzentrationen nach Gabe des Chemotherapeutikums, gruppiert nach männlichen (M) und weiblichen (F) Patienten

\section{ALPHA-1 MICROGLOBULIN}

$60.71 \%$ der Patienten des Kollektivs zeigten bereits erhöhte Konzentrationen der a1MG/Crea-Rate im Basiswertbereich.

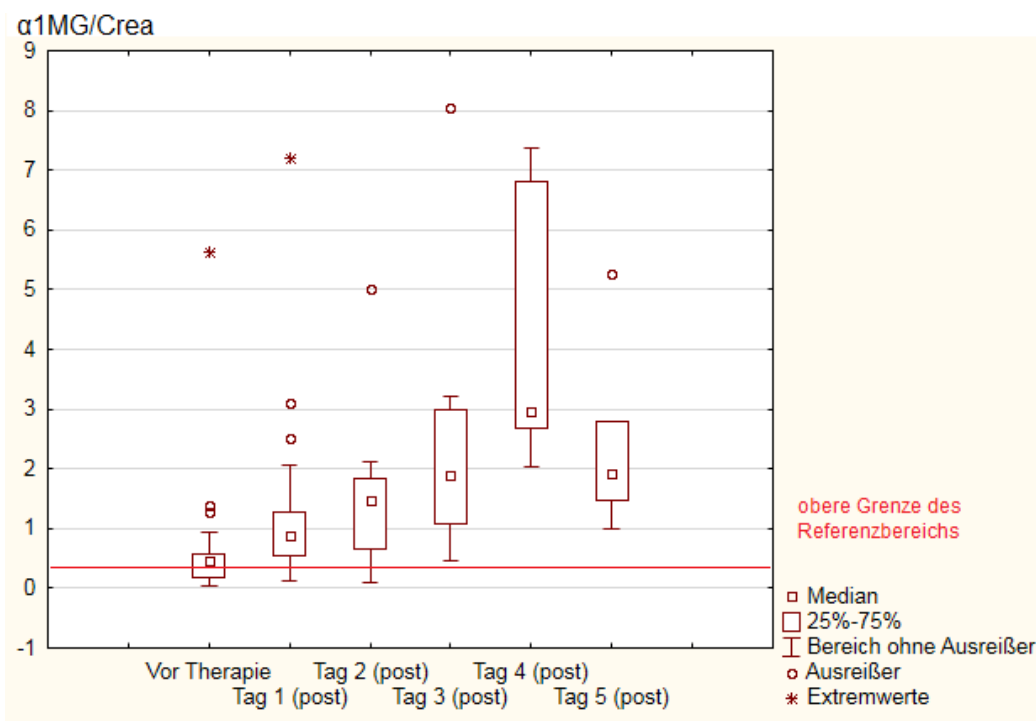

Abbildung 21: Darstellung $\alpha 1 \mathrm{MG} /$ Crea-Konzentrationen an den Tagen vor und nach Gabe der Chemotherapie 
Statistisch ließ sich keine Signifikanz innerhalb der einzelnen Gruppierungen im Kollektiv darstellen. Nach Gabe des Chemotherapeutikums ließen sich signifikante Erhöhungen im Vergleich zu den Basiswerten an den Tagen eins bis fünf nachweisen ( $p=0.00001, p=0.003, p=0.01, p=0.02, p=0.03$ ) (Abbildung 21). Zwischen den Diabetikern und Nicht-Diabetikern wurde post curationem ein signifikanter Unterschied der a1MG/Crea-Konzentration deutlich $(p=0.03)$ : Die Diabetiker zeigten am dritten Tag nach der Chemotherapie im Mittel höhere Urinkonzentrationen (Mittelwert: $4.75 \mathrm{mg} / \mathrm{mmol}$ ) im Vergleich zu den nicht diabetischen Patienten (Mittelwert: $1.4 \mathrm{mg} / \mathrm{mmol}$ ) (Abbildung 22).

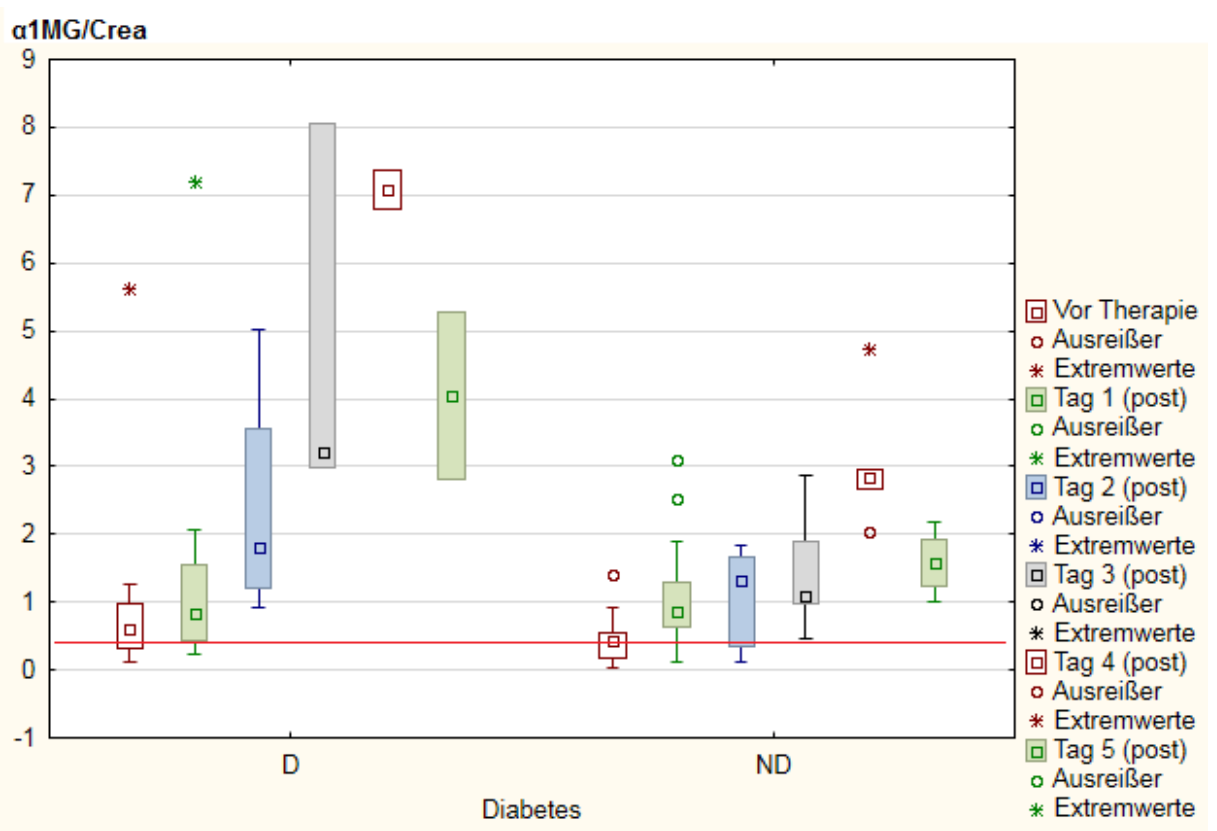

Abbildung 22: Darstellung der $\alpha 1 \mathrm{MG} /$ Crea-Konzentration vor und nach Gabe der Chemotherapie, gruppiert nach diabetischen (D) und nicht-diabetischen (ND) Patienten (die obere Grenze des Referenzbereichs ist durch eine rote Linie gekennzeichnet)

An Tag fünf zeigte sich eine rückläufige Tendenz der Konzentrationen oberhalb des Referenzbereichs. Eine normale Konzentration der a1MG/Crea-Rate, innerhalb des Referenzbereiches, stellt sich bis zu diesem Zeitpunkt jedoch nicht ein.

\section{BETA-2 MICROGLOBULIN}

Vor der Behandlung mit Cis- oder Carboplatin zeigte sich statistisch kein signifikanter Unterschied innerhalb der Gruppen des Patientenkollektivs; jedoch wiesen zwölf Patienten erhöhte Konzentrationen vor der chemotherapeutischen Intervention auf. 
Nach der Chemotherapie wurden statistisch signifikante Konzentrationserhöhungen im Vergleich zu den Basiswerten an den Tagen eins, zwei, vier und fünf $(p=0.02, p=0.004, p=0.02, p=0.04$ ) erkennbar (Abbildung 23). Dabei zeigte sich ein generalisierter Konzentrationsanstieg der $\beta 2 \mathrm{MG} /$ Crea-Rate.

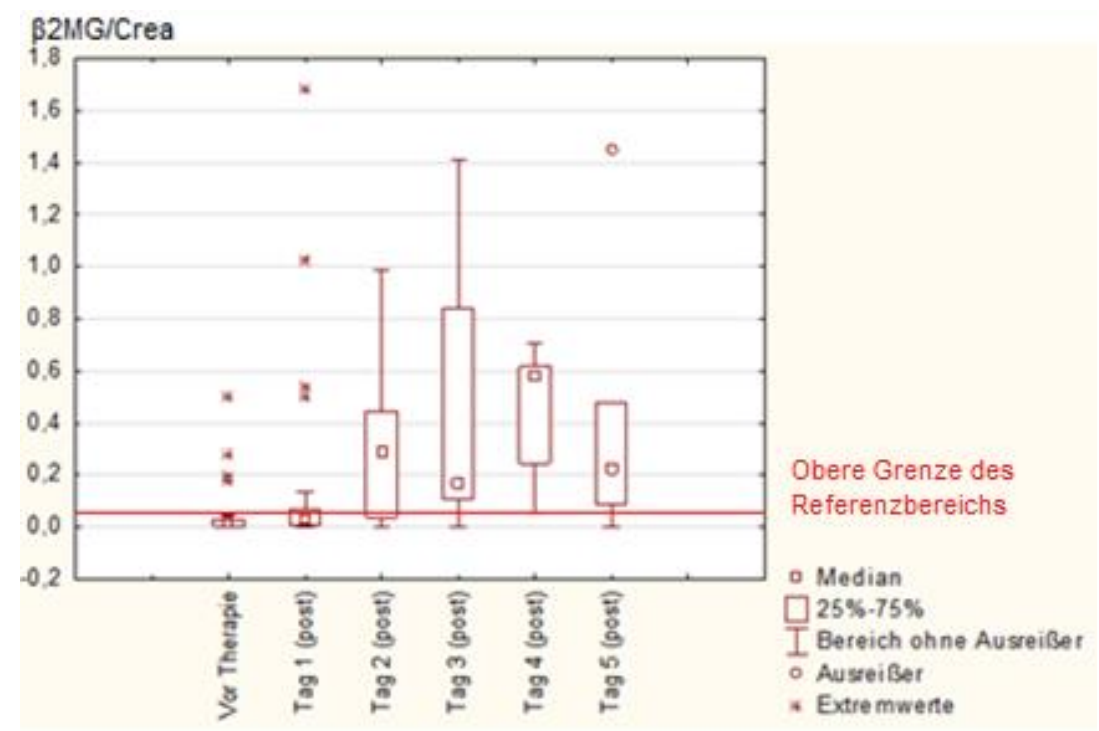

Abbildung 23: Darstellung der $\beta 2 \mathrm{MG} /$ Crea-Konzentration an den Tagen vor und nach der Chemotherapie

\section{CLUSTERIN}

Vor der Behandlung mit Cis-/Carboplatin ließen sich im Patientenkollektiv statistisch keine signifikanten Unterschiede der Clu/Crea-Konzentrationen nachweisen.

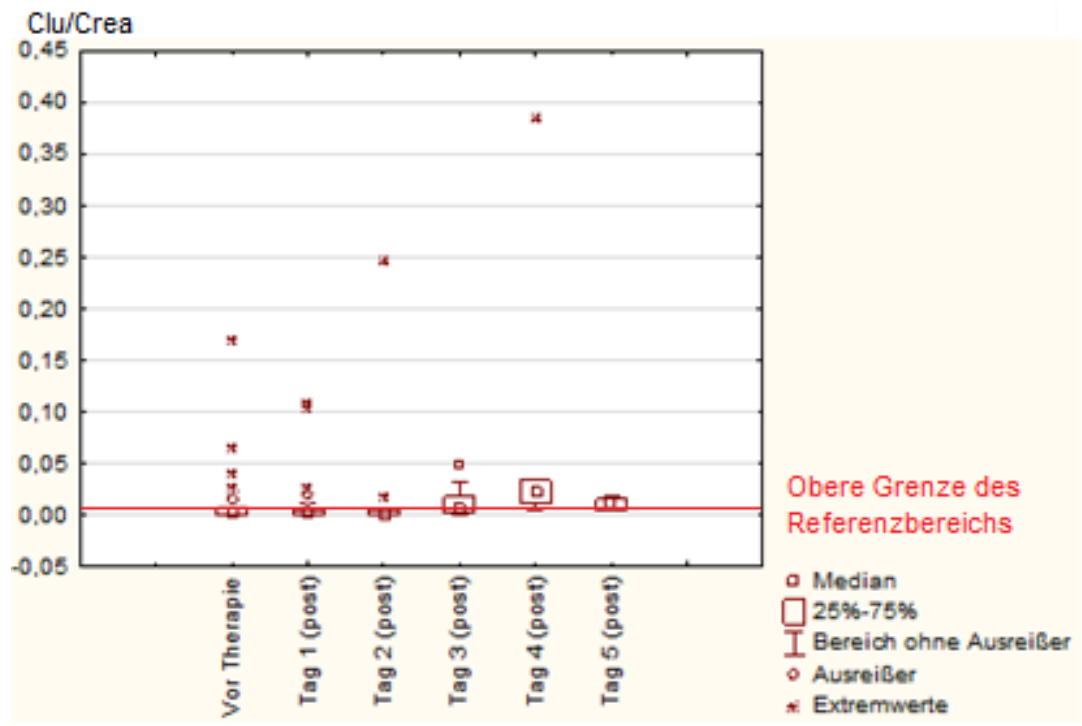

Abbildung 24: Darstellung der Clu/Crea-Konzentration an den Tagen vor und nach der Chemotherapie 
Nach der Chemotherapie zeigte der Omnibustest, dass die Clu/CreaKonzentration über den gesamten Verlauf, im Vergleich zu den Basiswerten, signifikant erhöht war $(p=0.04)$. Diese Signifikanz ließ sich nicht durch den Wilcoxonmatched-pairs-Test auf spezifische Tage differenzieren. Ebenso konnte keine Gruppenspezifität mit dem Mann-Whitney-U-Test herausgestellt werden. Der Effekt der Chemotherapeutika stellte sich zunächst als leichter Konzentrationsabfall von $\mathrm{Clu} / \mathrm{Crea}$ dar. Ab dem zweiten Tag nach Gabe von Cis-/Carboplatin zeigte sich ein Konzentrationsanstieg (Abbildung 24).

\section{GLUTATHION-S-TRANSFERASE $\alpha$}

Vor der Behandlung mit Cis- oder Carboplatin zeigte sich ein signifikanter geschlechtsspezifischer Unterschied $(p=0.001)$. Die weiblichen Patientinnen wiesen eine höhere GSTa/Crea-Konzentration auf (Mittelwert: $1.76 \mathrm{ng} / \mathrm{ml}$ ) als die männlichen Patienten (Mittelwert: $0.24 \mu \mathrm{g} / \mathrm{mmol}$ ).

Die GSTa/Crea-Konzentration war im Vergleich zu den Basiswerten an den Tagen drei, vier und fünf nach Gabe des Chemotherapeutikums signifikant erhöht $(p=0.01, p=0.02, p=0.02)$ mit einem Maximum an Tag vier (Abbildung 25).

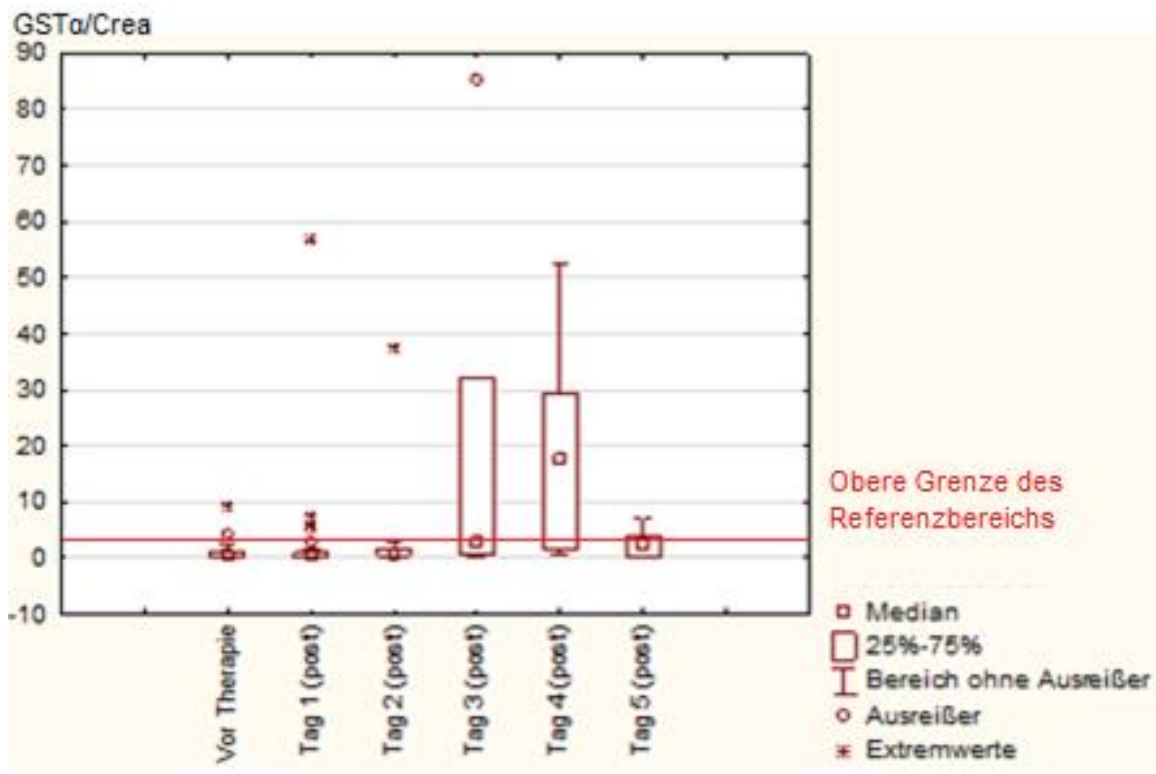

Abbildung 25: Darstellung der GST $\alpha$ /Crea-Konzentration an den Tagen vor und nach Gabe des Chemotherapeutikums

Es wurde statistisch kein signifikanter Unterschied zwischen den einzelnen Patientengruppen sichtbar. Ein Unterschied zwischen den Geschlechtern war nach Gabe des Chemotherapeutikums statistisch nicht nachweisbar. 
KIDNEY-INJURY-MOLECULE-1

$55.17 \%$ der Patienten/-innen aus dem Kollektiv wiesen, im Bereich der Basiswerte vor der Behandlung, KIM1/Crea-Konzentrationen oberhalb des Referenzbereichs auf. Ein signifikanter Unterschied zwischen den verschiedenen Gruppierungen des Patientenkollektivs ließ sich durch den Wilcoxon-matched-pairs-Test nicht darstellen. Nach Gabe des Chemotherapeutikums kam es zu einem Anstieg mit einem Maximum an den Tagen drei und vier. Dieser Effekt war bei Patienten, die Medikamente gegen Hypertonie erhalten, hatten besonders ausgeprägt; jedoch nicht statistisch signifikant im Vergleich zu der Gruppe der normotonen Patienten $(p=0.07)$ (Abbildung 26).

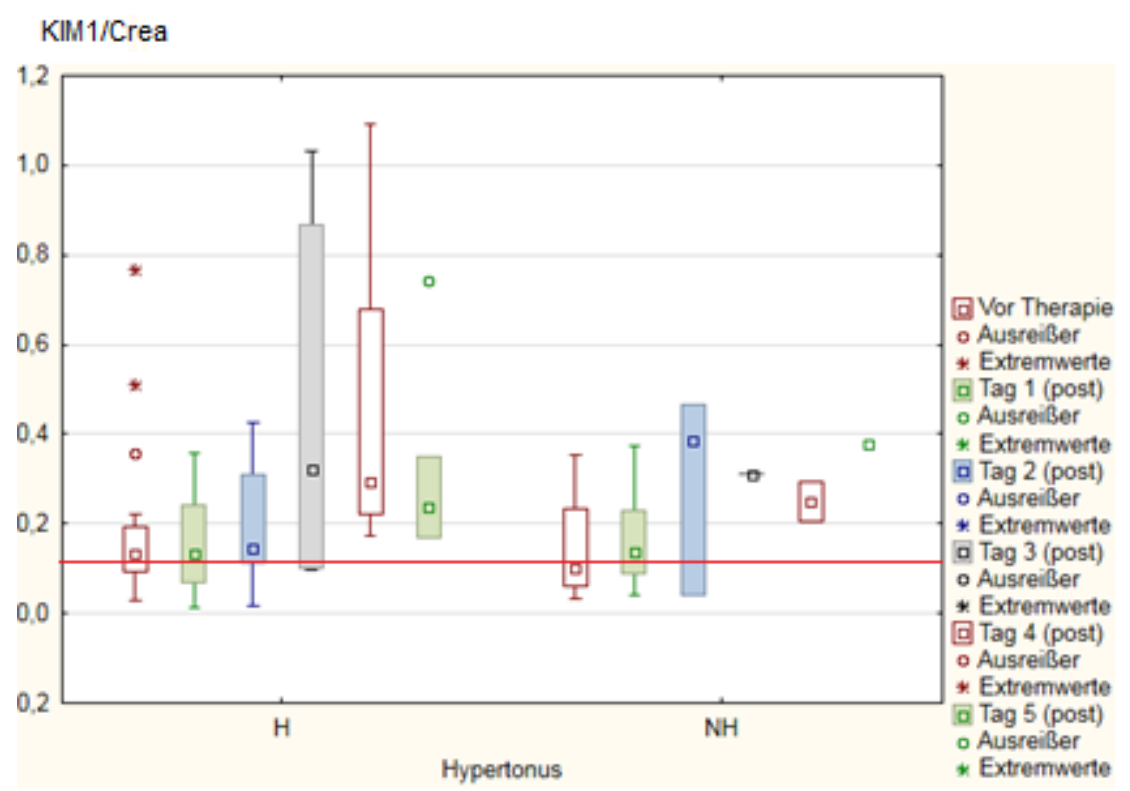

Abbildung 26: Darstellung der KIM1/Crea-Konzentration an den Tagen vor und nach Gabe des Chemotherapeutikums, gruppiert nach Hypertonikern $(\mathrm{H})$ und Normotonikern $(\mathrm{NH})$ (die obere Grenze des Referenzbereichs ist durch eine rote Linie gekennzeichnet)

Zwischen den diabetischen und nicht-diabetischen Patienten ließ sich statistisch ein signifikanter Unterschied, an Tag drei nach Gabe des Chemotherapeutikums, feststellen $(p=0.03)$ :

Die Diabetiker wiesen mit einen Mittelwert von $0.87 \mu \mathrm{g} / \mathrm{mmol}$ eine höhere KIM1/Crea-Konzentration auf als die Nicht-Diabetiker im Kollektiv (Mittelwert: 0.21 $\mu \mathrm{g} / \mathrm{mmol}$ ) (Abbildung 27). 


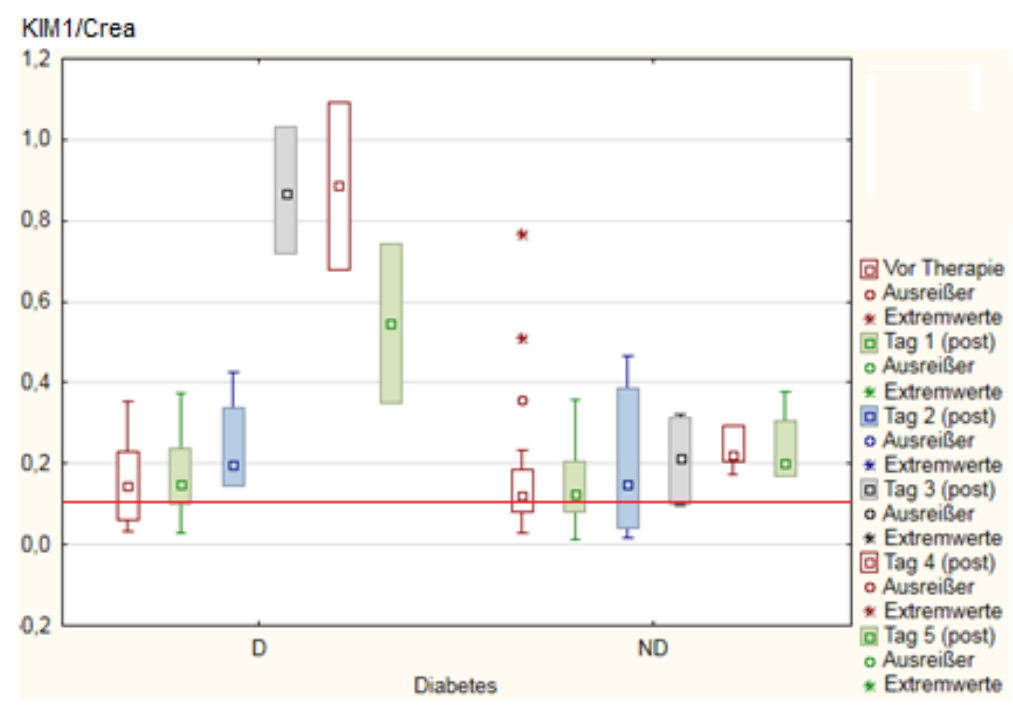

Abbildung 27: Darstellung der KIM1/Crea-Konzentration vor und nach Gabe des Chemotherapeutikums, gruppiert nach diabetischen (D) und nicht-diabetischen (ND) Patienten (die obere Grenze des Referenzbereichs ist durch eine rote Linie gekennzeichnet)

Die Maximalwerte der KIM1/Crea-Konzentration zeigten sich an Tag zwei und vier nach Gabe des Chemotherapeutikums (Abbildung 27).

\section{TREFOIL-FACTOR 3}

Weder bei den TFF3/Crea-Konzentrationen vor der Chemotherapie, noch bei den Konzentrationen an den Tagen nach der Therapie, konnten signifikante Unterschiede innerhalb oder zwischen den einzelnen Patientengruppen des Kollektivs festgestellt werden.

Im Probandenkollektiv konnte statistisch eine signifikante Erhöhung der TFF3/Crea-Konzentration der weiblichen Probanden gegenüber den männlichen Probanden nachgewiesen werden (Mittelwert: $0.64 \mathrm{mg} / \mathrm{mmol}$ vs. $0.05 \mathrm{mg} / \mathrm{mmol}$ ), $(p=0.000025)$. Der geschlechtsspezifische Unterschied konnte im Patientenkollektiv nicht bestätigt werden.

\subsubsection{MARKER DES DISTALEN TUBULUS}

\section{ASPARTAT-AMINOTRANSFERASE}

Vor der Behandlung mit Cis-/Carboplatin zeichnete sich ein signifikanter, geschlechtsspezifischer Unterschied in den Basiskonzentrationen von AST/Crea ab $(p=0.0003)$ : 
Die weiblichen Patientinnen wiesen eine höhere Ausscheidungsrate (Mittelwert: $0.072 \mathrm{U} / \mathrm{mmol}$ ) im Vergleich zu den männlichen Patienten (Mittelwert: 0.25 $\mathrm{U} / \mathrm{mmol}$ ) auf. Am Tag nach Gabe des Chemotherapeutikums wurde ein signifikanter Unterschied zwischen den Geschlechtern deutlich $(\mathrm{p}=0.04)$. Die weiblichen Patientinnen wiesen weiterhin einen höheren Mittelwert auf als die männlichen Patienten (Mittelwert: $0.89 \mathrm{U} / \mathrm{mmol}$ vs. $0.62 \mathrm{U} / \mathrm{mmol}$ ) (Abbildung 28).

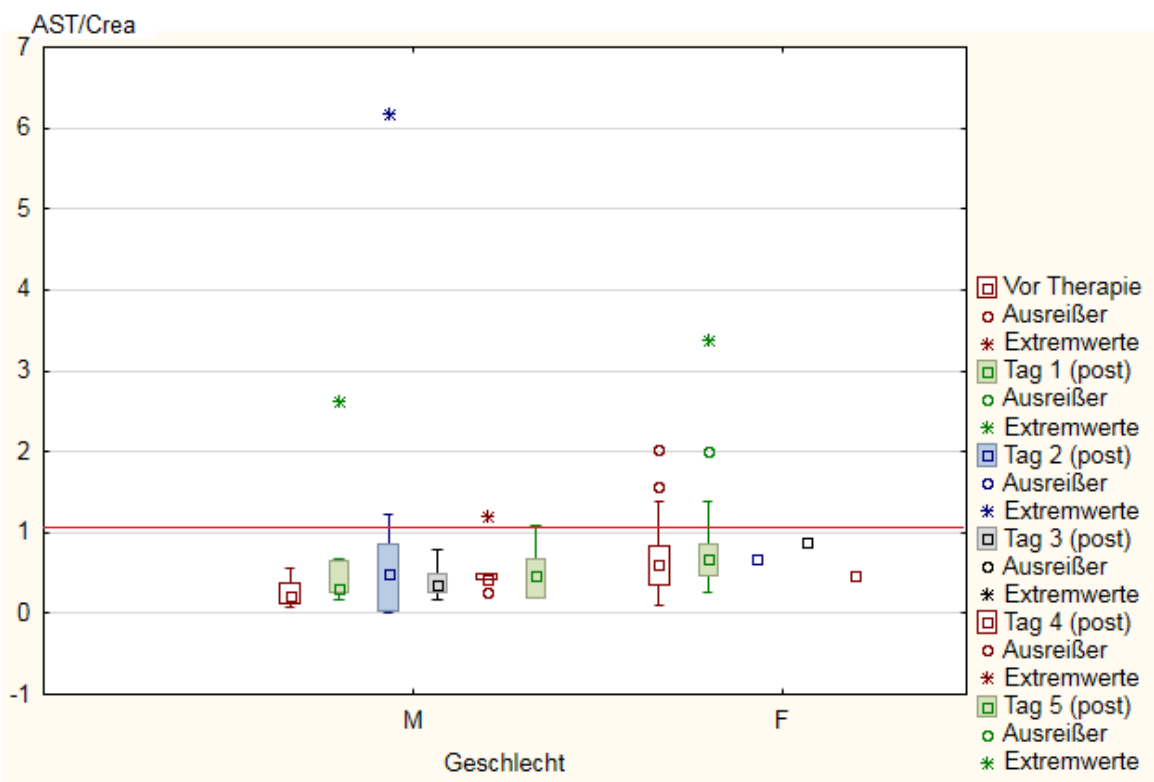

Abbildung 28: Darstellung der AST/Crea-Konzentration an den Tagen vor und nach der Chemotherapie, gruppiert nach männlichen (M) und weiblichen (F) Patienten (die obere Grenze des Referenzbereichs ist durch eine rote Linie markiert)

\section{NEUTROPHILE GELATINASE-ASSOZIERTES LIPOCALIN}

Die Basiswerte der NGAL/Crea-Konzentration zeigten einen signifikanten, geschlechtsspezifischen Unterschied $(\mathrm{p}=0.04)$. Die weiblichen Patientinnen wiesen mit einer gemittelten Ausscheidungsrate von $84.7 \mu \mathrm{g} / \mathrm{mmol}$ zum einen, einen Mittelwert oberhalb des Referenzbereichs $(60.36 \mu \mathrm{g} / \mathrm{mmol})$ auf und zum anderen einen deutlich erhöhten Wert gegenüber den männlichen Patienten im Kollektiv (Mittelwert: $24.3 \mu \mathrm{g} / \mathrm{mmol}$ ). Dieser signifikante Unterschied der Geschlechtergruppen wurde bereits im Probandenpool $(\mathrm{p}=0.007)$ deutlich, wobei die weiblichen Probanden einen Mittelwert von $7.1 \mu \mathrm{g} / \mathrm{mmol}$ aufwiesen, die männlichen Probanden einen Mittelwert von $3.13 \mu \mathrm{g} / \mathrm{mmol}$. Nach Gabe des Chemotherapeutikums wurde statistisch ein signifikanter Unterschied in der Geschlechtergruppe deutlich ( $p=0.03)$ :Die weiblichen Patientinnen zeigten an Tag eins einen dreifach höheren Mittelwert (44.7 $\mathrm{\mu g} / \mathrm{mmol})$, im Vergleich zu den männlichen Patienten (Mittelwert: 
$13.2 \mu \mathrm{g} / \mathrm{mmol}$ ) (Abbildung 29). Sowohl bei den männlichen als auch bei den weiblichen Patienten kam es nach der Behandlung mit Cis- oder Carboplatin zu einem Abfall der NGAL-Ausscheidung. Dieser Abfall war aber statistisch nicht signifikant.

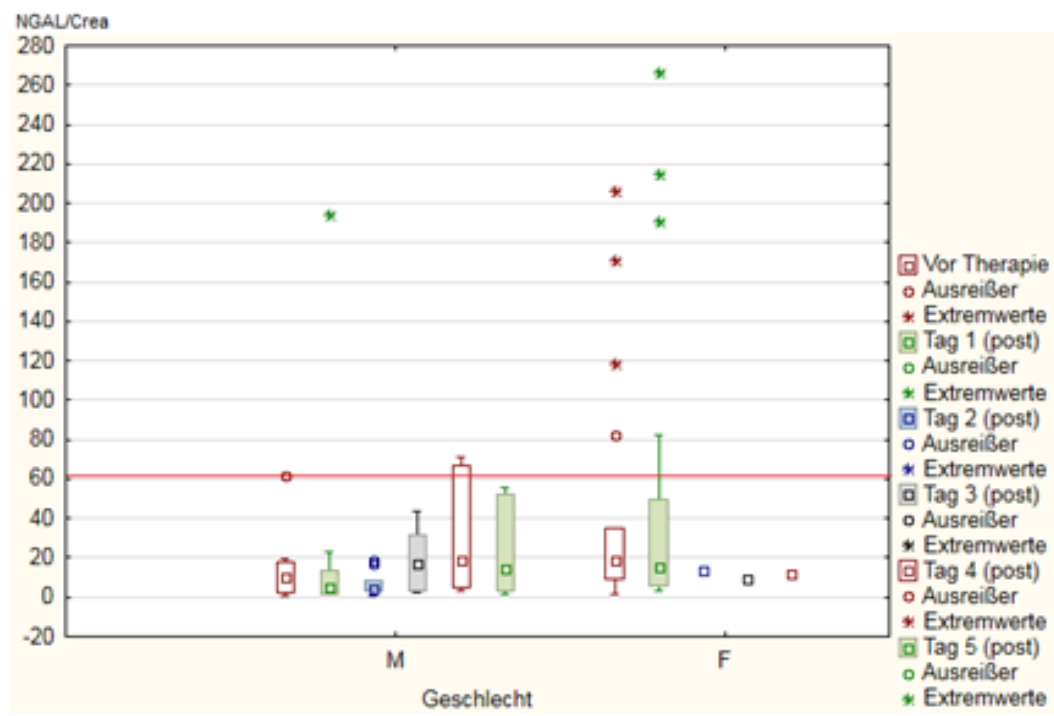

Abbildung 29: Darstellung der NGAL/Crea-Konzentrationen vor und nach Gabe des Chemotherapeutikums, gruppiert nach männlichen (M) und weiblichen (F) Patienten (die obere Grenze des Referenzbereichs ist durch eine rote Linie markiert)

\section{TAMM-HORSEFALL-PROTEIN}

Im Patientenkollektiv ließ sich vor der Behandlung ein signifikanter Unterschied der THUP/Crea-Konzentrationen in der Gruppe der Diabetiker im Vergleich zu den nicht-diabetischen Patienten ( $p=0.0003)$ nachweisen.

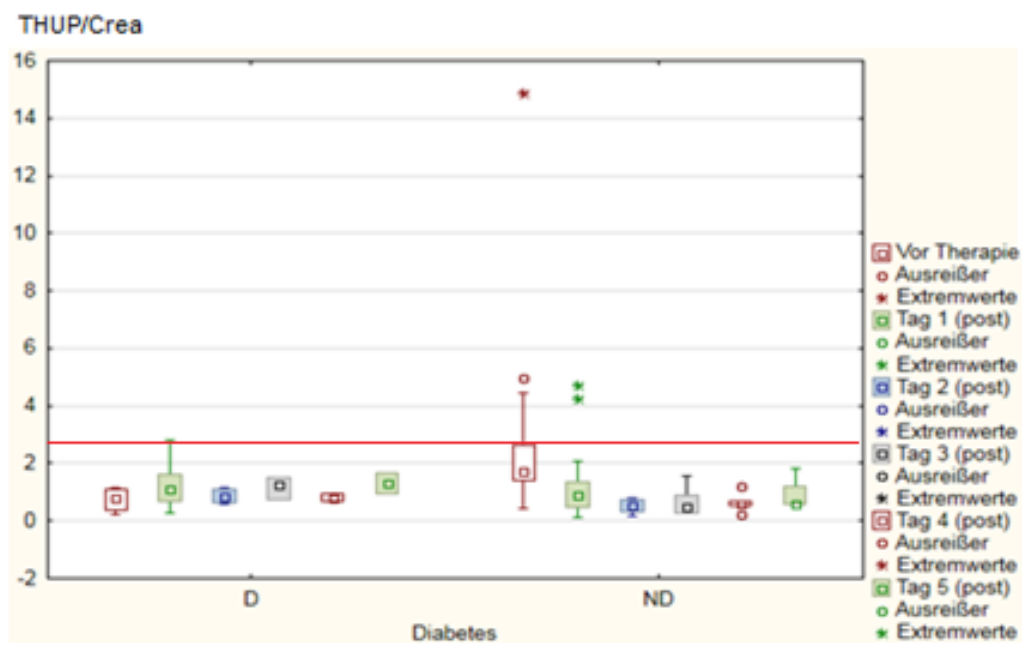

Abbildung 30: Darstellung der THUP/Crea-Konzentration an den Tagen vor und nach der Chemotherapie, gruppiert nach diabetischen (D) und nicht-diabetischen (ND) Patienten (die obere Grenze des Referenzbereichs ist durch eine rote Linie markiert) 
Die Nicht-Diabetiker wiesen eine höhere THUP/Crea-Konzentration im Urin auf als die diabetischen Patienten (Mittelwert: $2.76 \mathrm{mg} / \mathrm{mmol} v \mathrm{ss} .0 .74 \mathrm{mg} / \mathrm{mmol}$ ) (Abbildung 30).

Nach der Therapie zeigten sich die THUP/Crea-Konzetrationen an den Tagen eins und zwei signifikant erhöht $(p=0.02, p=0.02)$, bewegten sich aber innerhalb des Referenzbereichs. In der Probandengruppe waren die Konzentrationen der weiblichen Probanden signifikant erhöht, im Vergleich zu den männlichen Probanden $(p=0.026)$, wobei die weiblichen Patientinnen durchschnittlich eine Konzentration von $1.2 \mathrm{mg} / \mathrm{mmol}$ aufwiesen, die männlichen Patienten einen Mittelwert von $0.8 \mathrm{mg} / \mathrm{mmol}$. Diese Geschlechtsspezifität ließ sich im Patientenkollektiv nicht nachweisen.

\section{VASCULAR ENDOTHELIAL GROWTHS FACTOR}

$34.48 \%$ der Patienten wiesen bereits vor der Behandlung mit Cis-/Carboplatin erhöhte VEGFA/Crea-Konzentrationen im Urin auf. 70 \% davon waren weiblich. Mit dem Mann-Whitney-U-Test konnte statistisch jedoch kein signifikanter geschlechtsspezifischer Unterschied der VEGFA/Crea-Konzentrationen, vor der Behandlung von Cis-/ Carboplatin, herausgestellt werden.

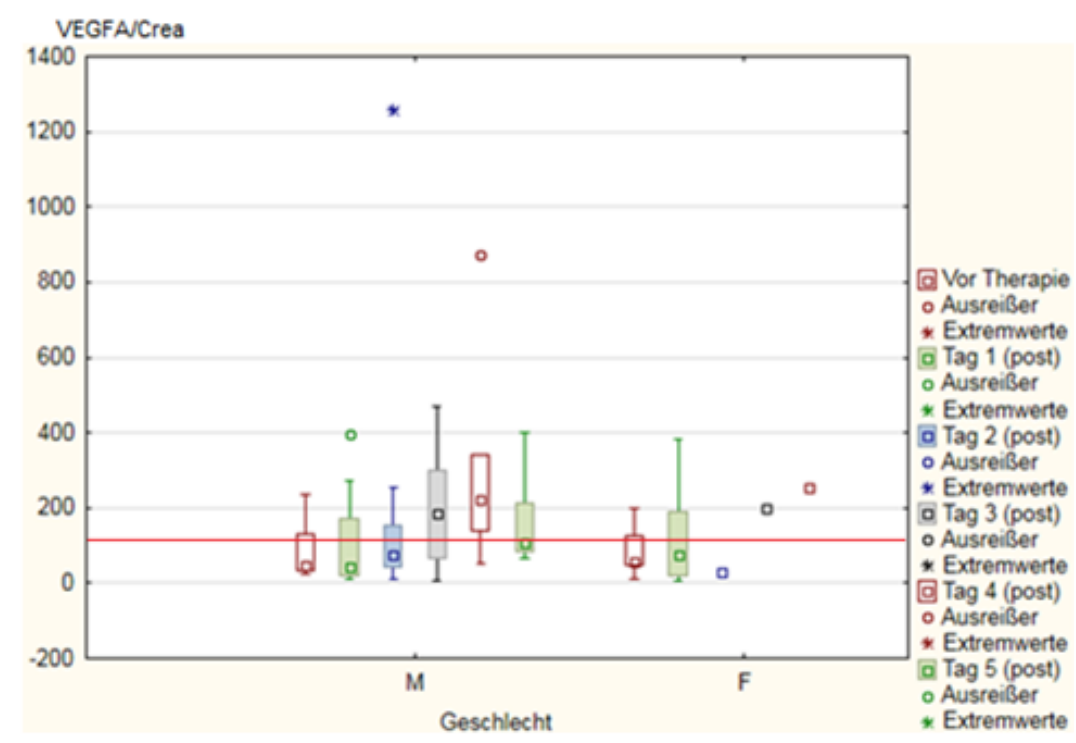

Abbildung 31: Darstellung der VEGFA/Crea-Konzentration an den Tagen vor und nach der Gabe des Chemotherapeutikums, gruppiert nach männlichen (M) und weiblichen (F) Patienten (die obere Grenze des Referenzbereichs ist durch eine rote Linie markiert)

An Tag vier nach Gabe des Chemotherapeutikums zeigte sich im Vergleich zu den Basiswerten ein signifikanter Anstieg der VEGFA/Crea-Konzentration $(p=0.004)$ 
(Abbildung 31). Hier ließ sich kein Unterschied zwischen den einzelnen Gruppen im Kollektiv darstellen.

\subsubsection{MARKER DES SAMMELROHRS}

\section{CALBINDIN}

Vor der Behandlung mit Cis-/Carboplatin zeigte sich statistisch kein signifikanter Unterschied der Calb/Crea-Konzentration innerhalb der einzelnen Patientengruppen im Kollektiv. Der Omnibus-Test verzeichnete über den gesamten Zeitraum einen signifikanten Anstieg der Calb/Crea-Konzentration $(p=0.009)$, der sich aber über den Wilcoxon-matched-pairs-Test nicht auf spezielle Tage differenzieren ließ (Abbildung 32).

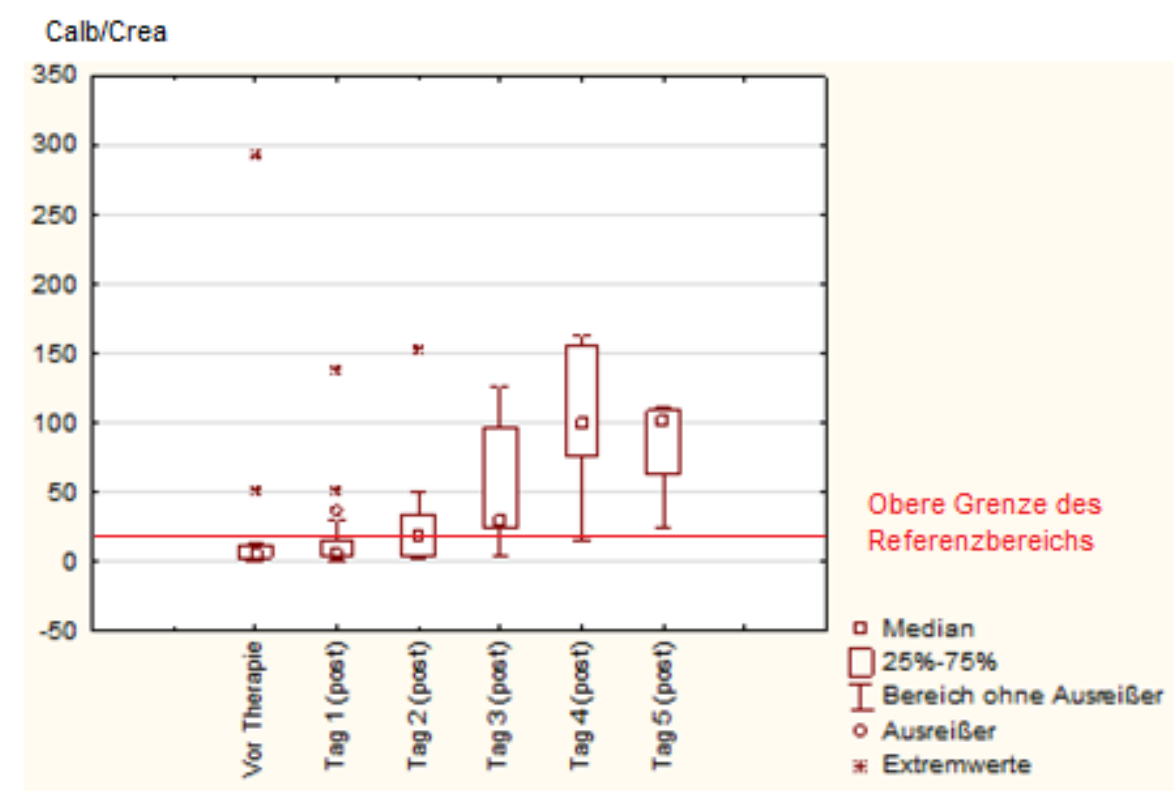

Abbildung 32: Darstellung der Calb/Crea-Konzentration an den Tagen vor und nach der Chemotherapie

\subsubsection{MARKER DES GLOMERULUMS}

\section{CYSTATIN-C}

Ante curatio zeigte sich kein signifikanter Unterschied innerhalb der verschiedenen Patientengruppen. Nach Gabe des Chemotherapeutikums wurde ein statistisch signifikanter Unterschied an den Tagen drei, vier und fünf $(p=0.007, p=0.018$, $p=0.046$ ) mit einem Maximum an Tag vier deutlich (Abbildung 33). Auch hier ließ 
sich keine Gruppendifferenzierung durch den Wilcoxon-matched-pairs-Test feststellen.

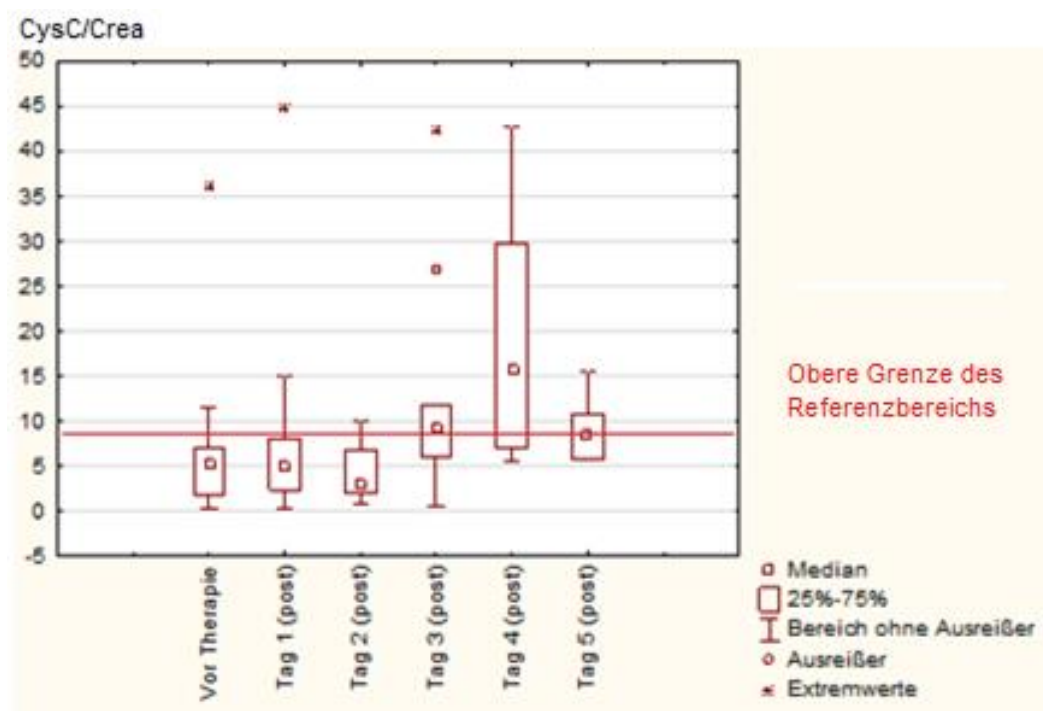

Abbildung 33: Darstellung der CysC/Crea-Konzentration an den Tagen vor und nach Gabe des Chemotherapeutikums

TISSUE INHIBITOR OF METALLOPROTEASE-2

Vor der Behandlung zeigte sich eine statistisch signifikante geschlechtsspezifische Differenzierung im Patientenkollektiv ( $p=0.02)$.

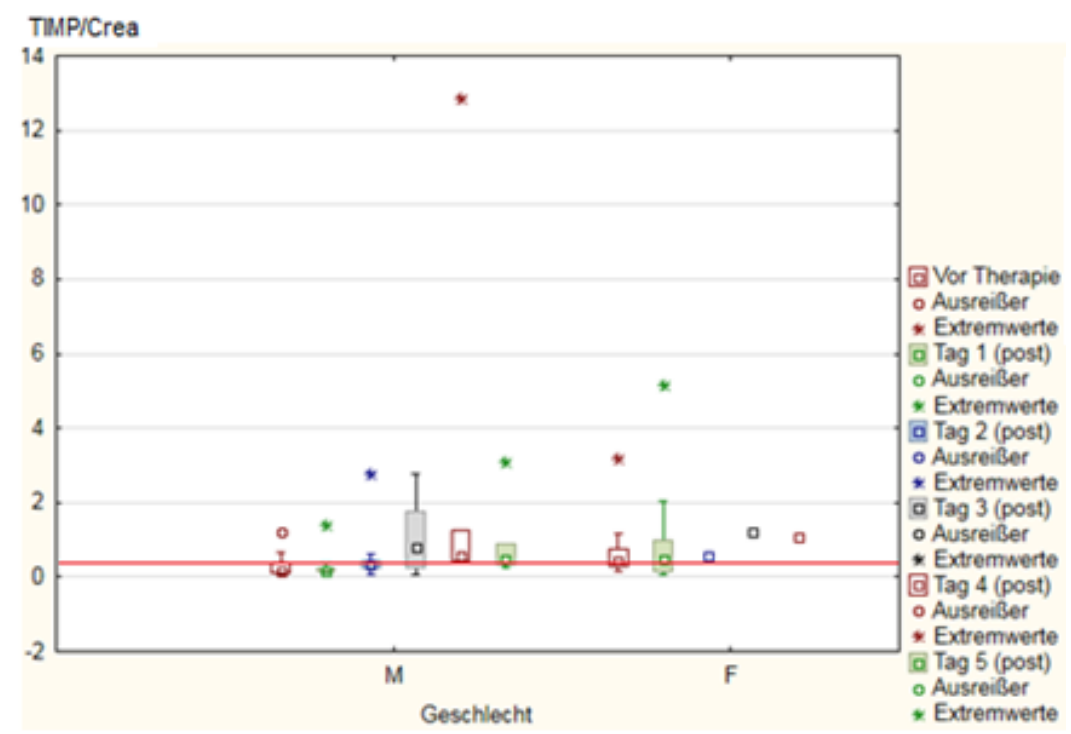

Abbildung 34: Darstellung der TIMP2/Crea-Konzentration an den Tagen vor und nach der Gabe des Chemotherapeutikums, gruppiert nach männlichen (M) und weiblichen (F) Patienten (die obere Grenze des Referenzbereichs ist durch eine rote Linie markiert) 
Die männlichen Patienten wiesen einen niedrigeren Mittelwert auf als die weiblichen Patientinnen $(0.31 \mu \mathrm{g} / \mathrm{mmol}$ vs. $0.63 \mu \mathrm{g} / \mathrm{mmol})$ (Abbildung 34). Im Probandenpool zeigte sich eine entgegengesetzte Verteilung der Geschlechter: Die männlichen Probanden zeigten mit einem Mittelwert von $0.18 \mu \mathrm{g} / \mathrm{mmol}$ eine signifikant erhöhte Konzentration der TIMP2/Crea-Rate $(p=0.003)$ im Vergleich zu den weiblichen Probanden (Mittelwert: $0.04 \mu \mathrm{g} / \mathrm{mmol}$ ). Nach Gabe des Chemotherapeutikums zeigte sich kein Unterschied zwischen den Geschlechtern. Alle diabetischen Patienten im Kollektiv, wiesen einen Anstieg der TIMP2/Crea-Konzentration über den Referenzbereich auf. Statistisch ließ sich kein signifikanter Unterschied bei den Patienten mit diabetischer Stoffwechsellage und den nicht diabetischen Patienten erkennen.

\section{OSTEOPONTIN}

Die Osteo/Crea-Konzentration im Urin zeigte statistisch im Bereich der Basiswerte keine signifikanten Konzentrationsunterschiede zwischen den Patientengruppen. Nach der Gabe des Chemotherapeutikums wurden signifikante Konzentrationsänderungen an den Tagen drei und fünf sichtbar $(p=0.04, p=0.005)$.

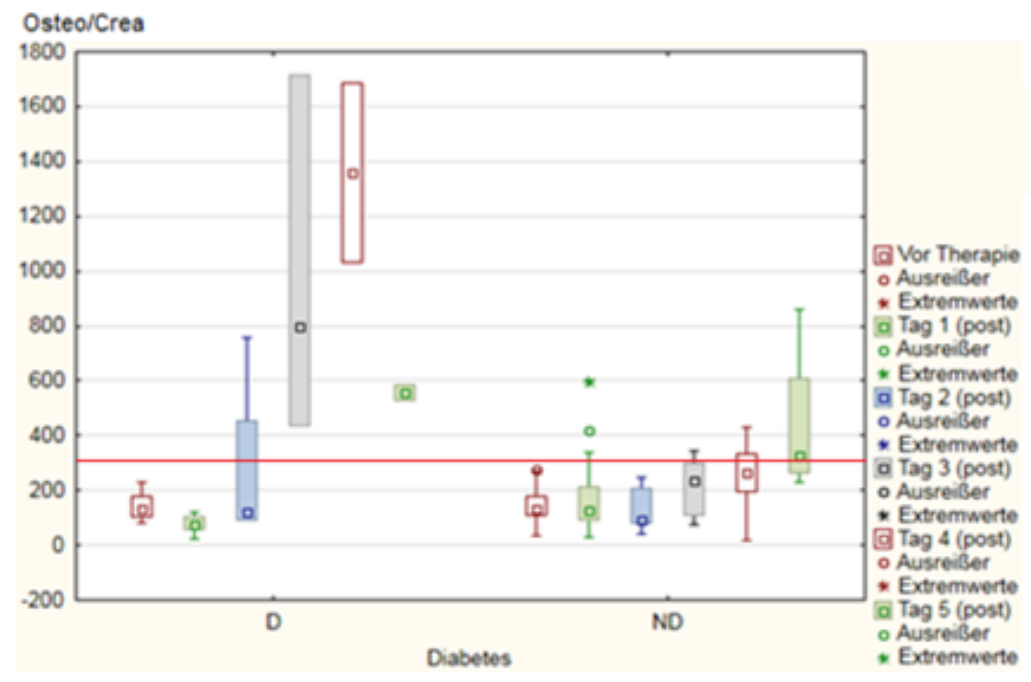

Abbildung 35: Darstellung der Osteo/Crea-Konzentrationen an den Tagen vor und nach Gabe des Chemotherapeutikums, gruppiert nach diabetischen (D) und nicht-diabetischen (ND) Patienten (die obere Grenze des Referenzbereichs ist durch eine rote Linie markiert)

An Tag eins und drei wurde ein statistisch signifikanter Unterschied zwischen den diabetischen und nicht-diabetischen Patienten deutlich (Abbildung 35); die Diabetiker des Kollektivs wiesen an Tag eins einen Mittelwert von $77 \mu \mathrm{g} / \mathrm{mmol}$ auf, die Nicht-Diabetiker einen Mittelwert von $173 \mu \mathrm{g} / \mathrm{mmol}$. Folglich zeigten die nicht- 
diabetischen Patienten, höhere Osteo/Crea-Konzentrationen im Urin. Die Konzentrationen bewegten sich innerhalb des Referenzbereiches $(311.2 \mu \mathrm{g} / \mathrm{mmol})$.

Gegensätzlich dazu zeigten sich an Tag drei die Osteo/Crea-Konzentrationen in der Gruppe der Diabetiker stark erhöht: die diabetischen Patienten zeigten einen Mittelwert von $982 \mu \mathrm{g} / \mathrm{mmol}$, die nicht-diabetischen Patienten einen Mittelwert von $216 \mu \mathrm{g} / \mathrm{mmol}$. Die Osteo/Crea-Konzentrationen wies als einziger Marker einen signifikanten Unterschied zwischen den Cisplatin- und Carboplatinpatienten auf ( $\mathrm{p}=0.0004$ ) (Abbildung 36).

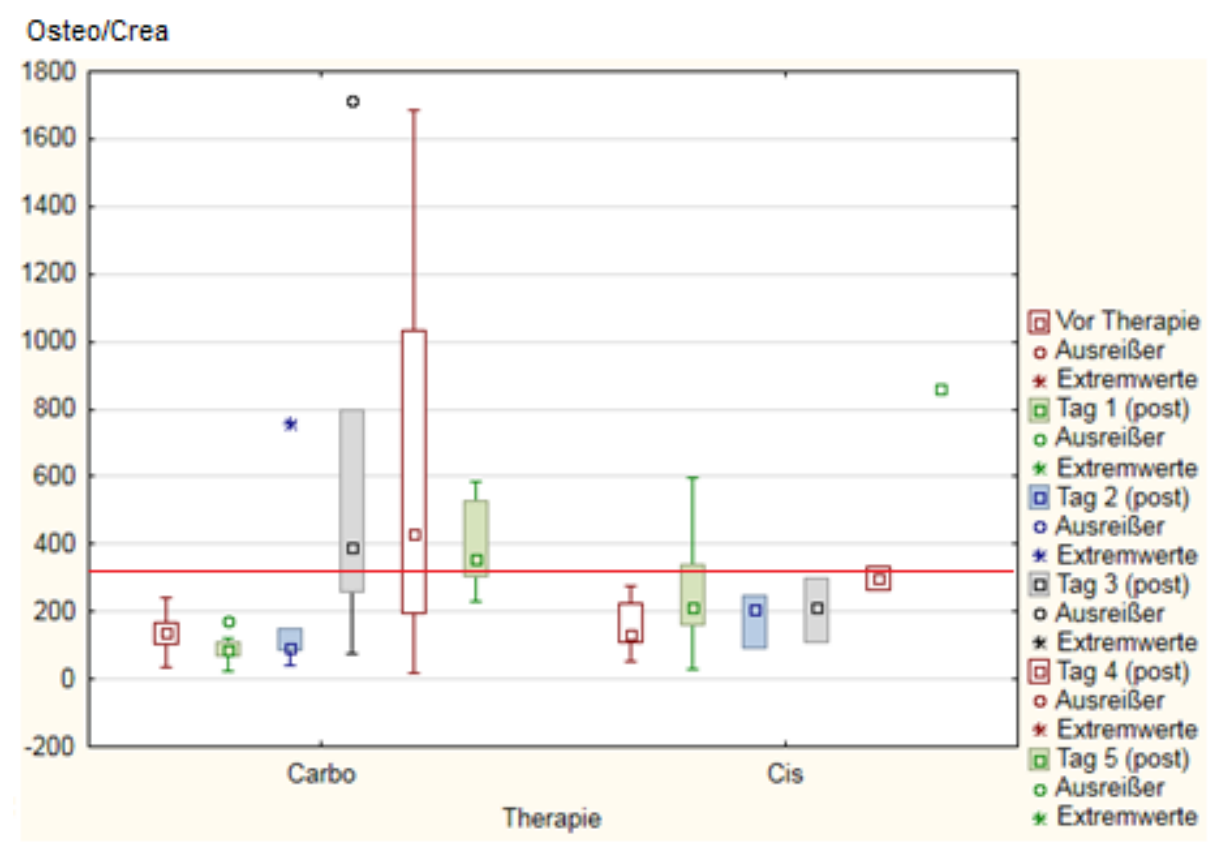

Abbildung 36: Darstellung der Osteo/Crea-Konzentration an den Tagen vor und nach der Chemotherapie, gruppiert nach Cisplatin (Cis) und Carboplatin (Carbo) (die obere Grenze des Referenzbereichs ist durch eine rote Linie gekennzeichnet)

Die Patienten, die als Chemotherapeutikum Cisplatin erhielten, zeigten an Tag eins postinterventionell einen Mittelwert von $244 \mu \mathrm{g} / \mathrm{mmol}$, die Patienten mit einer Carboplatintherapie einen Mittelwert von $88 \mu \mathrm{g} / \mathrm{mmol}$.

Folglich zeigte Cisplatin einen stärkeren Effekt auf die Osteo/Crea-Konzentration im Urin.

An den folgenden Tagen ließen sich keine signifikanten Unterschiede zwischen den beiden Therapieformen nachweisen. 


\subsubsection{KORRELATION DER SERUMKREATININWERTE}

Des Weiteren sollte der Fragestellung nachgegangen werden, ob einem Konzentrationsanstieg der Urinmarker eine Konzentrationserhöhung des Serumkreatinins vorrausgeht, zeitgleich geschieht oder der Erhöhung des Serumskreatinins dem Anstieg der Urinparameter folgt.

Es wird in dieser Studie vorausgesetzt, dass alle Marker, die nicht mit einem Anstieg der Serumkreatininwerte einhergehen, als sensitiver betrachtet werden als der bisherige Goldstandard.

Keiner der Marker korreliert direkt mit einer Verschlechterung der Serumkreatininwerte oder der GFR. Die meisten GFR-Verschlechterungen zeigten sich an Tag drei. Die Marker des proximalen Tubulus waren bereits an Tag eins nach der Therapie erhöht und an Tag zwei nach der Therapie zeigten 13 Marker aus allen Abschnitten des Tubulus, des Sammelrohrs und des Glomerulums signifikante Konzentrationserhöhungen. 


\section{DISKUSSION}

Es wurden 29 Patienten mit onkologischen Erkrankungen einen Tag vor und bis maximal fünf Tage nach der platinhaltigen Chemotherapie auf 30 Biomarker im Urin untersucht. Zudem wurde die Nierenfunktion anhand des standardmäßig erhobenen Serumkreatinins überwacht. $31 \%$ der Patienten reagierten nach der Gabe von Cis-/ Carboplatin mit einer Verschlechterung der Nierenfunktion.

Die Bewertung der Ergebnisse des Patientenkollektivs beruht auf einem Vergleich zu einem gesunden Probandenkollektiv. Es bestand ein deutlicher Altersunterschied zwischen den zwei Kollektiven ( $\varnothing$ Probanden: 39 Jahre vs. $\varnothing$ Patienten: 64 Jahre). Dies bedingt die erhöhte Prävalenz von Karzinomen in der sechsten Lebensdekade.

Der bisherige "Goldstandard“ der Nierenfunktionsbestimmung, das Serumkreatinin, wurde im Probandenkollektiv nicht erhoben, da das Studiendesign keine Blutentnahmen bei gesunden Probanden vorgesehen hatte.

Die Nierenfunktion der Probanden wurde als normal vorausgesetzt. Die 29 Patienten, die für die Studie gewonnen werden konnten, zeigten unterschiedliche Basisdaten (verschiedene Tumorenitäten, Grunderkrankungen und Medikationen) und Unterschiede in der Krankenhausliegedauer, wodurch nicht von allen Patienten an allen Tagen Urinproben gesammelt werden konnten.

Der Morgenurin der Patienten wurde auf die Biomarker des proximalen und distalen Tubulus, auf spezifische Marker des Sammelrohrs und des Glomerulus, auf ubiquitär auftretende Marker und auf Elektrolyte und Metabolite als Indikatoren der Nierenfunktion getestet.

\subsection{METHODISCHE LIMITIERUNG}

Durch die geringe $n$-Zahl konnten nicht immer klare Unterscheidungen getroffen werden, besonders in den Subgruppen, dadurch sind nicht alle Effekte statistisch erkennbar beziehungsweise verschleiert die geringe $n$-Zahl die Fixierung auf die Effekte und die statistische Signifikanz. Es können Urinproben engmaschiger und schon zu früheren Zeitpunkten (z.B. während der Therapie) gesammelt werden, um die zeitliche Varianz der Marker noch spezifischer darstellen zu können. 
Zudem ist die Beurteilung der Effekte an den Tagen vier und fünf erschwert, da nicht von allen Patienten an diesen Tagen Proben vorlagen.

\subsection{BASISWERTE DER BIOMARKER IM PATIENTENKOLLEKTIV}

Vor der Chemotherapie wiesen K, Prot, MIALB, a1MG, B2MG, KIM1, NGAL, THUP, VEGFA und TIMP2 erhöhte Basiswerte auf. Hierbei wurde deutlich, dass die weiblichen Patientinnen der Studie, wenn auch nicht immer statistisch signifikant, bei all diesen Markern durchschnittlich höhere Werte aufwiesen als die männlichen Patienten oder aber eine höhere Anzahl an Konzentrationserhöhungen zeigten. Dies wurde auch schon bei den Biomarkern Mg, ALT, AST, GGT und GSTa deutlich, wobei sich in diesen Fällen auch die signifikant erhöhten Messwerte der weiblichen Patientinnen gegenüber den männlichen Patienten noch innerhalb des Referenzbereichs bewegten. MIALB, NGAL und THUP zeigten bereits im Probandenkollektiv, dass die weiblichen Probanden signifikant höhere Konzentrationen der Biomarker im Urin aufwiesen als die männlichen Probanden. Somit liegt der Fokus dieser Marker weniger auf den Vorerkrankungen, da schon im gesunden Kollektiv geschlechtsspezifische Unterschiede auftraten. Zudem müssen diese Fakten bei der Auswertung der Reaktionen bzw. der Folgen der Therapie berücksichtigt werden.

Die männlichen Patienten zeigten auf Grund ihrer im Verhältnis vermehrten Muskelmasse signifikant erhöhte Konzentrationen des Urinkreatinins. An dieser Stelle muss somit berücksichtigt werden - da alle Messwerte auf den Urinkreatininwert normiert wurden, um Volumenschwankungen auszugleichen - dass die männlichen Patienten dadurch im Vergleich zu den weiblichen Patienten, verhältnismäBig niedrigere Werte aufweisen. Zur Kontrolle wurden hierfür die nicht auf den Urinkratininwert normierten Werte der Geschlechter betrachtet, um die Tendenz zu verifizieren (keine separate Statistik aufgeführt).

Die erhöhten Konzentrationen von Protein und Albumin vor der Gabe von Cis-/ Carboplatin können indizierend dafür sein, dass die Tumorerkrankungen (primär bei den weiblichen Patientinnen) eine Grundlage für eine Albuminurie und Proteinurie darstellen. In der Literatur finden sich keine Hinweise auf einen Zusammenhang zwischen gynäkologischen Tumorerkrankungen und einer vermehrten Ausscheidung der aufgeführten Biomarker. 
Des Weiteren könnte ein fortgeschrittener Therapiezyklus Einfluss auf die erhöhte Urinkonzentration haben: 15 Patientinnen erhielten bereits vor der Behandlung mit Cis- oder Carboplatin eine platinhaltige Chemotherapie und befanden sich somit mindestens im zweiten Therapiezyklus. Dies könnte grundlegend verantwortlich sein für eine Vorschädigung der Niere und somit für eine erhöhte Ausscheidungsrate von Protein, Albumin und auch von den Markern der anderen Nierenanteile, die im Basiswertbereich signifikante Erhöhungen aufzeigten.

\subsection{AUSWIRKUNG DER CHEMOTHERAPEUTIKA CIS- UND CARBOPLATIN AUF DIE BIOMARKER IM URIN}

Die Marker Ca, Ukrea, ALT, KIM1, VEGFA, TIMP2, TFF3 und LDH zeigten keine Reaktion auf die Gabe des Chemotherapeutikums. Ka, P, Harnstoff, der pH-Wert, GGT und ALP zeigten eine Reaktion auf Cis- und Carboplatin, allerdings bewegten sich alle gemessenen Werte innerhalb des Referenzbereichs und können somit nicht als Marker für eine Schädigung der Niere genutzt werden.

Die Parameter des proximalen Tubulus, BNAG, $\alpha 1 M G, \beta 2 M G$ und GSTa, reagierten am stärksten auf die Gabe des Chemotherapeutikums ebenso wie die ubiquitär vorkommenden Marker MIALB und Protein.

Toxische Effekte von platinhaltigen Therapien treten primär im proximalen Tubulus auf, besonders im S3-Segment der tubulären Epithelzellen, danach im Glomerulus und distalen Tubulus (dos Santos 2012).

In dieser Studie zeigte sich die zeitlich primäre Reaktion des proximalen Tubulus, da drei der acht Marker ( $\alpha 1 M G, \beta 2 M G$ und $\beta N A G$ ) bereits am ersten Tag signifikante Konzentrationserhöhungen anzeigten. Außerdem wird im proximalen Tubulus Glukose und Phosphat reabsorbiert (Curthoys und Moe 2014). Beide Parameter (Gluc, P) zeigten auch am ersten Tag nach Gabe des Chemotherapeutikums signifikant erhöhte Werte. In allen anderen Abschnitten der Niere war ein Konzentrationsanstieg frühestens an Tag zwei zu beobachten. 60-70 \% des Natriumchlorids werden im proximalen Tubulus reabsorbiert (Curthoys und Moe 2014). Der Elektrolythaushalt zeigte in den Ergebnissen dieser Studie jedoch erst am zweiten Tag signifikant erhöhte Werte im Urin ( $\mathrm{Na}, \mathrm{Cl}, \mathrm{K}$ und $\mathrm{Mg}$ ).

Patienten, die eine Cisplatintherapie erhielten, zeigten neben einer reduzierten GFR auch eine Hypomagnesieämie und Hypokaliämie innerhalb von zehn Tagen 
nach Gabe des Chemotherapeutikums (dos Santos 2012). Da am zweiten Tag nach Gabe von Cis- oder Carboplatin, die Ausscheidungsrate von $\mathrm{Mg}$ und $\mathrm{K}$ im Vergleich zu den Basiswerten der Patienten aus dem Kollektiv signifikant erhöht war, ist davon auszugehen, dass die Konzentration von Magnesium und Kalium im Blut der Patienten im Vergleich zu den Tagen vor der Therapie erniedrigt war.

Die Ausscheidung des Elektrolyts Kalium ist abhängig von der Aufnahmemenge und wird beeinflusst von einer diuretischen Therapie (Binia 2015). Da aber nicht nur die medikamentös behandelten Hypertoniker erhöhte Basiswerte zeigten, ist dieser Einfluss zu vernachlässigen. Die weiblichen Patientinnen wiesen im Vergleich zu den männlichen Patienten vermehrte Konzentrationsanstiege der Biomarker auf.

Die P-Konzentration zeigte am ersten Tag nach Gabe des Chemotherapeutikums einen signifikanten Anstieg der Werte im Vergleich zu den Basiswerten, wobei die $\mathrm{Mg} / \mathrm{Crea-Konzentration} \mathrm{über} \mathrm{den} \mathrm{gesamten} \mathrm{Zeitraum} \mathrm{keinen} \mathrm{signifikanten} \mathrm{Ände-}$ rungen unterlag. Somit konnte eine enge Kopplung der beiden Elektrolythaushalte in dieser Studie aufgezeigt werden.

Die zirkadiane Rhythmik kann hier unberücksichtigt bleiben, da bei den Patienten Morgenurin gesammelt wurde.

Laut des Medikamentenbeipackzettels für Cisplatin (Medac Gesellschaft für klinische Spezialpräparate $\mathrm{GmbH}$, Stand der Information: 02/2011) und Carboplatin (Ebewe Pharma Ges.m.b.H. Nfg. KG: Vertrieb: Sandoz GmbH, Stand der Info: November 2013) führt die Anwendung der Medikamente zu einer Senkung der Serumelektrolyte (Magnesium, Kalium, Natrium und Calcium bei Carboplatin und zu einer Hypomagnesiämie und Hypokalziämie bei Cisplatin).

Eine Senkung der Serumkonzentration bedeutet, dass Magnesium entweder vermehrt verbraucht beziehungsweise im Köper verwendet wird, oder eine erhöhte Ausscheidung die Konzentration im Blut absenkt. In dieser Studie zeigte sich kein Unterschied in den Ausscheidungsraten der einzelnen Elektrolyte bezüglich der beiden Chemotherapeutika.

Die Glukosekonzentration zeigte als metabolischer Marker der Nierenfunktion und Schädigung signifikant erhöhte Werte gegenüber den Basiswerten. Eine experimentelle Studie von Pinches et al. wies am Tiermodell nach, dass die Glukoseausscheidung bei Cisplatin behandelten Ratten dosis-, zeit- und geschlechtsab- 
hängig ist; demnach reagiert das männliche Geschlecht signifikanter als das weibliche Geschlecht, gerade bei hohen Dosen (Pinches et al. 2012).

Diese Ergebnisse ließen sich klinisch in dieser Studie nicht validieren: Es wurde weder ein geschlechtsspezifischer noch ein dosisabhängiger, chemotherapeutischer Unterschied im Patientenkollektiv sichtbar.

Wainford et al. deuteten in einer Studie darauf hin, dass die intrazelluläre GGTKonzentration bei der Metabolisierung von Cisplatin durch eine Spaltung zu einem Nephrotoxin eine Rolle spielt (Wainford et al. 2008). Die Ergebnisse dieser Studie konnten keinen Zusammenhang zwischen der intrazellulären GGT-Konzentration und einer erhöhten nephrotoxischen Wirkung nachweisen. Eine erhöhte Ausscheidung von GGT im Urin müsste demnach mit einer intrazellulären Konzentrationserniedrigung einhergehen. Eine niedrigere Konzentration des Enzyms in den Zellen würde somit eine geringere Spaltungsrate der nephrotoxischen CisplatinKonjugate bewirken. Die GGT-Konzentration war am vierten Tag nach Gabe des Chemotherapeutikums signifikant erhöht gegenüber den Basiswerten. Am Tag vier zeigten neun der 31 Marker signifikante Erhöhungen in den Messwertkonzentrationen. Somit kann eine geringere Toxizität nicht belegt werden.

Nejat et al. stellten in einer Studie dar, dass die Gamma-Glutamyltransferase bei denjenigen Patienten keine signifikante urinäre Erhöhung zeigt, die ein prärenales akutes Nierenversagen aufweisen (Nejat et al. 2012). Die Ergebnisse dieser Studie konnten bestätigen, dass eine Verschlechterung der Nierenfunktion nicht mit einer erhöhten GGT/Crea-Konzentration im Urin korreliert, zumal davon ausgegangen wird, dass Cis- und Carboplatin ein intrarenales Nierenversagen verursachen.

Als weiterer Marker zur Identifizierung einer Schädigung des proximalen Tubulus zeigte die BNAG/Crea-Konzentration signifikante Änderungen an den Tagen eins bis fünf nach Gabe des Chemotherapeutikums. In einer Studie mit schwerkranken Patienten konnten Westhuyzen et al. zeigen, dass der BNAG-Spiegel im Urin (zusammen mit einigen anderen tubulären Enzymen) hochsensitiv ein akutes Nierenversagen detektiert - zwölf Stunden (bis vier Tage), bevor ein Anstieg des Kreatininwertes im Serum erkannt wird (Westhuyzen et al. 2003). In einer weiteren Veröffentlichung von Liangos et al. wird festgestellt, dass das Risiko der Dialyseabhängigkeit und die Mortalitätsrate abhängig ist von der Höhe der BNAG- 
Konzentration im Urin - je höher die Konzentration desto größer ist das Risiko der Dialyseabhängigkeit und die Mortalitätsrate (Liangos et al. 2007). Dies soll zeigen,

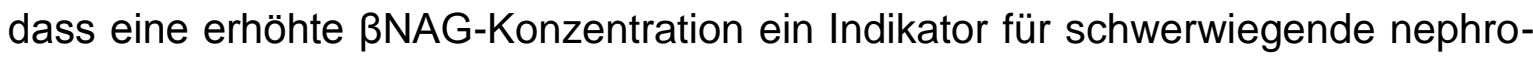
toxische Schädigungen darstellt.

Die großen Vorteile dieses Markers (hohe Sensitivität und die einfache photometrische Messung im Urin) werden jedoch durch sein unspezifisches Reaktionsmuster relativiert: zum einen wird BNAG von endogenem Urea (Bondiou et al. 1985) inhibiert, zum anderen wurden, abgesehen vom akuten Nierenversagen, noch einige andere klinische Krankheitsbilder erkannt, bei denen $\beta N A G$ auch angestiegen ist; dazu zählen die rheumatische Arthritis (Iqbal et al. 1998), die beeinträchtigte Glukosetoleranz (Fujita et al. 2002) und eine Hyperthyreose (Tominaga et al. 1989). Im Patientenkollektiv dieser Studie wurde ebenfalls ein unspezifisches Muster deutlich. Bereits vor der Therapie waren die Werte der BNAG/CreaKonzentration signifikant erhöht. Eine Differenzierung der einzelnen Untergruppen im Kollektiv ließ sich bei den Werten nach Gabe des Chemotherapeutikums nicht erkennen.

Dennoch zeigte sich ein generalisierter, signifikanter Anstieg der $\beta 2 \mathrm{MG} /$ CreaKonzentration im Urin an den Tagen eins bis fünf nach Gabe des Chemotherapeutikums in Bezug auf die Basiswerte.

Ein Anstieg von $\beta 2 M G$ im Urin wird als früher Marker von Tubulusschäden bei verschiedenen Vorkommnissen detektiert: nach herzchirurgischen Eingriffen (Dehne et al. 1995), nach Nierentransplantationen (Schaub et al. 2005) und nach Nierenbestrahlung (Chapelsky et al. 1992) vor dem Anstieg des Serumkreatinins am vierten bis fünften Tag. Somit zeigt der Marker eine frühere Reaktion auf Schäden durch platinhaltige Toxine.

Ergebnisse einer klinischen Studie über den nephrotoxischen Einfluss von Cisoder Carboplatin auf den Biomarker $\beta 2 M G$ sind aktuell nicht zu finden, jedoch haben Sohn et. al. in einer In-vitro-Studie, in der humane HK-2 Zellen mit Cisplatin behandelt wurden, die Konzentration der Synthetisierung der mRNA von $32 \mathrm{MG}$ gemessen und verzeichnen keinen signifikanten Anstieg (Sohn et al. 2013). Die Synthetisierung der mRNA von KIM1 verzeichnet in der gleichen Studie einen signifikanten Anstieg (Sohn et al. 2013). 
Dies deutet darauf hin, dass bei toxischem Stress die renalen HK-2- Zellen wesentlich mehr KIM1 produzieren, was dann vermehrt im Urin zu finden ist. Dieser Anstieg ließ sich auch im Rattenmodell validieren (Sohn et al. 2013).

Der Anstieg von KIM1 im Urin nach Gabe von Cis-/Carboplatin lässt sich dadurch erklären, dass bei einem Zelluntergang (in diesem Fall beim Untergang der proximalen Tubuluszellen) der Körper mit einer inflammatorischen Reaktion antwortet. Hierbei steigt die Konzentration von freigesetztem KIM1 im Urin an, was eine Studie am Rattenmodell bestätigt (Kankuri et al. 2014). In dieser klinischen Studie zeigte KIM1 über den gesamten Messzeitraum einen deutlichen Anstieg der Konzentration, jedoch keine statistische Signifikanz.

Zudem ließ sich kein Unterschied innerhalb der einzelnen Patientengruppen im Kollektiv feststellen. In der Literatur wird KIM1 als hochspezifisch und sensitiv für die Identifizierung von toxischen Substanzen dargestellt, die den proximalen Tubulus der Nieren schädigen (Bonventre 2009).

In vorklinischen und klinischen Studien erwies sich KIM1 als viel sensitiverer Biomarker als konventionelle Marker wie Serumkreatinin, BUN, Proteine, GGT und BNAG (Vaidya et al. 2006). Diese hochspezifische Sensitivität bei Nierenschädigung durch Toxine ließ sich in dieser Studie durch die platinhaltige Therapie nicht validieren.

Zudem wird die Konzentration von KIM1 im Urin als potenter, non-invasiver Marker bei Patienten mit Nierenzellkarzinomen genutzt (Zhang et al. 2014). Im Kollektiv zeigte ein Patient ein Nierenzellkarzinom. Vor der Chemotherapie sowie in der Entwicklung nach der Therapie zeigte sich eine Erhöhung der Werte, was laut Zhang et al. indizierend für diese Tumorform ist.

Eine weitere Tiermodellstudie zeigte bei Ratten, die mit Cisplatin behandelt wurden, eine erhöhte GSTa Konzentration im Urin (Shin et al. 2014). In Bezug auf humane Studien wird GSTa bei renaler Dysfunktion (Walshe et al. 2009) und nach akutem Nierenversagen post Bypass-Operationen als nicht indizierend dargestellt, da es zu keinem Anstieg kommt (Susantitaphong et al. 2013). Nach der Gabe des Chemotherapeutikums zeigten sich signifikant erhöhte Messwerte der GSTa/CreaKonzentration an den Tagen zwei, drei und vier.

Somit zeigt diese Studie, dass GSTa nach Gabe eines nephrotoxischen Medikamentes verzögert ansteigt (nach den Markern des proximalen Tubulus). 
Dieser Biomarker war im Tiermodell erhöht und kann in der Niere (Matthaeus et al. 2001) und im Urin von Mäusen drei Stunden nach Cisplatinverabreichung nachgewiesen werden. So wurde er als früher diagnostischer Biomarker für akutes Nierenversagen vorgeschlagen (Mishra et al. 2004).

In einer humanen Studie zeigte sich eine Korrelation zwischen einer erhöhten NGAL-Konzentration und einer erhöhten Kreatininkonzentration und einer Verschlechterung der GFR (Peres et al. 2014). Entgegen diesen Studien zeigten die Ergebnisse dieser Arbeit keine signifikanten Konzentrationsänderungen von NGAL/Crea im Urin nach Behandlung mit Cis- oder Carboplatin.

Zudem konnte auch in der In-vitro-Studie von Sohn et al., in der humane HK-2 Zellen mit Cisplatin behandelt wurden, gezeigt werden, dass die Synthetisierung der mRNA von NGAL keinen signifikanten Anstieg verzeichnet (Sohn et al. 2013). Zu den weiteren Markern des Kollektivs zählt auch Clusterin. Vom Health and Envoiremential Science Institute (HESI) wurde Clusterin (zudem GSTa, mGST, und RPS 1) als potentieller Biomarker vorgeschlagen (Gautier et al. 2010). Jedoch zeigte die Clu/Crea-Konzentration keine signifikant erhöhten Messwerte über den gesamten Messzeitraum.

Bei der Untersuchung der Marker des Sammelrohrs war die Calb/CreaKonzentration im Omnibustest über den gesamten Zeitraum nach Gabe des Chemotherapeutikums in Bezug auf die Basiswerte signifikant erhöht.

In einer Studie von Takashi et al. wurde Calbindin im Urin und im Serum mittels eines hochsensitiven Enzyme-Immunassay-Systems in Patienten gefunden, die durch Cis- oder Carboplatintherapie einen Nierenschaden aufwiesen. Die Urinkonzentration von Calbinin stellte sich also als geeigneter Marker für renale Schäden heraus. Das Protein findet sich allerdings auch in Patienten, die an malignen oder benignen Tumoren im Urogenitalbereich erkrankt sind (Takashi et al. 1996).

Bei der Untersuchung der Marker des Glomerulums zeigte die CysC/CreaKonzentration im Omnibustest nach Gabe des Chemotherapeutikums in Bezug auf die Basiswerte des Patientenkollektivs signifikant erhöhte Werte. Eine Studie von Shliphak et al. zeigt, dass zwischen CysC und dem Serumkreatinin eine starke, direkte Korrelation bei älteren Patienten mit kardiovaskulären Geschehnissen besteht (Shlipak et al. 2005). 
In der In-vitro Studie von Sohn et al., in der humane HK-2 Zellen mit Cisplatin behandelt wurden, wurde auch eine erhöhte Konzentration der Synthetisierung der mRNA von CysC gemessen (Sohn et al. 2013). Somit werden die Ergebnisse dieser Studie von aktueller Literatur gestützt.

Osteopontin zeigte ebenfalls als Marker des Glomerulums eine generalisierte Konzentrationserhöhung über den gesamten Messzeitraum in Bezug auf die Basiswerte. Al-Malki zeigte in seiner Studie, dass die Osteo-Werte bei diabetischen Patienten mit einer Microalbuminurie, einen signifikanten Anstieg der OsteoKonzentration im Urin aufweisen (Al-Malki 2014).

In einer weiteren Studie von Bandopadhyay et al. vom Juni 2014 wird dem Osteo eine große Rolle in der Tumorentstehung zugeschrieben; genaugenommen in den Regulationsprozessen von Zellproliferation, Angiogenese und Metastasierungsprozessen (Bandopadhyay et al. 2014).

Die Zerstörung der Tumorzellen durch die chemotherapeutische Behandlung kann eine erhöhte Freisetzung von Osteo bedingen und somit eine Erhöhung der Ausscheidungsrate. Somit könnte die signifikante Erhöhung der Osteo/Crea-Werte im Urin auch eine Folge der Tumordestruktion gewesen sein. Die Ergebnisse zeigten zudem, dass Cisplatinpatienten mit einem signifikant höheren Konzentrationsanstieg reagierten. Hierzu sind keine Studien zu finden. Die bisherigen Beobachten stellen allerdings eine Grundlage dar für weitere Forschungen. Laut einer Studie der Universität Regensburg stellt TIMP2 ein parakrines Alarmsystem für unter Stress stehende Nierenzellen dar (Gocze et al. 2007).

Dieses Frühwarnsystem soll laut Gocze et al. innerhalb der ersten 48 Stunden anschlagen. Im Patientenkollektiv fällt auf, dass das Maximum der TIMP2Konzentration im Urin in den meisten Fällen erst nach 48 Stunden gemessen wurde und zwar erst an Tag drei beziehungsweise an Tag vier nach Gabe des Chemotherapeutikums. Allerdings sind diese Ergebnisse Einzelergebnisse; die Gesamtheit der Werte war nicht signifikant erhöht.

In einer weiteren Studie wird TIMP2 zusammen mit dem IGFBP7 als geeigneter Biomarker zur Früherkennung von akutem Nierenversagen bei Patienten mit chirurgischen Herzeingriffen beschrieben (Meersch et al. 2014). 
Zudem konnte in der In-vitro Studie von Sohn et al., in der humane HK-2 Zellen mit Cisplatin behandelt wurden, herausgestellt werden, dass die Synthetisierung der mRNA von TIMP2 signifikant anstieg (Sohn et al. 2013). Dies deutet darauf hin, dass bei toxischem Stress die renalen HK-2- Zellen wesentlich mehr TIMP2 ausschütten. Dies ist dann vermehrt im Urin zu finden. Solch ein Anstieg ließ sich auch im Rattenmodell validieren (Sohn et al. 2013). Die Ergebnisse der vorliegenden Studie können die Literaturangaben allerdings nicht unterstützen.

Für eine Proteinurie tubulären Ursprungs kommen eine Reihe von Erkrankungen in Frage: Tubulotoxische Nephropathie (Aminoglycoside, Cisplatin, Cadmium, Quecksilber, Blei, Lithium), Analgetika-Nephropathie, Chromoproteinniere und eine Myelomniere; als Marker tauchen hierfür die Microglobuline a1 und $\beta 2$ (sowie RBP, der aber in dieser Studie nicht mit gemessen wurde) im Urin auf (Edel et al. 2001).

\subsubsection{GESCHLECHTSSPEZIFISCHE AUSWIRKUNGEN AUF DIE BIOMARKER IM URIN NACH DER CHEMOTHERAPIE}

Schon vor Gabe des Chemotherapeutikums, zeigten die Patientinnen signifikant erhöhte Elektrolytwerte (Kalium, Magnesium) gegenüber den männlichen Patienten des Kollektivs; somit liegt der Fokus bei diesen Markern weniger auf den Folgen der Therapie.

In der Literatur finden sich keine Hinweise auf einen Zusammenhang zwischen gynäkologischen Tumorerkrankungen und einer vermehrten Kaliumausscheidung.

Laut der „Deutschen Gesellschaft für Ernährung e.V.“ liegt die Empfehlung der täglichen Magnesium Zufuhr bei $300 \mathrm{mg} / \mathrm{d}$ bei den Frauen und bei $350 \mathrm{mg} / \mathrm{d}$ bei Männern (ab dem 25. Lebensjahr). Mit einer durchschnittlichen Zufuhr von Magnesium bei Frauen $(205 \pm 72 \mathrm{mg} / \mathrm{d})$ und Männern $(266 \pm 92 \mathrm{mg} / \mathrm{d})$ in Deutschland, wird die Tagesdosis deutlich unterschritten (Anke et al. 1998).

Bei einer normalen Ausscheidungsmenge kann man also davon ausgehen, dass der Körper ein Defizit an Magnesium aufweist. Bei den Mg/Crea-Werten im Kollektiv zeigten die weiblichen Patientinnen signifikant erhöhte Konzentrationen gegenüber den männlichen Patienten im Basiswertbereich.

Neben der weiblichen Geschlechtsspezifität der Mg/Crea- und der K/CreaKonzentration zeigte sich ein signifikant geschlechtsspezifischer Unterschied zwi- 
schen den Patienten im Kollektiv, allerdings wiesen hier die männlichen Patienten eine signifikant erhöhte P/Crea-Ausscheidung auf. Der Phosphathaushalt ist im Körper hormonell reguliert und ist eng mit dem Calciumhaushalt verknüpft.

Die Konzentration im Serum und im Urin unterliegt einer circadianen Rhythmik (Black und Stanbury 1958).

ALT/Crea und GGT/Crea zeigten beide, dass die Konzentrationen im Urin bei den weiblichen Patientinnen signifikant höher waren als die der männlichen Patienten. Diese Geschlechtsspezifität blieb bei der GGT/Crea-Konzentration nach Cis-/ Carboplatingabe konstant und relativierte sich bei der ALT/Crea-Konzentration ab dem ersten Tag nach Gabe des Chemotherapeutikums.

Als weiterer Marker der Schädigung des proximalen Tubulus wurde die GSTa/Crea-Konzentration im Urin gemessen. Vor der Therapie zeigten die weiblichen Patientinnen im Kollektiv eine erhöhte GSTa/Crea-Konzentration im Vergleich zu den männlichen Patienten. Entgegen dieser Ergebnisse zeigte eine vorherige Studie am Rattenmodell, dass die Basiswertkonzentration von GSTa in männlichen Versuchstieren signifikant höher war, als die Konzentrationen der weiblichen Ratten (Gautier et al. 2014).

Die Marker des distalen Tubulus wiesen geschlechtsspezifische Unterschiede der NGAL/Crea- und AST/Crea-Konzentrationen im Urin auf. In den Basiswertkonzentrationen sowie in den Konzentrationswerten an den Tagen nach der Chemotherapie zeigten die weiblichen Patientinnen eine signifikante Erhöhung gegenüber den männlichen Patienten im Kollektiv.

Beide Marker zeigten bei den weiblichen Patientinnen signifikant höhere Werte im Vergleich zu den männlichen Patienten im Basiswertbereich.

Dies korrelierte mit einer signifikant schlechteren Clearance. Im Verlauf zeigten sich signifikante Erhöhungen der Konzentrationen im Urin der Prot/Crea- und Alb/Crea-Werte. Auch hier zeigten die weiblichen Patienten signifikant höhere Konzentrationen im Vergleich zu den männlichen Patienten. 


\subsubsection{AUSWIRKUNGEN VON DIABETES MELLITUS AUF DIE BIOMARKER IM URIN NACH DER CHEMOTHERAPIE}

Schildheuer et al. fassen in ihrer retrospektiven Studie zusammen, dass schlecht eingestellte Diabetiker oft einen Magnesiummangel aufweisen; die schlechte Stoffwechselsituation führt über eine Glykosurie zu einer inadäquaten Hypermagnesiurie (Schildheuer et al. 2000). In dieser Studie zeigt sich kein Unterschied zwischen den diabetischen und nicht-diabetischen Patienten bezüglich der Magnesiumausscheidung. Zudem gab die Aktenlage der Patienten keinen Aufschluss über HBA1c -Werte; somit lässt sich schlecht darstellen, welcher diabetische Patient eine gute oder schlechte Einstellung der Blutzuckerwerte aufwies. Die Ergebnisse dieser Studie zeigten in der Gruppe der Diabetiker am ersten Tag nach Gabe von Cis- oder Carboplatin einen signifikanten Anstieg der Gulkosekonzentration gegenüber den nicht-diabetischen Patienten des Kollektivs und in Bezug auf die Basiswertkonzentrationen. Laut einer Studie wird die Niere durch eine hyperglykämische Stoffwechsellage im Körper für eine nierenschädigende Wirkung toxischer Einflüsse sensibilisiert: insbesondere für schädigende Einflüsse der Hypertonie (Mann et al. 2001).

Um die Studie von Mann et al. zu bestätigen, müssten auf Grund der hyperglykämischen Stoffwechsellage bei den Patienten im Kollektiv erhöhte Konzentrationen weiterer Marker vorhanden sein, um eine nierenschädigende Wirkung des toxischen Einflusses zu verifizieren.

Da aber am ersten Tag nach Gabe des Chemotherapeutikums die diabetische Patientengruppe nur noch signifikant erhöhte Osteo/Crea-Werte zeigte, kann diese Aussage von Mann et al. in dieser Studie zunächst nicht bestätigt werden. Ein zeitverzögerter Anstieg kann jedoch nicht ausgeschlossen werde und könnte Grundlage für eine weitere Studie bilden.

Die schädigenden Einflüsse der Hypertonie konnten weder bei den diabetischen Patienten, noch bei den nicht-diabetischen Patienten herausgestellt werden.

Bouvet et al. zeigten in einer Studie, dass $\beta N A G$ als ergänzender Marker für eine Nierenschädigung bei Patienten mit Typ-2 Diabetes fungieren kann (Bouvet et al. 2014). 
Auch bei der a1MG/Crea-Konzentration zeigte sich eine gruppenspezi-fische Unterscheidung an Tag drei gegenüber den Basiswerten, wobei die Diabetiker signifikant höhere Werte gegenüber den nicht-diabetischen Patienten aufwiesen. Petrica et al. verdeutlichen, dass eine erhöhte a1MG-Konzentration bei Typ-2 Diabetikern im Urin mit einer Dysfunktion des proximalen Tubulus korreliert (Petrica et al. 2015).

Das Microglobuline wiesen in den Messungen weder einen spezifisch signifikanten Unterschied in der Gruppe der Diabetiker/nicht-Diabetiker noch in den anderen Gruppierungen auf. Die diabetischen Patienten sollten laut Studienlage, schon im Basiswertbereich erhöhte Proteinkonzentrationen aufweisen. Diese Studie konnte dies nicht bestätigen. Die weiblichen Patientinnen zeigten bis auf eine Patientin eine Proteinurie, unabhängig von einer pathologischen diabetischen Stoffwechsellage.

Da bis auf zwei Patientinnen alle anderen weiblichen Patienten schon mindestens einen Therapiezyklus erhielten, könnte eine Schädigung durch die Chemotherapie und/oder länger bestehende Tumoren zu einer stärkeren Proteinurie im weiblichen Kollektiv im Vergleich zu den männlichen Patienten, die sich mehrheitlich im ersten Therapiezyklus befinden, geführt haben.

Die einzige Patientin, die über den gesamten Sammelzeitraum keine Albuminurie aufzeigte, befand sich im ersten Therapiezyklus und zeigte eine physiologische, nicht-diabetische Stoffwechsellage.

In neueren Studien stellte sich KIM1 als Biomarker in Tiermodellen sensitiver für die Erkennung eines frühen Stadiums der diabetischen Nephropathie heraus; bei Menschen müssen die Werte noch verifiziert werden (Hosohata et al. 2014). Auch im Patientenkollektiv dieser Studie zeigten die diabetischen Patienten an Tag drei nach Gabe des Chemotherapeutikums eine signifikant höhere Konzentration im Urin als die nicht diabetischen Patienten.

Das „Journal of Diabetes and Metabolic Disorders“ unterstützt diese Ergebnisse, und verweist darauf, dass KIM1 einen wichtigen Marker in der Diagnostik und Prognostik bei diabetischen (ägyptischen) Patienten darstellt (Ahmed und Hamed 2015). 
Die diabetischen Patienten weisen an den Tagen eins und drei nach Gabe des Chemotherapeutikums signifikant erhöhte Osteo/Crea-Konzentrationen gegenüber den nicht diabetischen Patienten auf. Dies könnte indizierend dafür sein, dass Diabetiker eine stärkere Reaktion nach der Medikamentengabe von Cis- und Carboplatin zeigen.

\subsubsection{AUSWIRKUNGEN EINER ARTERIELLEN HYPERTONIE AUF DIE BIOMARKER IM URIN NACH DER CHEMOTHERAPIE}

Laut Mann et al. wird die Niere durch eine hyperglykämische Stoffwechsellage im Körper für eine nierenschädigende Wirkung toxischer Einflüsse sensibilisiert: insbesondere für schädigende Einflüsse der Hypertonie (Mann et al. 2001).

Mulè et al. verwiesen darauf, dass ein erhöhter Blutdruck eine Microalbuminurinie zur Folge hat (Mulè et al. 2015). In dieser Studie konnte kein Unterschied zwischen Hypertonikern und Normotonikern in Bezug auf die Microalbuminexkretion im Urin nachgewiesen werden.

Der einzige Parameter, der in der Gruppe der Hypertoniker eine signifikante Erhöhung der Werte zeigte, war die Urea/Crea-Konzentration. Jedoch zeigten hier die Normotoniker eine höhere Ausscheidungsrate als die Hypertoniker. Es kann somit nicht verifiziert werden, dass eine für nephrotoxische Reize (in diesem Fall: Cisoder Carboplatin) sensibilisierte Niere durch hypertensive Druckverhältnisse geschädigt wird.

\subsection{RESÜMEE}

Es lassen sich folgende Schlussfolgerungen aus den hier diskutierten Ergebnissen ziehen: Die Entwicklung nicht-invasiver Methoden zur Diagnose des akuten Nierenversagens toxischer Genese (in diesem Fall durch ein Chemotherapeutikum initiiert) hat eine wichtige Bedeutung für die Prognose und die einzuleitenden Therapiemaßnahmen. Hierfür wurden in dieser Studie 31 Biomarker und ihre Reaktion auf die Chemotherapie mit Cis- und Carboplatin gemessen. Es konnte gezeigt werden, dass die Basiswerte der einzelnen Parameter der Patienten im Kollektiv schon starke Konzentrationsunterschiede im Geschlechtervergleich aufwiesen: Die Clearance zeigte im Mittelwert eine Nierenschädigung mit geringer Einschränkung der GFR bei den weiblichen Patientinnen und eine normale Nierenfunktion der männlichen Patienten bei den Basiswerten. Die weiblichen Patientinnen zeig- 
ten auch bei den Markern K, Mg, ALT, GGT, GSTa, NGAL, AST, TIMP2, ALP, Prot und MIALB eine signifikant höhere Ausscheidungsrate als die männlichen Patienten. Die männlichen Patienten hingegen zeigten nur bei den Urinkreatininkonzentrationen signifikant höhere Werte im Vergleich zu den weiblichen Patientinnen. Die erhöhten Wertekonzentrationen und die signifikant schlechtere Nierenfunktion der weiblichen Patientinnen machen deutlich, dass beim weiblichen Geschlecht ein höheres Risiko für Schädigungen durch nephrotoxische Medikamente vorlag.

Allerdings zeigte sich keine signifikante Verschlechterung der Nierenfunktionswerte der weiblichen Patientinnen an den Tagen nach Gabe von Cis- oder Carboplatin. Dennoch zeigten fünf der Marker, die auch schon im Basiswertbereich erhöht waren, beim weiblichen Geschlecht auch weiterhin signifikante und spezifische Anstiege unter der Therapie (GGT, NGAL, AST, Prot und MIALB).

In dieser Studie konnte ebenfalls gezeigt werden, dass die Marker des proximalen Tubulus ( $\alpha 1 M G, \beta 2 M G, \beta N A G$ ) gleich am ersten Tag nach Gabe des Chemotherapeutikums signifikant und vor den Markern des Glomerulums (signifikanter Anstieg der Werte ab Tag zwei) und der weiteren Abschnitte der Niere ansteigen. Die Elektrolyte stiegen am zweiten und vierten Tag nach Gabe von Cis- und Carboplatin signifikant an und reagierten somit ebenfalls verzögert auf die Chemotherapie.

Der zweite posttherapeutische Tag zeigte 13 signifikant erhöhte Wertekonzentrationen der Biomarker ( $\mathrm{Na}, \mathrm{Cl}, \mathrm{K}, \mathrm{Mg}$, Urea, pH, BNAG, B2MG, a1MG, THUP, MIALB, Prot, ALP). Die Ausscheidungsrate der Biomarker war also an diesem Tag am höchsten. Diese Werte korrelieren allerdings nicht mit einer signifikanten Verschlechterung der Nierenfunktion.

Diese Studie konnte zudem noch zeigen, dass ein Hypertonus keine schlechtere Voraussetzung für die nephrotoxische Therapie mit Cis- oder Carboplatin darstellt. Im Patientenkollektiv wurden keine signifikanten Unterschiede zwischen Hypertonikern und Normotonikern über den gesamten Beobachtungszeitraum sichtbar.

Diabetiker hingegen wiesen eine sensiblere Reaktion auf die nephrotoxische Medikation auf, besonders an Tag drei nach der Therapie: a1MG, KIM1, Osteo und ALP zeigten signifikant höhere Wertekonzentrationen im Urin bei den diabetischen Patienten im Vergleich zu den Patienten mit nicht-diabetischer Stoffwechsellage. 
Ein Unterschied zwischen den beiden platinhaltigen Therapieformen wurde nicht deutlich.

Da kein Parameter eine direkte Korrelation zur Clearance zeigte, ist davon auszugehen, dass die Parameter $\beta N A G$, $\alpha 1 M G, \beta 2 M G$ sich als frühe Biomarker einer proximalen Schädigung nach Gabe der nephrotoxischen, platinhaltigen Chemotherapie eignen. Der toxische Einfluss von Cis- und Carboplatin zeigt sich laut dieser Studie primär in den proximalen Tubuluszellen, sekundär gefolgt von einer ubiquitären Schädigung, bei der am zweiten posttherapeutischen Tag MIALB, Protein und auch die Elektrolyte in erhöhten Konzentrationen mit dem Urin ausgeschieden werden. GSTa als weiterer Marker des proximalen Tubulus und CysC als Marker des Glomerulums eignen sich ebenfalls als ANV-Biomarker nach platinhaltiger Chemotherapie, jedoch ein bis zwei Tage später.

Diese Studie bietet die Grundlage für weitere klinische Studien zum ANV durch Cis- und Carboplatin:

Es können Urinproben engmaschiger und schon zu früheren Zeitpunkten (z.B. während der Therapie) gesammelt werden, um die zeitliche Varianz der Marker noch spezifischer darstellen zu können.

Durch solch eine Versuchsanordnung stellen sich gegebenenfalls zeitlich und örtlich differenzierte Muster der ANV-indizierenden Biomarker dar. 


\section{LITERATURVERZEICHNIS}

Ahmed SA, Hamed MA (2015):

Kidney injury molecule-1 as a predicting factor for inflamed kidney, diabetic and diabetic nephropathy Egyptian patients.

J Diabetes Metab Disord 14, 6

Al-Malki AL (2014):

Assessment of urinary osteopontin in association with podocyte for early predication of nephropathy in diabetic patients.

Dis Markers 2014, 493736

Anke M, Glei M, Groppel B, Rother C, Gonzales D (1998):

Mengen-, Spuren- und Ultraspurenelemente in der Nahrungskette.

Nova Acta Leopoldina NF $\underline{79}, 157-190$

Bandopadhyay M, Bulbule A, Butti R, Chakraborty G, Ghorpade P, Ghosh P, Gorain M, Kale S, Kumar D, Kumar S et al.(2014):

Osteopontin as a therapeutic target of cancer.

Expert Opin Ther Targets, $\underline{4}, 1-13$

Binia A, Jaeger J, Hu Y, Singh A, Zimmermann D (2015):

Daily potassium intake and sodium-to-potassium ratio in the reduction of blood pressure: a meta-analysis of randomized controlled trials.

J Hypertens $\underline{33}(8), 1509-20$

Black DA, Stanbury SW (1958):

Renal insufficiency in terminal respiratory failure.

Br Med 1 (5075), 872-3

Bondiou MT, Bourbouze R, Bernard M, Percheron F, Perez-Gonzalez N, Cabezas JA (1985):

Inhibition of $A$ and $B ~ N$-acetyl-beta-D-glucosaminidase urinary isoenzymes by urea. Clin Chim Acta 149, 67-73

Bonventre JV (2009):

Kidney injury molecule-1 (KIM-1): A urinary biomarker and much more.

Nephrol Dial Transplant 24 (11), 3265-8

Bouvet BR, Paparella CV, Arriaga SM, Monje AL, Amarilla AM, Almará AM (2014):

Evaluation of urinary $\mathrm{N}$-acetyl-beta-D-glucosaminidase as a marker of early renal damage in patients with type 2 diabetes mellitus.

Arq Bras Endocrinol Metabol 58(8), 798-801 
Campistol JM, Grinyo JM (2001):

Exploring treatment options in renal transplantation: the problems of chronic allograft dysfunction and drug related nephrotoxicity.

Transplantation $\underline{71}, 42-51$

Cetin R, Devrim E, Kiliçoğlu B, Avci A, Candir O, Durak I (2006):

Cisplatin impairs antioxidant system and causes oxidation in rat kidney tissues: possible protective roles of natural antioxdant foods.

J Appl Toxicol 르, 42-6

Chapelsky MC, Nix DE, Cavanaugh JC, Wilton JH, Norman A, Schentag JJ (1992):

Renal tubular enzyme effects of clarithromycin in comparison with gentamicin and placebo in volunteers.

Drug Saf $\underline{7}, 304-9$

Ciarimboli G, Deuster D, Knief A, Sperling M, Holtkamp M, Edemir B (2010): Organic cation transporter 2 mediates cisplatin-induced oto- and nephrotoxicity and is a target for protective interventions.

Am J Pathol 176, 1169-80

Coudhury D, Ziauddin A (2005):

Drug-associated renal dysfunction and injury.

Nat Clin Pract Nephrol 2, 80-91

Curthoys NP, Moe OW (2014):

Proximal tubule function and response to acidose.

Clin J Am Soc Nephrol $\underline{9}, 1627-1638$

Daly JA, Ertingshausen G (1972):

Direct method for determining inorganic phosphate in serum with the "CentrifiChem".

Clin Chem 18, 263-265 (R97-0850)

D’Amico G, Bazzi C (2003):

Urinary protein and enzyme excretion as markers of tubular damage.

Curr Opinion in Nephrology and Hypertension 12, 639-643

Dehne MG, Boldt J, Heise D, Sablotzki A, Hempelmann G (1995):

Tamm-Horsfall protein, alpha-1- and beta-2-microglobulin as kidney function markers in heart surgery.

Anaesthesist $\underline{44}, 545-51$

dos Santos NA, Cavalho Rodrigues MA, Martins NM, dos Santos AC (2012): Cisplatin-induced nephrotoxicity and targets of nephropprotection: an update. Arch Toxicol 86, 1233-50 
Doumas BT (1975):

Standards for total serum protein assays--a collaborative study.

Clin Chem 21, 1159-1166 (R11-0482)

Ebewe Pharma Ges.m.b.H. Nfg. KG:

Vertrieb: Sandoz GmbH, Stand der Info: November 2013

Edel H, Guder W, Hofmann W, Ivandic M, Scherberich J (2001):

Harnuntersuchungen zur differenzierten Diagnostik einer Proteinurie: Bekanntes und Neues zu Teststreifen und Harnproteinen.

Dtsch Arztebl 98(12), A-756 / B-618 / C-578

FDA-News (2008):

European Medicines Agency to consider additional test results when assessing new drug safety.

FDA, 12.06.2008

Fujita H, Narita T, Mori T, Shimotomai T, Yoshioka N, Kakei M, Ito S (2002): Increased urinary excretion of Nacetylglucosaminidase in subjects with impaired glucose tolerance.

Ren Fail 24, 69-75

IFCC (1983):

IFCC methods for the measurement of catalytic concentration of enzymes, part 5. IFCC method for alkaline phosphatase.

J Clin Chem Clin Biochem 21, 731-748 (R04-1517)

IFCC (1994):

Enzymes, VIII IFCC method for lactate dehydrogenase.

Eur J Clin Chem Clin Biochem 32, 639-655 (R04-1492)

IFCC (2002a):

IFCC primary reference procedures for the measurement of catalytic activity concentrations of aspartate aminotransferase.

Clin Chem Lab Med 느, 725-733 (R04-1256)

IFCC (2002b):

IFCC primary reference procedures for the measurement of catalytic activity concentrations of enzymes at $37^{\circ} \mathrm{C}$. Part 6 . Reference procedure for the measurement of catalytic activity of $\delta$-glutamyltransferase.

Clin Chem Lab Med 40, 734-738 (R11-0380) 
Gautier JC, Riefke B, Walter J, Kurth P, Mylecraine L, Guilpin V, Barlow N, Gury T, Hoffman D, Ennulat D, Schuster K, Harpur E, Pettit S (2010):

Evaluation of Novel Biomarkers of Nephrotoxicity in Two Strains of Rat Treated with Cisplatin.

Toxicol Pathol $\underline{38}, 943$

Gautier JC, Gury T, Guffroy M, Khan-Malek R, Hoffman D, Pettit S, Harpur E (2014):

Normal ranges and variability of novel urinary renal biomarkers in Sprague-Dawley Rats: comparison of constitutive values between males and females and across assay platforms.

xicol Pathol 42(7), 1092-104

Gocze I, Koch M, Renner P, Zeman F, Graf BM, Dahlke MH, Nerlich M, Schlitt HJ, Kellum JA, Bein T (2015):

Urinary biomarkers TIMP-2 and IGFBP7 early predict acute kidney injury after major surgery.

PLoS One $\underline{10}(3)$, e0120863

Hosohata K, Ando H, Takeshita Y, Misu H, Takamura T, Kaneko S, Fujimura A (2014):

Urinary Kim-1 is a sensitive biomarker for the early stage of diabetic nephropathy in Otsuka Long-Evans Tokushima Fatty rats.

Diabetes and Vascular Disease Research 11, 243

Iqbal MP, Ali AA, Waqar MA, Mehboobali N (1998):

Urinary $\mathrm{N}$-acetyl-beta-D-glucosaminidase in rheumatoid arthritis.

Mol Med $\underline{30}, 165-69$

Jaffé M (1986):

Über den Niederschlag welchen Pikrinsäure in normalen Harn erzeugt und über eine neue Reaktion des Kreatinins.

Z Physiol Chem 10, 391-400 (R04-0945)

Janssen JW, Helbing AR (1991):

Arsenazo III: an improvement of the routine calcium determination in serum.

Eur J Clin Chem Clin Biochem 29, 197-201 (R11-0504)

Kankuri E, Mervaala E, Storvik M, Ahola AMJ, LevijokiJ, Muller DN, Finckenberg P, Mervaala EM (2014):

Exacerbation of acute kidney injury by bone marrow stromal cells from rats with persistent renin-angiotensin system activation.

Clin Sci (Lond) 128(11), 735-47 
Lajer H, Kristensen M, Hansen HH, Nielsen S, Frøkiaer J, Ostergaard LF, Christensen S, Daugaard G, Jonassen TE (2005):

Magnesium depletion enhances cisplatin-induces nephrotoxicity.

Cancer Chemother Pharmacol 56, 535-42

Lewey AS, Stevens LA,Schmid CH, Zhang YL, Castro AF, Feldman HI, Kursek JW, Eggers P, Van Lente F, Greene T, Coresh J (2009):

A new equation to Estimate Glomerular Filtration Rate.

Ann Intern Med 150 (9), 604-612

Liangos O, Perianayagam MC, Vaidya VS, Han WK, Wald R, Tighiouart $H$, MacKinnon RW, Li L, Balakrishnan VS, Pereira BJ, Bonventre JV, Jaber BL (2007):

Urinary $\mathrm{N}$-acetyl-beta-(D)-glucosaminidase activity and kidney injury molecule-1 level are associated with adverse outcomes in acute renal failure.

J Am Soc Nephrol 18, 904-12

Mann JF, Gerstein HC, Pogue J, Bosch J, Yusuf S (2001):

Renal insufficiency as a predictor of cardiovascular outcomes and the impact of ramipril: the HOPE randomized tria.

Ann Intern Med 134, 629-636

Matthaeus T, Schulze-Lohoff E, Ichimura T, Weber M, Andreucci M (2001):

Co-regulation of neutrophil gelatinase-associated lipocalin and matrix

metalloproteinase-9 in the postischemic rat kidney.

J Am Soc Nephro 12, 787A

Medac Gesellschaft für klinische Spezialpräparate GmbH.

Stand der Information: 02/2011

Meersch M, Schmidt C, Van Aken H, Martens S, Rossaint J, Singbartl K, Görlich D, Kellum JA, Zarbock A (2014):

Urinary TIMP-2 and IGFBP7 as early biomarkers of acute kidney injury and renal recovery following cardiac surgery.

PLoS One $\underline{27}, 9(3)$

Miller RP, Tadagavadi RK, Ramesh G, Reeves WB (2011):

Mechanisms of Cisplatin nephrotoxicity.

Toxins (Basel) 2 (11), 2490-518

Mishra J, Mori K, Ma Q, Kelly C, Barasch J, Devarajan P (2004):

Neutrophil gelatinase-associated lipocalin: a novel early urinary biomarker for cisplatin nephrotoxicity.

Am J Nephrol 24, 307-15 
Mulè G, Calcaterra I, Costanzo M, Morreale M, D'Ignoto F, Castiglia A, Geraci G, Rabbiolo G, Vaccaro F, Cottone S (2015):

Average real variability of 24-h systolic blood pressure is associated with microalbuminuria in patients with primary hypertension.

J Hum Hypertens

Nejat M, Pickering JW, Devarajan P, Bonventre JV, Edelstein CL, Walker RJ, Endre ZH (2012):

Some biomarkers of acute kidney injury are increased in pre-renal acute injury.

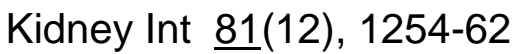

Ogura T, Takaoka M, Yamauchi T, Oishi T, Mimura Y, Hashimoto M, Asano N, Yamamura M, Otsuka F, Makino H, Ota Z, Takahashi K (1996):

Changes in urinary enzyme activity and histochemical findings in experimental tubular injury induced by gold sodium thiomalate.

Journal of Medicine 27, 41-55

Parviainen MT, Harmoinen A, Jokela, H (1985):

Serum albumin assay with bromcresol purple dye.

Scand J Clin Lab Invest 4도 , 561-564 (R11-0378)

Peres LA, da Cunha AD Jr, Assumpção RA, Schäfer A Jr, da Silva AL, Gaspar AD, Scarpari DF, Alves JB, Girelli Neto R, de Oliveira TF (2014):

Evaluation of the cisplatin nephrotoxicity using the urinary neutrophil gelatinaseassociated lipocalin (NGAL) in patients with head and neck cancer.

J Bras Nefrol $\underline{36}(3)$, 280-8

Petrica L, Vlad A, Gluhovschi G, Zamfir A, Popescu C, Gadalean F, Dumitrascu V, Vlad D, Popescu R, Velciov S, Gluhovschi C, Bob F, Milas O, Ursoniu $S$ (2015):

Glycated peptides are associated with proximal tubule dysfunction in type 2 diabetes mellitus.

Int J Clin Exp Med 8 $(2), 2516-25$

Pinches, M, Betts C, Bickerton S, Burdett L, Thomas H, Derbyshire N, Jones HB, Moores M (2012):

Evaluation of novel renal biomarkers with a cisplatin model of kidney injury: gender and dosage differences.

Toxicol Pathol $\underline{40}(3), 522-33$

Santos NA, Bezerra CS, Martins NM, Curti C, Bianchi ML, Santos AC (2008): Hydroxyl radical savenger ameliorates cisplatin-induced nephrotoxicity by preventing oxidative stress, redox state unbalance, impairment of nergetic metabolism and apoptosis in rat kidney mitochondria.

Cancer Chemother Pharmacol $\underline{61}$, 145-55 
Schaub S, Wilkins J, Antonovici M, Krokhin O, Weiler T, Rush D, Nickerson P (2005):

Proteomic-based identification of cleaved urinary beta2-microglobulin as a potential marker for acute tubular injury in renal allografts.

Am J Transplant $\underline{5}, 729-38$

Schildheuer M, Bauer A, Rob PM (2000):

Magnesium und Diabetes mellitus: Epidemiologie, klinische und experimentelle Daten.

Magnesium Bulletin

Schmidt C, Steinke T, Moritz S, Graf BM, Bucher M (2010):

Akutes Nierenversagen und Sepsis - Nur eine Organdysfunktion bei septischem Multiorganversagen?

Der Anästhesist $\underline{59}, 682-699$

Shin YJ, Kim TH, Won AJ, Jung JY, Kwack SJ, Kacew S, Chung KH, Lee BM, Kim HS (2014):

Age-related differences in kidney injury biomarkers induced by cisplatin.

Environ Toxicol Pharmacol $\underline{37}(3), 1028-39$

Shlipak MG, Sarnak MJ, Katz R, Fried LF, Seliger SL, Newman AB, Siscovick DS, Stehman-Breen C (2005):

Cystatin $\mathrm{C}$ and the risk of death and cardiovascular events among elderly persons. N Engl J Med 352, 2049-60

Sohn SJ, Kim SY, Kim HS, Chun YJ, Han SY, Kim SH, Moon A (2013):

In vitro evaluation of biomarkers for cisplatin-induced nephrotoxicity using HK-2 human kidney epithelial cells.

Toxicol Lett 217(3), 235-42

Susantitaphong P, Perianayagam MC, Tighiouart H, Kouznetsov D, Liangos O, Jaber BL (2013):

Urinary $\alpha$ - and $\pi$-glutathione s-transferases for early detection of acute kidney injury following cardiopulmonary bypass.

Biomarkers 18 $(4), 331-7$

Takashi M, Zhu Y, Miyake K, Kato K (1996):

Urinary $28-k D$ calbindin-D as a new marker for damage to distal renal tubules caused by cisplatin-based chemotherapy.

Urol Int $\underline{56}(3), 174-9$

Tiffany TO, Jansen JM, Burtis CA, Overton JB, Scott CD (1972):

Enzymatic kinetic rate and end-point analyses of substrate, by use of a GeMSAEC fast analyzer.

Clin Chem 18, 829-840 
Tominaga M, Fujiyama K, Hoshino T, Tanaka Y, Takeuchi T, Honda M, Mokuda O, Ikeda T, Mashiba H (1989):

Urinary $\mathrm{N}$-acetyl-beta-Dglucosaminidase in the patients with hyperthyroidism.

Horm Metab Res $\underline{21}$, 438-40

Trof RJ, Di Maggio F, Leemreis J, Groeneveld ABJ (2006):

Biomarkers of acute renal injury and renal failure.

Shock $\underline{26}, 245-253$

Vaidya VS, Ramirez V, Ichimura T, Bobadilla NA, Bonventre JV (2006):

Urinary kidney injury molecule-1: a sensitive quantitative biomarker for early detection of kidney tubular injury.

Am J Physiol Renal Physiol 290, F517-29

Vaidya VS, Ferguson MA, Bonventre JV (2008):

Biomarkers of acute injury.

Ann Rev Pharmacol Toxicol $\underline{48}$, 463-9

Wainford RD, Weaver RJ, Stewart KN, Brown P, Hawksworth GM (2008):

Cisplatin nephrotoxicity is mediated by gamma glutaryltranspeptidase, not via C-S lyase governed biotranformation pathway.

Toxicology $\underline{249}, 184-93$

Walshe CM, Odejayi F, Ng S, Marsh B (2009):

Urinary glutathione S-transferase as an early marker for renal dysfunction in patients admitted to intensive care with sepsis.

Crit Care Resusc $\underline{3}, 204-9$

Westhuyzen J, Endre ZH, Reece G, Reith DM, Saltissi D, Morgan TJ (2003):

Measurement of tubular enzymuria facilitates early detection of acute renal impairment in the intensive care unit.

Nephrol Dial Transplant $\underline{18}, 543-51$

Whiting PH, Brown PA (1996):

The relationship between enzymuria and kidney enzyme activities in experimental gentamicin nephrotoxicity.

Renal Failure 18, 899-909

Yamagami T, Suna T, Fukui Y, Ohashi F, Takada S, Sakurai H, Aoshima K, Ikeda M (2008):

Biological variations in cadmium, Alpha-1-microglobulin, B2-microglobulin and $\mathrm{N}$ acetyl-B-D-glucosaminidase in adult women in a non-polluted area.

Int Arch Occup Environ Health 81, 263-271 
Zhang PL, Mashni JW, Sabbisetti VS, Schworer CM, Wilson GD, Wolforth SC, Kernen KM, Seifman BD, Amin MB, Geddes TJ, Lin F, Bonventre JV, Hafron JM (2014):

Urine kidney injury molecule-1: a potential non-invasive biomarker for patients with renal cell carcinoma.

Int Urol Nephrol $\underline{46}(2), 379-88$

\section{INTERNETQUELLEN}

http://www.labor-limbach.de; Zugriff am 25.11.2013 


\section{DANKSAGUNG}

Mein besonderer Dank gilt Frau Prof. Dr. med. Sabine Blaschke, die mir dieses interessante Thema ermöglicht hat und Frau Dr. med. Sabine Pestel und Prof. Dr. med. Jürgen Steffgen für die fachliche, umfangreiche und hilfsbereite Betreuung und für unterstützende Gespräche und Anregungen während des gesamten Zeitraums.

Weiterhin ein ganz herzliches Dankeschön an Frau Astrid Jähnige, für die großartige Arbeit im Labor, die zuverlässige Zusammenarbeit und Bereitstellung ihrer fachlichen Kompetenz zu jeder Zeit. 